Portland State University

PDXScholar

Spring 6-3-2016

\title{
On Both Sides of the Tracks: Light Rail and Gentrification in Portland, Oregon
}

Nathan Eric Rochester

Portland State University

Follow this and additional works at: https://pdxscholar.library.pdx.edu/open_access_etds

Part of the Sociology Commons, Transportation Commons, and the Urban Studies Commons Let us know how access to this document benefits you.

\section{Recommended Citation}

Rochester, Nathan Eric, "On Both Sides of the Tracks: Light Rail and Gentrification in Portland, Oregon" (2016). Dissertations and Theses. Paper 2915.

https://doi.org/10.15760/etd.2911

This Thesis is brought to you for free and open access. It has been accepted for inclusion in Dissertations and Theses by an authorized administrator of PDXScholar. Please contact us if we can make this document more accessible: pdxscholar@pdx.edu. 
On Both Sides of the Tracks: Light Rail and Gentrification in Portland, Oregon

\title{
by
}

Nathan Eric Rochester

A thesis submitted in partial fulfillment of the requirements for the degree of

\author{
Master of Science \\ in \\ Sociology
}

Thesis Committee:

Amy Lubitow, Chair

Ginny Garcia-Alexander

Alex Stepick

Jason Jurjevich

Portland State University

2016 
C2016 Nathan Eric Rochester 


\begin{abstract}
This study draws on census data and geographic information systems (GIS) to investigate the relationship between light rail transit (LRT) infrastructure development and gentrification in Portland, Oregon. While recent research using comprehensive measures of neighborhood socioeconomic status (SES) supports a potentially causal link between transit development and gentrification, research into the effects of transit on property values alone tends to dominate the discourse. This study therefore seeks to build on previous research to develop an index measure of neighborhood SES and SES change based on measures of education, occupation, and income, using census data from 19802010. This multifaceted measure of neighborhood SES is analyzed in relation to LRT access using correlation, OLS regression, and GIS hot spot and choropleth mapping.
\end{abstract}

Findings: Throughout the study period, low SES neighborhoods largely disappeared from the City of Portland, while low-income households were gradually priced out. Simultaneously, the easternmost suburb of Gresham became more highly concentrated in low SES neighborhoods. No definitive relationship between LRT and SES is found along the Eastside Blue or Westside Blue Lines, but strong evidence is found supporting a positive effect of Yellow Line MAX development on the rapid gentrification of North Portland from 2000-2010. Regressions run on neighborhoods along the Yellow Line indicate that SES change was greatest for those that began the decade with large Black populations, low rents, and close proximity to stations. Findings 
are discussed through the theoretical framework of the urban growth machine, which suggests the differential relationship between LRT and neighborhood SES relates to the distinct values of different parts of the region for the pursuit of general growth goals. 


\section{Dedication}

Dedicated to the memory of Daniel Monroe Sullivan. 


\section{Acknowledgements}

I would like to acknowledge the invaluable support of my thesis committee, and especially of my thesis chair, Dr. Amy Lubitow, who's patience with me has at times bordered on saint-like. The guidance I have received from her and my thesis committee members, Dr. Ginny Garcia-Alexander, Dr. Alex Stepick, and Dr. Jason Jurjevich, has made an otherwise difficult experience extremely rewarding, and I hope to continue to benefit from their insights and expertise into the future.

I have benefitted greatly from the feedback and comradeship of my fellow cohort members and other graduate students in PSU's Department of Sociology. They represent an impressive group of talented individuals, whom I am fortunate to call colleagues and friends.

As a graduate worker I have been happy to develop professional experience in academic advising, for which I owe much to the advocacy of Associate Dean Matt Carlson (formerly Sociology Department Chair), and Assistant Dean Robert Mercer. You have both given me an opportunity to turn graduate funding into a passion for helping students succeed in higher education, and put me on the path to a fulfilling career.

Lastly (but certainly not least!), I would like to thank my amazing wife Mykie. I could not have completed this pursuit if not for her constant support and understanding. 


\section{Table of Contents}

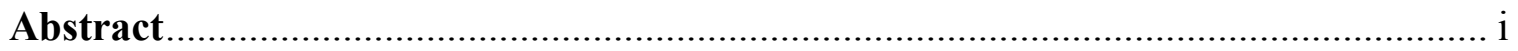

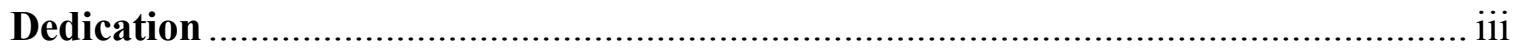

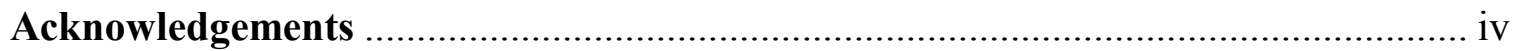

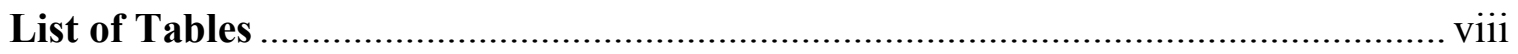

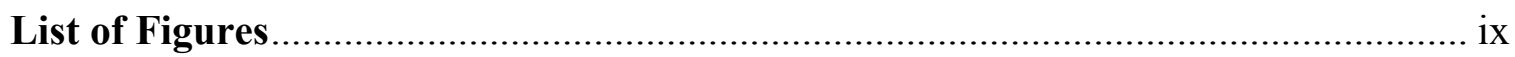

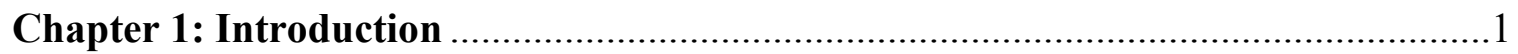

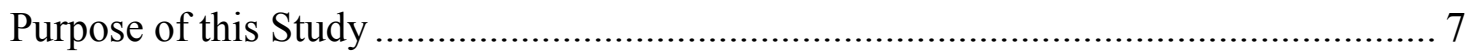

Research Questions and Hypotheses ................................................................ 10

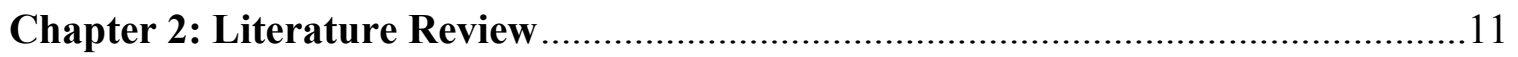

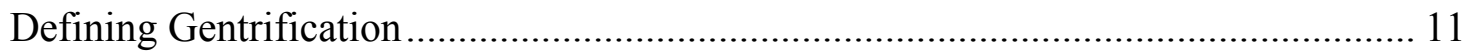

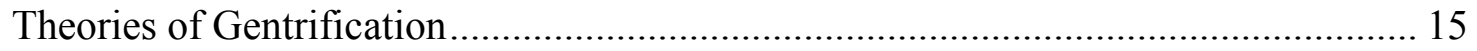

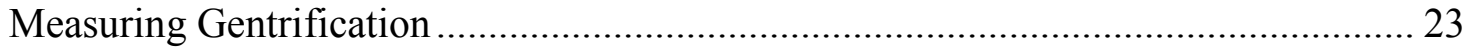

Role of Transit in Neighborhood Change ............................................................... 27

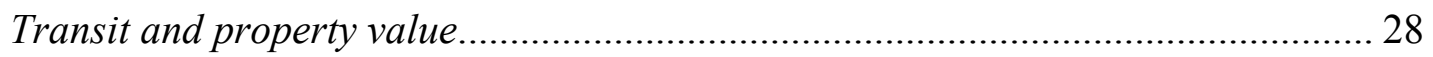

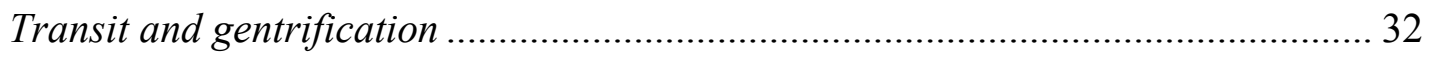

Gentrification and Transit in Portland, Oregon ................................................... 41

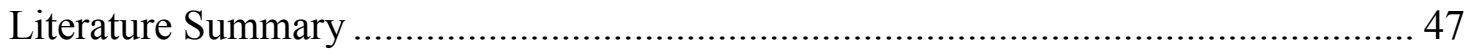

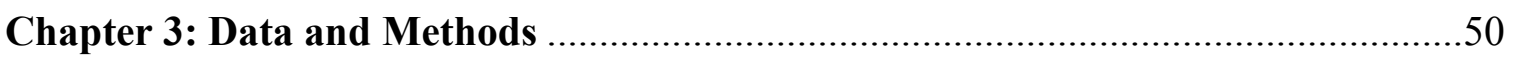

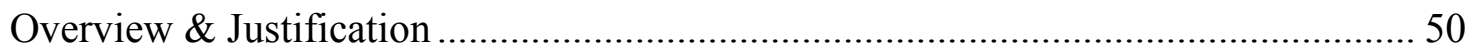

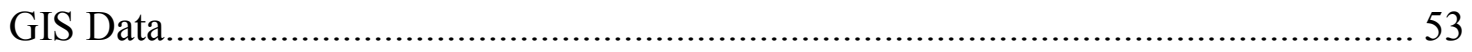

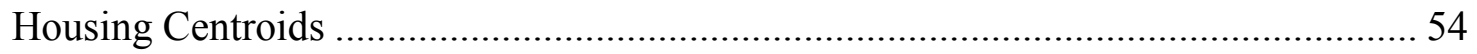


Independent Variables: Neighborhood LRT Access

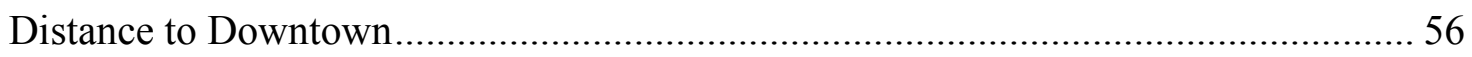

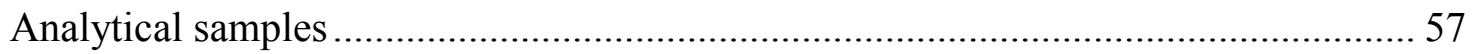

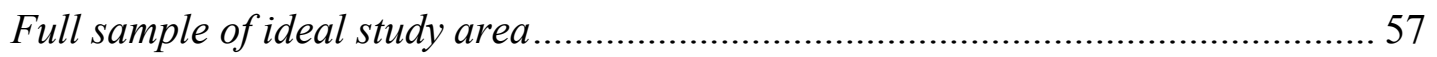

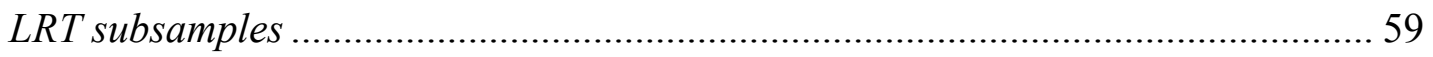

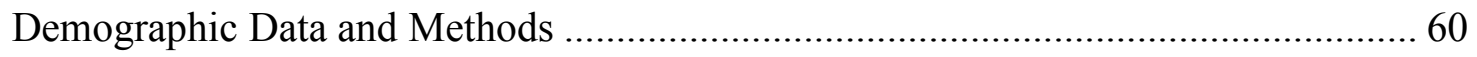

Demographic Dataset: Neighborhood Change Database (NCDB) ............................ 62

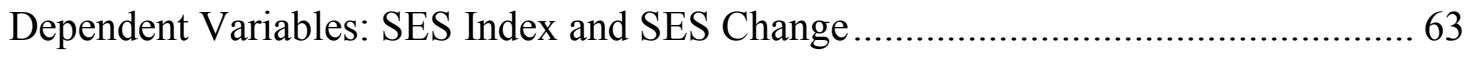

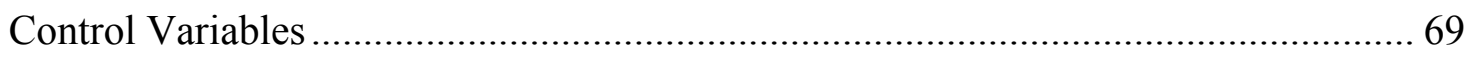

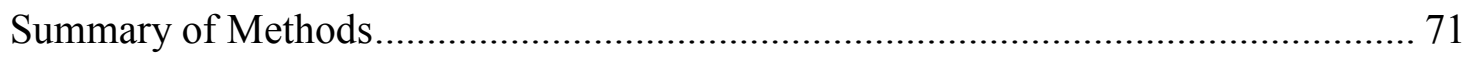

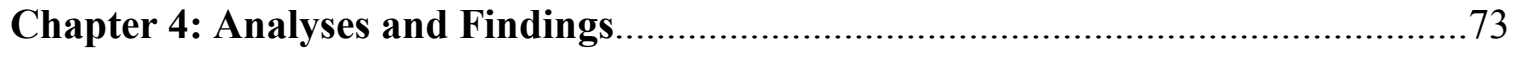

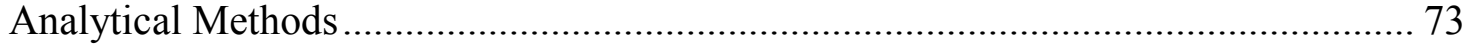

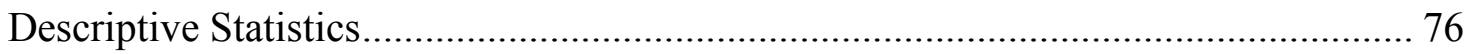

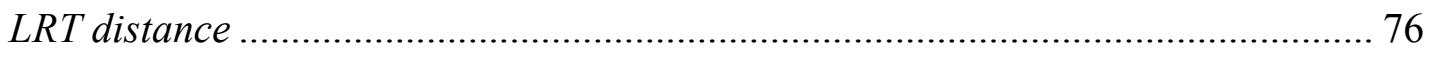

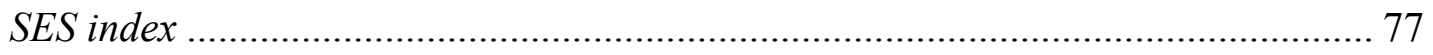

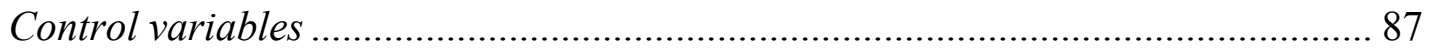

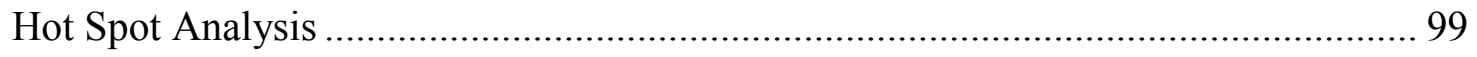

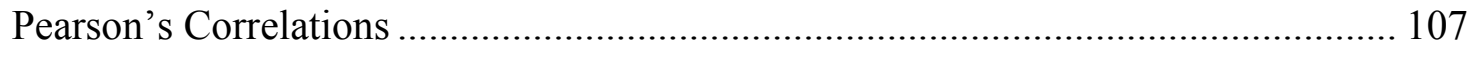

Multivariate Analyses: OLS Linear Regression ............................................. 111 
Chapter 5: Discussion and Conclusion

Neighborhood Contexts

Portland's Urban Growth Machine ......................................................................... 126

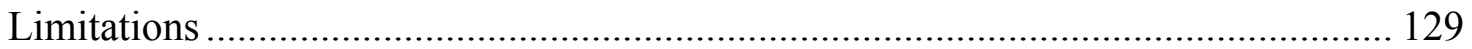

Implications for Gentrification Research....................................................... 132

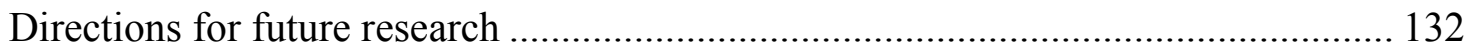

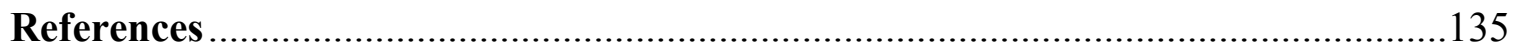

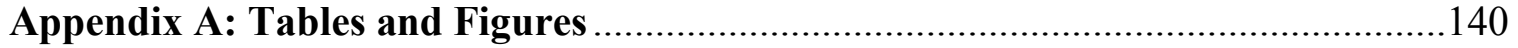

Appendix B: Alternative Sampling Methods Considered .....................................145

Appendix C: Changes to Census Questions and Coding........................................148 


\section{List of Tables}

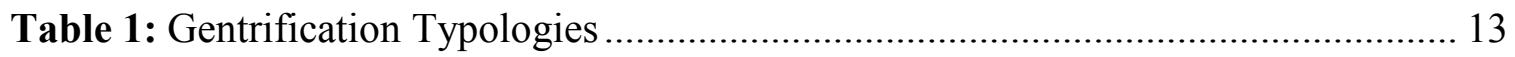

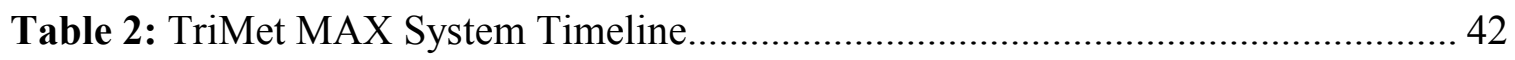

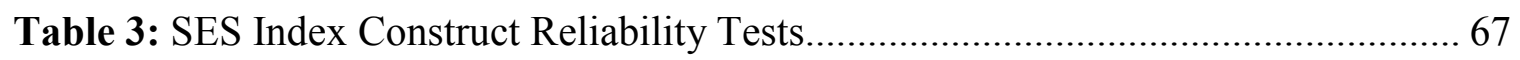

Table 4: Descriptive Statistics: LRT Distance by Subsample .................................... 77

Table 5: Descriptive Statistics: SES Index by Sample and Census Year,

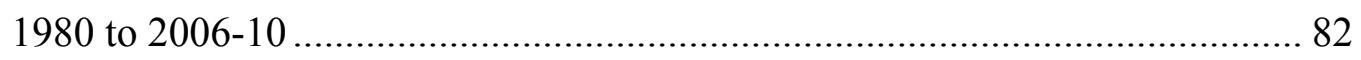

Table 6: Descriptive Statistics: Control Variables by Sample and Census

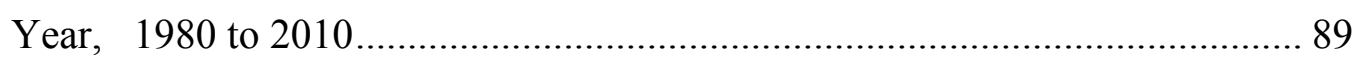

Table 7: Correlations: LRT Distance with SES Index and SES Change,

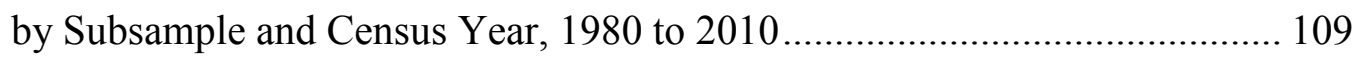

Table 8: Regression Analysis: SES Index 1990-2006-10, Regressed on

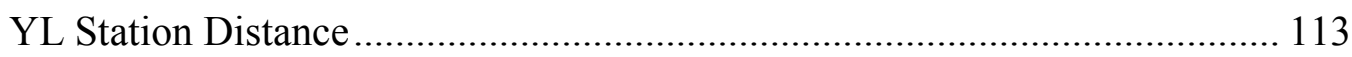

Table 9: Regression Analysis: SES Index Change 2000 to 2006-10,

Regressed on YL Station Distance .................................................... 118 


\section{List of Figures}

Figure 1: Map: Portland-Vancouver-Hillsboro MSA (sampling frame) ....................... 57

Figure 2: Map: Full Sample of Study Area Census Tracts ........................................ 58

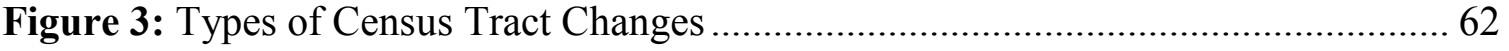

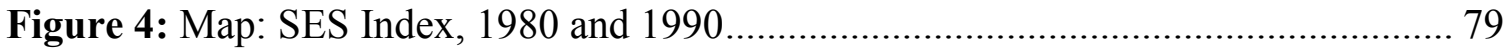

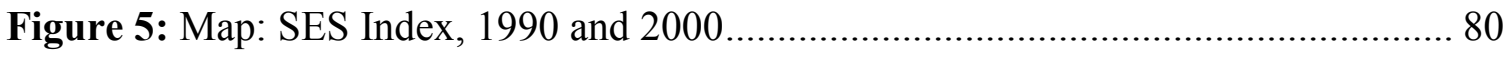

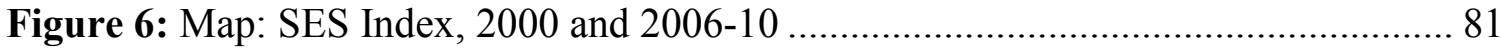

Figure 7: Mean SES Index by Sample and Census Year, 1980-2010 .......................... 85

Figure 8: Mean SES Index Change by Sample and Census Year Interval, 1980-2010... 86

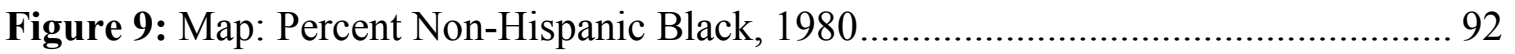

Figure 10: Map: Percent Non-Hispanic Black, 2010 ............................................. 92

Figure 11: Map: Change in Percent Non-Hispanic Black, 1980 to 1990 ...................... 93

Figure 12: Map: Change in Percent Non-Hispanic Black, 2000 to 2010 ...................... 94

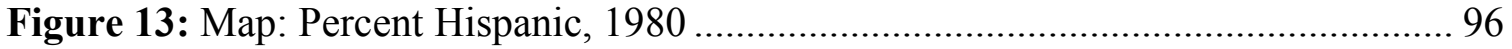

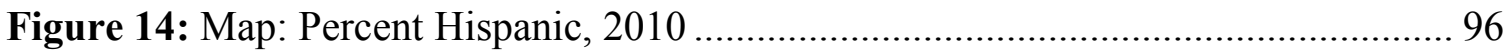

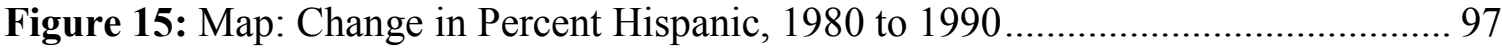

Figure 16: Map: Change in Percent Hispanic, 1990 to 2000 ........................................ 98

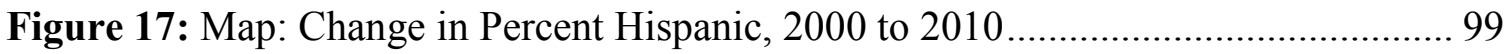

Figure 18: Map: Hot Spot Analyses: SES Index and SES Change, 1980 to 1990 ........ 102

Figure 19: Map: Hot Spot Analysis: SES Index and SES Change, 1990 to 2000 ......... 104

Figure 20: Map: Hot Spot Analysis: SES Index and SES Change, 2000 to 2006-10... 106 


\section{Chapter 1: Introduction}

This study aims to bridge a gap in the research literature by exploring the relationship between rail transit development and gentrification through a case study of the Portland, Oregon metropolitan region. Recent research suggests a potentially causal link between the development of mass transit rail infrastructure and subsequent gentrification in the neighborhoods served by those transit systems (Lin 2002; Dominie 2012; Grube-Cavers and Patterson 2014; Kahn 2007; Pollack, Bluestone, and Billingham 2010). However, such studies are sparse in number, employ a wide variety of research methods and theoretical frameworks, and their findings pertaining to the nature of the relationship between transit and gentrification have varied between different regions, complicating their generalizability to the broader gentrification literature.

Those few studies explicitly investigating the transit-gentrification relationship are greatly outnumbered by those concerned with the relationship between metropolitan rail transit development and property values near those rail stations (Al-Mosaind et al. 1993; Bajic 1983; Bowes and Ihlanfeldt 2001; Chen, Rufolo, and Dueker 1998; Diaz 1999; Kahn 2007; Kilpatrick, Throupe, Carruthers, and Krause 2007; Mohammad, Graham, Melo, and Anderson 2013; Wardrip 2011). Although the strength and magnitude of the relationship varies across different cities and types of rail systems, there remains a general consensus in much of the literature that "proximity to public transit does lead to higher home values and rents in many cases" (Wardrip 2011:2). 
Taking it one step further, some researchers (e.g., Lin 2002) have relied on property values as a proxy for measuring the socioeconomic characteristics of transitserved neighborhood residents. Such studies have essentially worked from an argument or assumption that increased property values are indicative of gentrification, which generally refers to a process of higher income residents moving into a lower income community, resulting in the displacement of the original residents and eventually changing the overall character of the neighborhood (Kennedy and Leonard 2001). However, property value is only one of several socioeconomic variables that are more appropriately used together to measure gentrification (Hammel and Wyly 1996; Lees, Slater and Wyly 2008). Without accompanying demographic neighborhood measures, property values simply reflect the cost of purchasing a home in a given neighborhood at a given time, and do not necessarily indicate the types of people moving into or out of the area.

The sociological perspective can serve as a valuable tool for placing the relationship between transit development and property values within the broader context of gentrification theory, which is an essential step to developing this area of inquiry. However, sociological contributions to the gentrification literature, and indeed to the research literature in general, have been notably limited in their adoption of spatial research methods (Gieryn 2000), which are crucial for operationalizing fundamentally spatial concepts such as neighborhood access to particular amenities and services including transit. On the other hand, studies of transit and property value - largely found 
in the transportation and land use literature, which is predominated by planning-related fields - regularly utilize geographic information systems (GIS) to manipulate, combine and analyze spatial data. In that body of research, property value tends to be heavily relied on as the neighborhood outcome of interest, and other components of neighborhood-level socioeconomic status (SES) are rarely incorporated (Zuk, Bierbaum, Chapple, Gorska, Loukaitou-Sideris, Ong, and Thomas 2015). This constitutes a gap in the literature that has only just begun to be explored, and since it stems from methodological and theoretical divides between disciplines, bridging that gap will require an interdisciplinary approach.

Gentrification research in general is hindered by intense debate around its positive and negative implications for cities, neighborhoods, and marginalized populations therein (Lees et al. 2008). Gentrification could be seen as beneficial to long-time residents because of generally positive neighborhood changes such as increased social mix and improved infrastructure. However, due to increased likelihood of residential displacement in gentrifying neighborhoods, long-time residents' experience of gentrification would likely differ greatly between those who are and are not able to remain in the community. Long-time residents who are able to remain in a gentrifying neighborhood may benefit from some changes, but ultimately those households will face a higher cost of living due to loss of affordable housing, as well as a climate of resentment and conflict with newcomers in their communities, making it increasingly difficult to stay (Atkinson and Bridge 2005). Conversely, long-time residents who are unable to remain not only 
experience displacement from their homes and neighborhoods, but they are contingently re-placed in other neighborhoods that may be far removed from their established employment, support networks of family and friends, and other vital resources for day to day living. Such a loss of resources has numerous negative implications for individuals, families, and communities. ${ }^{1}$

In this context, transportation infrastructure in general is an especially vital resource to all residents of a city or region, because it connects them to multiple other resources. By extension, access specifically to public transportation is especially important in the day-to-day living of low-income urban populations regardless of neighborhood, because they are disproportionally transit-dependent compared to the middle and upper class (Bullard 2003). According to an American Public Transportation Association (APTA 2007) national survey of transit riders from 2000 to 2005, rail transit riders were disproportionately comprised of racial/ethnic minorities (57.7\%), and mostly walked (44.1\%) or transferred from other transit (14.2\%) to get to rail stations, suggesting a high degree of dependence on public transportation. Furthermore, of all rail transit riders surveyed, $42.4 \%$ indicated having no available vehicle as an alternative to transit for their trip - a subset of transit users sometimes referred to by transportation planners and researchers as "captive riders" (Bullard 2003; Pollack et al. 2010).

\footnotetext{
${ }^{1}$ For example, Formoso, Weber and Atkins (2010) finds that the experience of displacement from gentrifying neighborhoods in childhood increases the risk of depression later in life, related to the loss of institutional resources, personal role models, and social networks.
} 
These APTA statistics emphasize the importance of transit accessibility for socioeconomically disadvantaged populations; however, transit equity research identifies significant barriers to access along lines of race/ethnicity and class in US neighborhoods in general (Bullard 1997; Bullard 2003) as well as in Portland specifically (McKenzie 2013). In the more general sense, Bullard (2003) posits that a regional transit system that serves a combination of low-income neighborhoods with high ridership and high-income neighborhoods with low ridership is likely to result in the provision of two separate and unequal transit services, with the transit revenues from lower-income "captive riders" essentially subsidizing the transit services received by higher-income "discretionary riders." In Portland specifically, a recent study by McKenzie (2013) finds that neighborhoods of high Black concentration as well as neighborhoods of high Latino concentration both declined in access to transit during the 2000s. Rather than this being the result of changes to the public transportation system, which actually expanded from 2000 to 2009, McKenzie (2013) attributes the decline to changes in the geographic distributions of Black and Latino populations during that period, in which many of the

\footnotetext{
${ }^{2}$ In this hypothetical scenario, one transit service amounts to a living amenity that serves the daily needs of "captive riders" - who are disproportionately low-income and racial/ethnic minorities. The other amounts to a recreational amenity that serves the occasional needs of "discretionary riders" - who are more likely to be white and middle class. Bullard (2003) argues that because the former amenity is overburdened by the consistently unmet demand of transit-dependent riders whose fares contribute substantially to serviceprovider revenue, while the latter has comparably lower levels of demand, crowding, and revenue, the fact that they are both treated as parts of the same transit system charging the same fares and feeding into the same revenue pool amounts to the subsidization of public transportation for wealthier neighborhoods at the expense of residents in poorer neighborhoods.
} 
transit-rich, historically Black neighborhoods nearest to the urban center experienced particularly rapid gentrification.

In this context, any possibility that the development of new transit infrastructure may contribute to increasing rents and the potential displacement of vulnerable populations in the neighborhoods it serves is especially concerning. Transit-induced gentrification would not only contribute to the displacement of populations most dependent on those services, but the loss of connectivity to jobs and other resources would likely compound and exacerbate the numerous other negative impacts of gentrification on the health and wellbeing of individuals, families, and communities. A better understanding of the intricacies of this relationship is therefore of substantial social importance in order to mitigate or prevent the potential disruptive negative impacts, including gentrification and displacement, of LRT development in Portland and elsewhere.

The Portland, Oregon region offers an ideal study area to investigate this relationship for two main reasons. First, Portland contains a widely celebrated LRT system that was developed over the past three decades, with segments in multiple parts of the region, and particularly high rates of transit ridership (APTA 2014). Second, there is a well-documented history of gentrification and displacement in particular Portland neighborhoods, which allows for some degree of validation of the methods employed to measure and analyze such trends over time. These and other factors are described in greater detail in Chapter 2. 


\section{Purpose of this Study}

This study utilizes geographic information systems (GIS), combined with quantitative analysis of three decades of census data, to assess the extent to which LRT development in the Portland, Oregon metropolitan region has been associated with neighborhood socioeconomic change indicative of gentrification. Findings are interpreted through the theoretical framework of the urban growth machine, which considers the collaborative roles of particular actors, motivated by the pursuit of perpetual economic growth, within a political economy of place (Logan and Molotch 1987). In this context, a growth machine can be understood as the interconnected workings of multiple coalitions of actors within a particular urban landscape, oriented around common growth goals By taking an interdisciplinary approach that makes use of sociological theory and methods, in combination with geospatial data and analytical methods, this study serves to bridge a major gap in the literature, in which prior sociological investigations of gentrification have not empirically assessed the role of transit, while investigations focused on transit - conducted in other disciplines - have not accounted for the sociodemographic components of neighborhood change associated with the most commonly accepted definitions of gentrification. After establishing a working definition of gentrification, I consider the relationship between transit development and neighborhood socioeconomic change within the broader theoretical discourse of the urban growth machine. Gentrification, in this context, is understood as a process of neighborhood 
transformation resulting from the inequitable flow of public and private capital, which is controlled by growth machines intent on land use intensification.

Three components of the methodology employed in this study have particularly great potential for replication and refinement in future neighborhood-level investigations using aggregate data. The first of these, the dependent variables operationalizing neighborhood-level SES, and the rate of change in neighborhood SES over time, is a set of multi-item constructs adapted from Ley (1986). Second, GIS hot spot analysis (using the Getis-Ord Gi* statistic) is employed as a method for mapping general geographic neighborhood trends in demographic data at a regional level (Mitchell 2011). Lastly, a GIS method for calculating housing centroids - the points most central to all housing units within neighborhood geographies - was developed for use in the calculation of neighborhood distance variables (e.g., distance to a transit station).

Using these and other methods, analysis is carried out in three phases, including univariate, bivariate, multivariate, and geospatial/geostatistical analyses. The use of multiple measures is valuable as a means of validating the outcomes and confirming the robust nature of the findings. Findings indicate that the relationship between transit and neighborhood SES is not consistent throughout the region, suggesting that the effects of major transit infrastructure on residential distributions are dependent upon the sociohistorical context of the neighborhoods receiving such infrastructure. A history of disinvestment appears to be inadequate on its own for transit investment to spur gentrification; however, when combined with a history of social and political 
marginalization, and strategic location in relation to the urban core, and accompanied by other sources of economic re-investment - which is characteristic of the North Portland neighborhoods along the MAX Yellow Line - especially rapid gentrification, positively associated with transit proximity becomes increasingly possible. 


\section{Research Questions and Hypotheses}

\section{Research Questions}

1. How has neighborhood SES changed in the Portland Metro region overall since the first MAX line was installed?

2. How has neighborhood SES changed in relation to different LRT developments since the first MAX line was installed?

3. To what extent is LRT development associated with gentrification in Portland Metro area neighborhoods?

Hypotheses

H1 Neighborhood SES will increase more in neighborhoods close to downtown than in those further away from downtown.

H2 Low-SES neighborhoods receiving new LRT infrastructure will increase in SES relative to the rest of the region following those stations opening for service.

H3 SES increases indicative of gentrification in newly transit-served neighborhoods will be greater in those with close proximity to new transit stations than in those further away. 


\section{Chapter 2: Literature Review}

\section{Defining Gentrification}

Before reviewing gentrification literature, it is important to acknowledge that gentrification is a highly provocative subject, and the term itself has varying definitions and implications depending on the discourse in which it is discussed. Generally, in social science research, gentrification is defined as a process in which higher income residents move into a predominantly low-income or working class community, displacing the original residents and eventually changing the overall character of the neighborhood (Kennedy and Leonard 2001). However, preferred definitions have varied markedly over time, with newer iterations tending to add specificity to previous definitions. Lees et al. (2008) suggests that the definition has changed over time to account for the emergence of previously undocumented varieties of gentrification taking place.

First coined in 1964 by British sociologist Ruth Glass, the term gentrification originally referred to middle and upper-middle class households (the 'gentry') purchasing and renovating older single-family homes for their own residences in relatively poor urban neighborhoods. Those neighborhoods were typically close to downtown, which was desirable for professionals employed there, and home prices were low due to deteriorating infrastructure. Increasingly, middle class households purchased and renovated homes, displacing the original working class residents until "the social character of the district is changed" (Glass 1964: xviii-xix, as quoted in Lees, et al. 
2008:4). Thus, the term originally was very specific to inner urban core neighborhoods with incumbent working class households living in single family homes.

Lees et al. (2008) describes the original understanding of the meaning of gentrification as "first-wave" or "classical" gentrification, and posit that its occurrence was sporadic and specific to a relatively few small neighborhoods in large developed cities in years prior to 1973. This was followed by a period of increased investment on the part of developers during the late 1970s that fed into second-wave gentrification throughout the 1980s (Lees et al. 2008). The pattern in the 80s was distinct in the predominance of what Florida (2006) calls "the creative class" as gentrifiers. Third-wave gentrification during the 1990s was characterized by an increase in public and private capital being inserted into urban development projects (Lees et al. 2008).

More recently discussed in the gentrification literature is the emergence of fourthwave gentrification, which is distinguished by "tight integration of local gentrification with national and global capital markets" (Lees et al. 2008:180). This market integration into gentrification processes is encouraged and even facilitated by state programs and may involve socioeconomic change in new housing developments (Davidson and Lees 2005), retail locations (Sullivan and Shaw 2011), and neighborhoods further from the urban core (Lees et al. 2008). These general typologies of gentrification as it has changed over time, including several of the newer variations that have emerged as fourth-wave typologies in recent years, are described further in Table 1. 
Table 1: Gentrification Typologies

\begin{tabular}{|c|c|}
\hline Variation & Description \\
\hline $\begin{array}{l}\text { First-Wave } \\
\text { Gentrification } \\
\text { (Classical) }\end{array}$ & $\begin{array}{l}\text { From the 1950s through the early } 1970 \text { s, disinvested urban } \\
\text { neighborhoods in the US, Western Europe, and Australia were } \\
\text { gentrified through middle class purchase of older single-family } \\
\text { homes. This process was proliferated by individual home-buyers } \\
\text { ("pioneer gentrifiers"), but also by urban renewal programs that } \\
\text { resulted in widespread leveling of vulnerable neighborhoods (Lees et } \\
\text { al. 2008; Glass 1964). }\end{array}$ \\
\hline Secc & entrification was characterized by a \\
\hline Gen & $\begin{array}{l}\text { wealthier, more executive class of gentrifier, and stabilization of the } \\
\text { neighborhood changes begun in the first wave. The influx of } \\
\text { individual private capital was accompanied by increased corporate } \\
\text { investment, redevelopment of downtown areas, and an emphasis on } \\
\text { the arts and urban leisure economies, resulting in "a highly polarized } \\
\text { landscape between an incoming affluent population and a disinherited } \\
\text { working-class population" (Lees et al. 2008:177). }\end{array}$ \\
\hline
\end{tabular}
Third-Wave In the 1990s, the processes of capital accumulation associated with Gentrification second-wave gentrification were extended and intensified. This intensification was characterized by the increased activity of corporate developers, accompanied by more explicit facilitation of neighborhood transformations by local and federal government. This state-backing of corporate redevelopment projects is associated with weakened resistance from marginalized anti-gentrification movements, and the diffusion of gentrification trends into more remote neighborhoods of some cities (Hackworth and Smith 2001; Lees et al. 2008).

Fourth-Wave
Gentrification

New varieties of gentrification in the $21^{\text {st }}$ century are defined by differentiation into more specific typologies of neighborhood change than were seen in prior decades (as detailed further below). Often described as the "mutation" of the gentrification process (Davidson and Lees 2005:1187; Lees et al. 2008), an important characteristic of fourth-wave gentrification is its growing presence in neighborhoods further away from the urban core (Lees et al. 2008).

New-Build
Gentrification
(4 ${ }^{\text {th }}$ wave)

The socioeconomic transformation of poor or working class neighborhoods associated with increasing middle class presence and the displacement of lower social class residents resulting primarily from new-build housing as opposed to the restoration of older structures (Davidson and Lees 2005). 
Retail Longtime locally owned retail businesses in gentrifying

Gentrification neighborhoods are displaced by newcomers oriented towards the ( $4^{\text {th }}$ wave) tastes and budgets of gentrifier households (Sullivan and Shaw 2011).

\begin{tabular}{ll}
\hline $\begin{array}{l}\text { Environmental } \\
\text { Gentrification } \\
\left(4^{\text {th }} \text { wave }\right)\end{array}$ & $\begin{array}{l}\text { Urban developments that improve neighborhood environments and } \\
\text { environmental amenities to attract higher income residents, resulting } \\
\text { in gentrification and displacement of original residents (Checker } \\
(2011) .\end{array}$ \\
\hline $\begin{array}{l}\text { Rural } \\
\text { Gentrification } \\
\left(4^{\text {th }} \text { wave }\right)\end{array}$ & $\begin{array}{l}\text { Highly related to environmental gentrification, rural gentrification is } \\
\text { attributed to middle and upper-middle class populations drawn to } \\
\text { scenic, rural areas for their various environmental amenities (Ghose } \\
\text { 2004; Lees et al. 2008). }\end{array}$ \\
\hline $\begin{array}{l}\text { Super } \\
\text { Gentrification } \\
\left(4^{\text {th }} \text { wave }\right)\end{array}$ & $\begin{array}{l}\text { The gentrification of gentrified neighborhoods: an intensification of } \\
\text { prior redevelopment efforts instigated by even higher status in- } \\
\text { migrants, resulting in many of the original gentrifiers being priced- } \\
\text { out of the neighborhood. This is evidence of the continuing mutation } \\
\text { of the gentrification phenomenon (Lees 2003). }\end{array}$
\end{tabular}

\section{Working Definition of Gentrification for this Study}

Based on the common elements of typologies described above, gentrification is defined in this study as a process of socioeconomic ascent of previously working class, poor, or disinvested neighborhoods. This process involves (1) the in-migration of new residents of a higher social class than the neighborhood's original residents (Smith 1998; Eckerd 2011); (2) the out-migration, displacement, or "pricing out" of those original residents by the wealthier newcomers (Kennedy and Leonard 2001; Lees et al. 2008); and (3) the reinvestment of public and private capital into neighborhood infrastructures and services (Hackworth and Smith 2001; Smith 1998) - not necessarily in that order. Such demographic changes often include a racial component, and they result in an increased average SES for the neighborhood and a qualitative change in the neighborhood's overall character (Kennedy and Leonard 2001). This general definition, of which manifold 
variations can be found throughout the literature, is the working definition used in this study, and its components are explored in further detail in the sections below.

\section{Theories of Gentrification}

Prior research into the effect of urban rail transit development on nearby property values is not an adequate basis in and of itself for a theoretical model of the relationship between rail transit and gentrification. However, since it does comprise the largest body of literature directly assessing the relationship between transit infrastructure development and any single component of gentrification, consideration of the theoretical merits of such research is worthwhile.

Empirical studies linking transit and property value have commonly relied, either implicitly or explicitly, on neoclassical urban economic theory. The neoclassical urban economic framework, which dominated scholarly research related to neighborhood change through the 1960s (Molotch 1993), typically considers transportation in terms of the cost in time and money of commuting to employment centers in the urban core (Revington 2015). From this heavily economistic perspective, new transit infrastructure is expected to have the effect of decreasing the transportation burdens that counterbalance the benefits of larger and less costly homes in neighborhoods further from downtown. In other words, if a potential home's size, cost, and proximity to employment are the primary factors of a householder's rational choice of residential location, a new LRT station in an outer-lying suburb is expected to mitigate the negative impacts of a long driving commute and the expense of fuel and parking. 
However, in a review of transportation economics studies, Foster (2010:394) argues that "when the modal choice is between an automobile and public transportation, comfort, and privacy, the ability to use transit time for some productive end, and variability of travel time all differ among modes," suggesting that this theoretical model is perhaps overly-simplistic. Furthermore, as Revington (2015) notes, neoclassical urban economic theory incorrectly assumes that all households are equally positioned to make such a choice in the first place. Revington (2015:157) argues that since changes to the built, social, or economic environment alter the geographic distribution of opportunity in the city, households with pre-existing advantages "are apt to use [them] to further their own interests... [and] in this way, redistribution of wealth within the city tends toward inequality." This connection between residential location and self-interested rational choice within the context of class-based structural constraints is reminiscent of a political economy approach to urban sociology, which integrates production-oriented and consumption-oriented explanations of urban stratification.

Broadly speaking, production-oriented explanations of gentrification revolve around the geographically uneven development of urban space, the resulting production of housing and changes in housing tenure, and the stratification within and between neighborhoods along lines of race and social class that is perpetuated by such processes (Lees et al. 2008). A widely discussed production-oriented explanation of gentrification is Neil Smith's rent gap thesis (Smith 1979; Smith 1987; Smith 1998). Proposed at a time when gentrification research was dominated by the neoclassical economic framework, 
Smith's (1979) original iteration of the rent gap thesis argued that capital disinvestment in poor neighborhoods relates to the exploitation of working class residential renters by capitalist property-owning landlords. The argument states that landlords will neglect their rental properties in such neighborhoods, benefitting at the expense of their working class renters, until the "rent gap" - the difference in capital between the capitalized ground rent currently collected and the potential ground rent that could be gained from the development and/or sale of the property - widens sufficiently for the property owner to pursue development or sale, making room for wealthier households to move in at the cost of low-income renters' displacement (Smith 1979; Smith 1987).

Conversely, consumption-oriented explanations of gentrification focus on consumer demand for (as opposed to developer supply of) quality residential property with access to desirable amenities and other more qualitative neighborhood assets (Lees et al. 2008). For example, access to shopping and cultural attractions, the presence of existing residents who adopt particular lifestyles or political ideologies, and racial/ethnic diversity all could attract specific types of households to a given neighborhood. This makes the development of transit infrastructure theoretically significant to consumptionoriented gentrification, because it connects neighborhood residents to the rest of the city and region, providing access to amenities near and far. Simultaneously, it helps explain resistance to LRT development in higher-SES communities, in which residents are less likely to be transit-dependent and, indeed, are more car-dependent for various reasons. 
In this context, neoclassical urban economic theory can be considered a subset of consumption theories. Although access to downtown employment centers, larger homes and taxlots, and the potential of expendable income (which economic theory suggests are counterbalancing factors of neighborhood choice) are all arguably oriented towards consumption, the theory's previously described tendency towards equilibrium fails to account for variances in demand among different classes of consumers, as well as the associated unequal distribution of resources necessary for individuals and households to actually exercise choice in their residential location. Thus, while the neoclassical economic framework is not on its own adequate for explaining the social and demographic dynamics of neighborhood change, it does include consideration of certain factors that are likely to be influential on a neighborhood's desirability to a given person or household regardless of their ability to actually move there. In this context, factors such as proximity to downtown, and the characteristics and costs of residential properties are all relevant to a given neighborhood's ability to attract residents of higher social class, and, by extension, its susceptibility to gentrifying forces.

It is also important to note that production and consumption factors of neighborhood change, similar to the economic concepts of supply and demand, are inherently interdependent upon one another. Desirable neighborhood characteristics are not products of random chance, but rather are the outcomes of production processes, and those processes are informed and controlled by individuals and organizations in both the public and private sphere. Growing recognition of this interdependence, and more 
importantly, of the motivated actors behind the production and consumption relationship, gives rise to the political economy approach to explaining neighborhood change (Schwirian 1983). Discussing the various models of neighborhood change found in the sociological literature, Schwirian (1983:94) describes the political economy approach as a consideration of community change "in terms of the complex linkages among economic and political institutions and the various segments of the business and housing markets," and identifies the theory of the city as a "growth machine" (Logan and Molotch 1987; Molotch 1976; Molotch 1993) as a prime example of such an approach.

The urban growth machine theory suggests that, with a common orientation around growth objectives, elite actors and organizations possessing influence over urban policy and structure are in at least tacit cooperation with one another, forming "growth coalitions," to reach those objectives (Logan and Molotch 1987). Essential to the overarching nature of such growth coalitions and their objectives are the interrelated concepts of exchange values and use values. In describing these two important concepts, Logan and Molotch (1987) make the distinction that exchange value refers to the quantitative economic value of a given place as a commodity in the open marketplace; whereas use value refers to the qualitative personal worth of a place as a basis of home and community (Logan and Molotch 1987). In order to maximize and control the flow of capital in an urban area, and therefore ensure continued growth, it is in the interest of growth actors to prioritize the exchange values of urban neighborhoods over the use 
values those neighborhoods offer to the communities inhabiting them (Logan and Molotch 1987). Further reflecting on this prioritization, Molotch (1993:45) posits:

In terms of neighborhood decline, traffic intensification, and pollution of the earth, there is a tendency for those with direct pecuniary interest to perceive less of a genuine threat to well-being, even if they, too, suffer when things go wrong. Within individuals and organizations, there is a balance of use and exchange value interests such that for some actors the latter can overwhelm the former.

In short, the urban growth machine theory suggests that "the objective of growth unites otherwise pluralistic interests in relation to a city" (Rodgers 2009:4).

Through this theoretical lens, LRT development is understood as a collaboration between public and private actors intending to maximize the exchange value of place, with the city's economic growth (rather than environmental or social sustainability) being the ultimate goal. Logan and Molotch (1987) describe the pursuit of exchange values as an especially high priority of public figures and organizations seeking a larger tax base from more affluent residents, as well as of rentiers (i.e., landlords), entrepreneurs (i.e., developers), and (to a lesser extent) homeowners seeking larger returns on property investments. In contrast to the exchange values of place, which fluctuate with the market but are generally consistent between actors, the use value of a given neighborhood has disproportionate relevance to the residents who inhabit it, including homeowners and renters. This is due largely to use values often relating to personal or sentimental values that are not appreciated by the actors involved in growth coalitions, whose structural decisions affect both use and exchange values (Logan and Molotch 1987). 
The introduction of mass transit to a low-income neighborhood improves that neighborhood's use value by increasing connectivity to the larger region, resulting in an improved experience of residents making their daily rounds. However, as a product of urban growth machines, transit development is pursued by municipalities and the growth actors therein primarily in the interest of stimulating subsequent development by other growth coalition actors, and ultimately elevating exchange values to benefit all coalition members (Logan and Molotch 1987; Yago 1983). When such an increase in neighborhood use value contributes to increasing exchange values (i.e., property values), the resulting increase in property taxes and rents is likely to drive out the most vulnerable populations for whom the use value of community and transit connectivity is greatest (Logan and Molotch 1987). Displaced residents are then replaced by higher SES residents, whose personal income and particular tastes spur the development of still other amenities, which in turn attract more in-movers of a comparable class. In this context, “transportation doesn't just serve growth, it creates it" (Logan and Molotch 1987:74).

This potentially applies to any community development that adds an amenity or some other desirable characteristic to a neighborhood that is gentrifying or at risk of gentrifying. For example, Sullivan's (2007) survey of residents in a gentrifying area in Portland, Oregon found that although renters and longtime residents were less likely than homeowners or new residents to have a positive perception of changes to their neighborhood (such as a monthly art festival), a majority of residents overall had positive perceptions of changes and a positive outlook on continued changes in the future. This 
was despite the clear occurrence of displacement of low income and Black residents from the neighborhood (Sullivan 2007).

Social equity is considered in the context of the disproportionate capacity of growth machines over residents to influence either exchange or use values. Logan and Molotch (1987:69) argue that this dynamic commonly manifests itself in the ability to "influence higher-level political actors in their growth distribution decisions." For example, the decision to zone a low income neighborhood for larger and higher density developments while granting historical status to a higher income neighborhood, dictates where such development takes place. Such a decision could easily result in a massive increase in exchange values for developers (for example, if a high-rise containing 300 condos is constructed on what was originally 4 tax lots for single-family houses), and a simultaneous decrease in the use value of the neighborhood for existing residents (for example, due to the increased noise and traffic congestion associated with a large influx of new residents in a relatively small area).

Furthermore, it is in a city's short-term economic interest to clear out as many low-income households as possible to make way for higher-income residents who will do more to improve the tax base. As such, local, state, and federal agencies are prone to label a neighborhood that has suffered disinvestment from public resources for a prolonged period as "blighted" and slated for urban renewal. In the 1940s, 50s and 60s urban renewal equated to tearing down houses in the name of safety, health, or some other "greater public good," causing the direct displacement of those residents. By the 1980s 
the practice was typically operated through tax increment financing, in which major public investments in a neighborhood would be funded through loans with the understanding that they would be paid back in full by the revenue from increased property values in the future (Logan and Molotch 1987). The impacts of urban renewal on neighborhoods in Portland's Albina District are discussed further below.

These factors together suggest that the only places where socioeconomically disadvantaged populations fit neatly into a theoretical model of gentrification are (a) at the beginning, in disinvested and amenity-poor neighborhoods that subsequently undergo gentrification, (b) at the end, in the disinvested and amenity-poor neighborhoods to which they relocate following displacement, and (c) throughout the model, in the disinvested and amenity-poor neighborhoods for which exchange value and use value are both depressed, and for which the need for land has not become dire enough to deploy gentrifying capital. A sociological model that accounts for changes in neighborhood-level social class as the outcome of inter-neighborhood dynamics, embedded in a larger metropolitan region, is therefore a significant contribution to the study of gentrification.

\section{Measuring Gentrification}

To measure this type of neighborhood change with a high degree of content and construct validity is not easily accomplished, but there are precedents in the literature for doing so using quantitative as well as qualitative methods. Each approach of course has its own strengths and limitations, but since the present study takes a quantitative approach that will be the focus of this section. 
Hammel and Wyly (1996) conducted a house-by-house qualitative field survey in Minneapolis-St. Paul, assessing each housing structure as being either "improved," "unimproved," or "new." The condition of census tract housing was then used to code each tract as either having already undergone such a transition, possibly being in the process of gentrification, being disinvested and thus having potential for gentrification, or not being disinvested and thus ineligible for gentrification. Stepwise and canonical discriminant analysis identified several census variables that were statistically significant in predicting most of these a priori gentrification statuses. Those variables included (in no particular order): population size; median household income; median rent; number of employed workers; percent of workers in managerial, professional, and technical occupations; and percent of population with $4+$ years of college. The extent of change from the previous census year in census tract median income, rent, and house value was also used to assess gentrification status (Hammel and Wyly 1996).

Subsequent research has further refined and built on Hammel and Wyly's (1996) list. For instance, Freeman (2005) used several of those variables and added the variable of average age of housing stock. Owens (2012), studying the dynamics of neighborhood ascent in general, which includes gentrification as well as other forms of socioeconomic upgrading, used variables pertaining to household income, rent, home value, education, and occupation to develop an aggregate score of census tract SES relative to all tracts in a metropolitan statistical area (MSA). The study found that in most American cities, 
neighborhood ascent was disproportionately in white suburban neighborhoods from 1970 to 1990 , and in minority urban neighborhoods from 2000 onward (Owens 2012).

In a study of recent trends in Portland, Bates (2013) combined tract-level census data with data from the Department of Housing and Urban Development to develop a neighborhood typology representing different stages of gentrification. This typology is based on three dimensions of gentrification and displacement. First, population vulnerability is determined from higher than average proportions of renters, racial minorities, adults without college degrees, and low-income households. Second, demographic change is concerned with increases between 2000 and 2010 in homeownership, white population, college degree holders, and household income. Third, housing market conditions were assessed based on the median home value for each tract as a percentage of the citywide median home value (Bates 2013).

Depending on a given tract's combination of statuses in these three dimensions, it was categorized as one of six potential neighborhood types corresponding to a specific stage of gentrification. These include a "susceptible" stage indicating increased risk for future gentrification; two "early" stages indicating the possible onset of gentrification; a "dynamic" stage of "current and ongoing significant gentrification pressures;" a "late" stage indicating that gentrification is in process but vulnerable populations remain; and lastly a stage of "continued loss" indicating that a tract is mostly gentrified, but "remaining vulnerable households may be in a precarious situation" (Bates 2013:30). 
Many of the methods described above rely on the use of neighborhood typologies to identify particular stages of gentrification. While such typologies are important for understanding the progression of gentrification as a process and identifying at-risk areas for the targeted deployment of policy, reliance on a categorical indicator is not ideal for measuring neighborhood level socioeconomic characteristics more generally and their changes over time. This is largely because transition from one typology to another does not reflect a very fine level of detail with regard to the extent of change required to make that categorical transition. Thus, to capture the extent of neighborhood change indicative of gentrification, an interval-ratio level measure is preferable over neighborhood typologies.

David Ley (1986) constructed a simple measure of neighborhood SES based on Canadian census data for exactly this reason. The social status index was calculated for census tracts as the mean value of a tract's percentage of the workforce employed in professional, managerial, technical, and administrative jobs, and the percentage of the population with a college degree. Although Ley (1986) acknowledged that income would normally be a component of such an index, it was intentionally omitted in order to identify the earliest stages leading up to gentrification just prior to the influx of higherearning households. Having calculated this index value for two separate time points, Ley (1986) calculated a new variable as the difference between them and dubbed it the gentrification index, which measures change in residential socioeconomic status at the neighborhood level. This method has been replicated in other studies (e.g., Danyluk and 
Ley 2007; Eckerd 2011), but also sharply criticized as over-simplistic due in part to the omission of income change as a component of the gentrification process (Smith 1987).

The methods employed in this project, discussed in greater detail in Chapter 3, draw from these and similar approaches found in the literature. However, in the interest of ensuring manageability and simplicity while addressing the stated need for more comprehensive measures of SES, an adaptation of Ley's (1986) approach that incorporates a measure of neighborhood income is preferable for operationalizing neighborhood SES and SES change in the greater Portland area. Using an index method such as this lends itself to quantitative analysis of the relationship between LRT and gentrification or neighborhood SES more generally, which is integral to bridging the clear gap in the literature.

\section{Role of Transit in Neighborhood Change}

A review of the literature found that research pertaining to the relationship between transit development and neighborhood change is spread across a range of academic disciplines, and thus comprises multiple bodies of literature that often do not speak to one another. The vast majority of research pertaining to this relationship comes not from sociology but from urban economics, real estate, and planning-related fields, in which transit is the topic of focus and gentrification as defined here is rarely discussed, let alone measured and analyzed. Research in the transit literature has been primarily or exclusively concerned with measuring the effect of rail transit on property values. While this does not address socioeconomic change in the residents of transit-served 
neighborhoods, the research methods employed in such studies have been fairly consistent and their findings informative of the general relationship between transit development and property values. ${ }^{3}$

In stark contrast to the expansive literature on property values, there is very little research to be found on the effects of transit development on neighborhood demographic characteristics. The handful of studies directly investigating that relationship come from both academic and non-academic publications (with a wide variety of intended audiences), and each employs a unique methodological approach, which makes generalization from their findings problematic. This section briefly reviews these two sets of literature, and in doing so makes an argument for bridging the divide between them.

\section{Transit and property value}

In "Gentrification, Displacement and the Role of Public Investment: A Literature Review," Zuk et al. (2015) note that in the large research literature pertaining to the effect of transit development on housing cost, two methods of analysis have been dominant: the "Pre/Post" method and hedonic price modeling. First, in the "Pre/Post" method, which is the less commonly employed of the two, home prices are compared in a particular neighborhood before and after transit development occurs (Zuk et al 2015). The time sequence element is valuable for establishing causal links, but Zuk et al. (2015) suggest that "Pre/Post" studies are less common due to the need for longitudinal data. Second, in

\footnotetext{
${ }^{3}$ Given the large number of studies that have been published on transit and property values, this section focuses on prior literature reviews, meta-analyses, and research focusing on the Portland region.
} 
hedonic price modeling, which does not require longitudinal data, property values are regressed on property characteristics, with the primary independent variable typically being distance from stations along street networks (Zuk et al. 2015). By controlling for other property characteristics (e.g., acreage, square footage, number of rooms, distance to other amenities, etc.), hedonic price modeling attempts to isolate the effect of transit accessibility on property values, holding all else constant.

With dozens of property value studies published since the 1990s, several literature reviews have noted wide variations in their findings (Cervero and Duncan 2004; Diaz 1999; Hess and Almeida 2007; Zuk et al. 2015; Wardrip 2011). Attempting to explain that variation, two recent meta-analyses have supported a mixed but overall positive relationship between proximity to rail transit and rising property values in U.S. cities (Debrezion, Pels, and Rietveld 2007) as well as internationally (Mohammad et al. 2013). The relationship is found to be more variable and lower in its impact on property values in North American than in European and East Asian cities, more consistently positive for commercial than residential properties, and greater in magnitude for (undeveloped) land than (developed) properties; however, holding these factors as constant, there remains a generally positive effect of proximity to stations on property values (Debrezion et al. 2007; Mohammad et al. 2013). 
This overall positive relationship is supported by research specific to LRT station development and property values in the Portland region. ${ }^{4}$ At least two studies (AlMosaind et al. 1993; Chen et al. 1998) have found increases in the property values of single family homes in relation to their proximity to Eastside Blue Line MAX stations, which opened in 1986. In the earlier study, Al-Mosaind et al. (1993) analyzed 1988 home sales in a section of the rail corridor spanning East Portland and the suburb of Gresham. Using a dummy (i.e., dichotomous) variable to indicate residential properties located within 500 meters (1640 feet) of a station, the study found property values in that vicinity were expected to be $10.6 \%$ greater than values of properties over 500 meters away.

However, in a second model that limited analysis to only include property sales within that 500-meter zone, and, instead of using a dichotomous variable, regressed property values on a continuous measure of walking distance to stations, the (negative) relationship between station distance and home values was not statistically significant (Al-Mosaind et al. 1993). The study concludes that although there is an apparent increase in home values closer to stations, the relationship is "not strong enough to imply a significant price gradient of distance to LRT stations," and suggests this may be due to the confounding factor of "nuisance effects" - such as noise and increased traffic near rail lines - counteracting the capitalization effects of proximity to stations (Al-Mosaind et al. 1993:92). Commenting on these findings, Diaz (1999:3) argues that the significant result

\footnotetext{
${ }^{4}$ See section below titled "Gentrification and Transit in Portland, Oregon" for a detailed discussion of the region's LRT system.
} 
from regressing on the dummy variable is evidence of a net benefit of house proximity to LRT stations, which "shows that, at least in the case of this particular area within metropolitan Portland, the benefit of rail transit overshadows the nuisance effects."

Following up on Al-Mosaind et al. (1993), Chen et al. (1998) conducted an analysis of single family residential properties sold in the same geographical area from 1992 to 1994 , controlling for distance to the rail line to better account for nuisance effects. The study found that property values respond both positively and negatively to LRT station accessibility and LRT line nuisances, respectively, which supports the supposition that these factors work in combination with one another and should be controlled for separately (Chen et al. 1998). Results of the study indicate that house prices are estimated to decrease at an accelerating rate with greater distances from stations, reaching a minimum at 1402 feet (about a quarter mile) of $10.5 \%$ lower than those immediately adjacent to a station. Dueker and Bianco (1999) elaborate on the Chen et al. analysis, reporting that in comparison to single family homes adjacent to stations, property values 400 feet away were $5.1 \%$ lower, 600 feet away were $7.1 \%$ lower, and 800 feet away were $8.5 \%$ lower.

Similar effects have been found in relation to the Westside MAX line from Portland to Hillsboro, which built stations with much more undeveloped land in their immediate vicinity than was possible with the previous installment. Knaap, Ding and Hopkins (2001) analyzed data from all the sales of vacant residential parcels within the Portland Metro area from 1992 to 1996 and found that land values around station 
locations increased sharply following the official approval and announcement of specific locations for the line and stations in mid-1993. Land values within half a mile of planned stations, which were not significantly different from the region's other vacant residential parcels in 1992 and 1993, were 71\% higher than those other parcels in 1994 and 21\% higher in 1995 (Knaap et al. 2001). Expanding their study area to include land sales within a full mile of planned stations found these were still 10\% and 9\% higher in 1994 and 1995, respectively, than the values for vacant residential parcels elsewhere in the study area (Knaap et al. 2001).

\section{Transit and gentrification}

The findings from property value studies discussed above suggest the Portland region has high potential for gentrification and displacement around LRT development. However, to adhere to the working definition of gentrification as a socioeconomically prescribed, neighborhood-level process of residential in- and out-migration, analysis of demographic change is essential to the study of this relationship. The approach taken in this thesis therefore focuses on the effects of transit development on the socioeconomic and demographic characteristics of neighborhoods receiving such infrastructure - an emphasis shared by very few prior studies. In an extensive search of the literature, only five studies could be found that pertain directly to the relationship between transit development and gentrification. Of those five studies, three were multi-regional analyses, with each using distinct methods for selecting metropolitan regions and neighborhoods 
therein for analysis (Grube-Cavers and Patterson 2014; Kahn 2007; Pollack et al. 2010); ${ }^{5}$ and two were published as reports for third party organizations (Dominie 2012; Pollack et al. 2010). ${ }^{6}$ All five studies utilized GIS to select samples and/or calculate distance variables, and only one was published in a sociological journal (Grube-Cavers and Patterson 2014).

Remarking on research pertaining to "transit-induced" gentrification, the earliest study cited in the literature review by Zuk et al. (2015) was conducted by Lin (2002), focusing on Northwest Chicago. Although Lin (2002) explicitly connects rail transit development to gentrification, that connection relies on property values alone as a proxy for gentrification, interpreted through neoclassical economic theory. Due to its exclusive reliance on property values, the study by Lin (2002) fails to address the component of demographic change that is essential to the working definition of gentrification for this study. However, it is included here because the approach taken by Lin (2002) differs from most other property value studies in two important ways.

First, study design and findings relate to a clearly stated application of economic theory that explicitly considers gentrification as a process of socio-demographic neighborhood change. Lin (2002) acknowledges that it would be preferable to analyze

\footnotetext{
${ }^{5}$ The broad scope of multi-regional analyses can limit their ability to account for the influence of unique neighborhood histories on public and private investment and community responses to urban development, and generalization from their findings is complicated by their variety of methodological approaches.

${ }^{6}$ Although it is assumed that they went through some process of review, the implication of being published in reports for third party organizations is that they were not put through the same peer review process as is associated with publication in a scholarly journal.
} 
housing market data in combination with demographic measures, specifically citing the method developed by Ley (1986), but argues that "household status variables, as drawn from the census, are clumsy because of their lack of sufficient geographic detail and their decennial frequency," and suggests that such an approach is incompatible with a "transitcentered" focus (Lin 2002:178). ${ }^{7}$ Second, rather than using hedonic price modeling or "Pre/Post" methods, Lin (2002) uses rate of change in property values as the dependent variable, which is in line with gentrification as a process of neighborhood change, even though it fails to directly address the demographic components of such changes.. Utilizing housing market data for Northwest Chicago between 1975 and 1991, and operationalizing transit access as the straight-line distance to the nearest rail transit station, Lin (2002) finds that properties closer to transit stations are found to have experienced a greater rate of increase in their values than those further away during the periods 1975-1980 and 1985-1991 (but not 1980-1985), and concludes this is evident of transit-induced gentrification.

In the only other single-region study found to explicitly relate transit and gentrification, Dominie (2012) essentially investigates the reverse of the relationship of focus in the present study - that is, the effect of gentrification on transit use. Dominie (2012) measures neighborhood change in Los Angeles County from 1990 to 2010 using several demographic variables drawn from the 1990 and 2000 decennial censuses and the

\footnotetext{
${ }^{7}$ While investigating the demographic effects of transit access at the neighborhood level using census data does impose substantial limitations to study design, the integration of ancillary geographic data on housing distribution (as described in Chapter 3) can effectively mitigate some of these limitations.
} 
2006-10 American Community Survey (ACS) 5-year estimates. This is accompanied by two index variables constructed from socioeconomic statistics: (1) the socioeconomic change index, and (2) the gentrification index (Dominie 2012). ${ }^{8}$

Limiting analyses to "station areas" composed of tracts within a half-mile of rail stations, Dominie (2012) finds that from 1990 to 2010, transit-served neighborhoods in Los Angeles County increased to a greater extent than the county average in median rent, median home value, and median household income, as well as the number of managerial workers, college degree-holders, and households with income over $\$ 75,000$.

Simultaneously, station areas decreased less than the county average in number of nonLatino whites, and, in terms of transit use, station areas increased more than the county average in number of households with two or more cars, and decreased less than the county average in number of zero-car households (Dominie 2012). Regression analysis of the number of census tract workers commuting by transit, regressed separately on the two indexes and other neighborhood-level variables, found that gentrification (according to its index) was the greatest predictor of transit use, while housing cost variables were not significantly related to transit commuting (Dominie 2012). Taken together, these findings

\footnotetext{
${ }^{8}$ First, the socioeconomic change index is based on differences between the decennial censuses and the 2006-10 ACS in the number of high-income households, low-income households, managerial workers, and highly educated adults in each census tract compared to the county mean. Second, the gentrification index is calculated as the product of the socioeconomic change index multiplied by the percentage of low-income households in 1990 and 2000 (Dominie 2012). To compare neighborhoods to the county mean, both indexes are calculated from z-scores of these variables (Dominie 2012).
} 
are clearly indicative of a relationship between transit and gentrification, but are not conclusive with regard to whether that relationship amounts to correlation or causation.

Other than the articles by Lin (2002) and Dominie (2012), the studies found to directly assess the transit-gentrification link are all based on multi-regional analyses (Kahn 2007; Pollack, Bluestone and Billingham 2010; Grube-Cavers and Patterson 2014). Kahn (2007) analyzed 14 U.S. metropolitan regions (including Portland) that received new rail transit lines between 1970 and 2000. Gentrification was operationalized as an increase in average home price and percentage of adults with college degrees, which were analyzed separately along with other demographic variables. GIS was employed to sample all census tracts within 20 miles of the central business district in each region, omitting tracts that were within 1 mile of a rail transit station in 1970 (Kahn 2007). Using this large sample of tracts, Kahn (2007) compared the socioeconomic outcomes of census tracts within 1 mile of new "park and ride" or "walk and ride" transit stations (comprising two treatment groups) to tracts that were never near any rail transit (control group).

Based on regression analyses run separately for the two dependent variables, Kahn (2007) found that in most cities, average home prices and share of tract populations with college degrees both increased in walk and ride neighborhoods but not in park and ride neighborhoods (Kahn 2007). Portland, along with Los Angeles, was an exception to this finding. Analysis of the Portland region showed no evidence of gentrification based on either indicator in relation to walk and ride stations, and a significant negative 
relationship to park and rides on both indicators, indicating that communities close to those mostly-outlying stations actually declined in SES (Kahn 2007). This finding is particularly important because it contradicts the positive findings of previous studies that analyzed land and property values along segments of individual LRT developments in Portland, including near at least two park and ride stations along the Eastside Blue Line (Chen et al. 1998) and at least 3 along the Westside Blue Line (Knaap et al. 2001).

Taking a different approach to multi-regional analysis compared to Kahn (2007), Pollack et al. (2010) analyzed 42 "transit-rich neighborhoods" (TRNs) across 12 U.S. cities that received new light, heavy, or commuter rail transit infrastructure between 1990 and 2000. GIS was employed to identify all census block groups with a majority of their areas within a half-mile of new stations, and stations for which surrounding block groups did not have boundary changes between 1990 and 2000 were selected as the TRNs for analysis. Gentrification was operationalized as an increase in property values and incomes 20 percentage points or more above the percent of change in the respective metropolitan statistical areas, but the authors do not describe setting any criteria to assess prior neighborhood disinvestment as a condition for TRN eligibility for gentrification (Pollack et al. 2010). Percentage changes between the two time points were calculated for a variety of demographic and economic census variables related to transit as well as gentrification, and the difference between percentage change in each TRN and the change in the MSA containing it is used to compare TRNs across different cities (Pollack et al. 2010). 
Among their many conclusions, Pollack et al. (2010) found that TRNs associated with new LRT had higher rates of low-income and renter households before station development in comparison to TRNs with other types of rail transit. Furthermore, they following station development in LRT-served TRNs, "almost every aspect of neighborhood change was magnified: rents rose faster and owner-occupied units became more prevalent... [and] in-migration by higher-income families appears to have disproportionately changed the demographic structure and substantially increased the risk and pace of gentrification" (Pollack, et al. 2010:33). While these findings support a generally positive effect of LRT station development on subsequent socioeconomic ascent in the neighborhoods those stations serve, assessment of this relationship is not qualified by pre-existing conditions of neighborhood disinvestment, which somewhat limits the applicability of this study to gentrification research more broadly. Additionally, analysis of neighborhood changes using census data at the block group level, while an improvement in geographic precision compared to census tracts, greatly increases the statistical uncertainty (margin of error) of certain variables, presenting a limitation that the study's authors neither address nor acknowledge (Pollack et al. 2010).

Most recently, Grube-Cavers and Patterson (2014) analyzed the effects of rail transit on subsequent gentrification in the Canadian cities of Montreal, Toronto, and Vancouver, measuring gentrification with multiple Canadian census variables that correspond closely with U.S. census measures previously discussed. Grube-Cavers and Patterson (2014) depart from the previously discussed studies by defining gentrification 
as an event rather than as a process of neighborhood change. However, in practical terms this is essentially the same as defining a typology indicative of neighborhoods in the early stages of change following the initial onset of gentrification. With gentrification defined as an event, survival analysiswas employed to find the "time-to-gentrify" following rapid transit system development in Montreal, Toronto, and Vancouver. ${ }^{9}$

Gentrification was operationalized as a dichotomous variable (i.e., 1=Gentrifying; $0=$ Not Gentrifying) based on Canadian census variables for average monthly rent, proportion of people in professional occupations, percentage of owner-occupied dwellings, average family income, and number of degrees per capita (Grube-Cavers and Patterson 2014). Census tracts with average family income and number of degrees per capita below the average value for the metropolitan area were considered "gentrifiable" and retained for analysis based on SES variables in the subsequent census year. A tract was coded as 1 on the dependent variable only if all five SES variables increased from the prior census year to a greater extent than the average change in the metropolitan area overall.

Grube-Cavers and Patterson (2014) also included in their analysis certain geographic variables generated using GIS, including straight line distance to the CBD and straight line distance to the nearest transit station. The study found a significant

\footnotetext{
${ }^{9}$ Grube-Cavers and Patterson (2014:8) describe survival analysis as "a collection of statistical procedures for analyzing data where the outcome variable is time until an event occurs." Although it is most often used in bio-statistical research to estimate the time until death of patients given certain conditions, it has also been utilized substantially to estimate the time to failure of a physical component such as a mechanical or electrical device (Grube-Cavers and Patterson 2014; Miller 2011).
} 
positive relationship between census tract exposure to transit stations and subsequent gentrification in Toronto and Montreal, but not Vancouver. Furthermore, for the former two cities they report an interaction effect between exposure and time, indicating that the gentrification effect is greatest in the census year immediately following the installment of new transit and decreases over subsequent years (Grube-Cavers \& Patterson 2014). Although the study's findings suggest that transit development contributed to closing the rent gap in affected neighborhoods (see Chapter 2 section, "Theories of Gentrification"), the authors did not explicitly discuss their findings within such a theoretical framework.

Taken as a whole, this small research literature suggests that urban rail transit development often, but not always, relates to socioeconomic changes indicative of neighborhood ascent and even gentrification in station areas. However, numerous and substantial limitations apply. Due to their over-reliance on property values to measure neighborhood characteristics, findings from Lin (2002) and Kahn (2007) have limited applicability to gentrification as presently defined. A similar limitation, related to lack of accounting for neighborhood disinvestment as a prerequisite of gentrification, applies to the findings of Lin (2002), Kahn (2007), and Pollack et al. (2010). Additionally, the wide variety of methods used to select samples, operationalize gentrification, and analyze neighborhood change limits the generalizability of these studies overall to the broader discourses on gentrification and transit. Mixed findings from multi-regional studies suggests that the relationship between LRT development and neighborhood change may be influenced by certain characteristics of metropolitan regions, cities, or neighborhoods 
that have yet to be identified or adequately explored. This line of research therefore stands to benefit from closer analysis of individual regions for differences within them. Lastly, the study by Dominie (2012) serves to remind that just as urban development shapes neighborhoods, these types of neighborhood changes can also influence the policies and practices of urban transportation planning that lead to transit development.

The present study improves on prior research by utilizing a demographic measure of gentrification based on socioeconomic characteristics of neighborhood residents, as opposed to relying on housing market status. Limiting analysis to a single metropolitan area (Portland) and analyzing individual LRT installments in the region separately from one another serves to more fully account for the unique neighborhood context of transit development based on the time and place in which it occurred.

\section{Gentrification and Transit in Portland, Oregon}

The Portland, Oregon region offers an ideal setting for the focus of an investigation of the relationship between transit and gentrification for at least two reasons. First, Portland is home to a highly successful regional light rail transit (LRT) system - the Metropolitan Area Express (MAX), operated by the Tri-County Metropolitan Transportation District of Oregon (TriMet). Since the first line opened for use on Portland's Eastside nearly 30 years ago, TriMet has periodically expanded the MAX system with multiple new lines of service (see Table 2 for complete timeline). TriMet's MAX is now recognized as one of the most utilized LRT systems in the United States, surpassed in annual ridership only by those in Boston, Los Angeles, and San 
Francisco (APTA 2014). These factors make analysis of its long term effects a promising opportunity.

Table 2: TriMet MAX System Timeline

\begin{tabular}{|c|c|c|c|c|}
\hline $\begin{array}{l}\text { MAX } \\
\text { Line }\end{array}$ & $\begin{array}{l}\text { Decision } \\
\text { to Build } \\
\text { Approved }\end{array}$ & $\begin{array}{c}\text { Construction } \\
\text { started }\end{array}$ & $\begin{array}{l}\text { Opened } \\
\text { for use }\end{array}$ & Project \\
\hline $\begin{array}{l}\text { Eastside } \\
\text { Blue } \\
\text { (EB) }\end{array}$ & 1979 & 1982 March & 1986 Sept & $\begin{array}{l}\text { Connects downtown Portland, } \\
\text { Gateway TC and Gresham } \\
\text { Added } 30 \text { stations over } 15 \\
\text { miles }\end{array}$ \\
\hline $\begin{array}{c}\text { Westside } \\
\text { Blue } \\
(W B)\end{array}$ & 1988 & 1993 July & 1998 Sept & $\begin{array}{l}\text { Connects downtown Portland, } \\
\text { Beaverton and Hillsboro } \\
\text { Added } 20 \text { stations over } 18 \\
\text { miles }\end{array}$ \\
\hline Red & 1997 & 1999 May & $2001 \mathrm{Sept}$ & $\begin{array}{l}\text { Connects Beaverton, } \\
\text { downtown Portland, Gateway } \\
\text { TC and Portland Airport } \\
\text { Added } 4 \text { stations over } 5.5 \\
\text { miles }\end{array}$ \\
\hline $\begin{array}{c}\text { Yellow } \\
(Y L)\end{array}$ & 1999 & $2000 \mathrm{Nov}$ & 2004 May & $\begin{array}{l}\text { Connects downtown Portland } \\
\text { and Expo Center } \\
\text { Added } 10 \text { stations over } 5.8 \\
\text { miles }\end{array}$ \\
\hline Green & 2006 & 2007 Feb & 2009 Sept & $\begin{array}{l}\text { Connects downtown Portland, } \\
\text { Gateway TC and Clackamas } \\
\text { Town Center TC } \\
\text { Added } 20 \text { stations ( } 12 \text { in } \\
\text { downtown Portland and } 8 \\
\text { from Gateway to Clackamas) } \\
\text { over } 8.3 \text { miles }\end{array}$ \\
\hline Orange & 2008 & 2011 June & $2015 \mathrm{Sept}$ & $\begin{array}{l}\text { Connects downtown Portland } \\
\text { and Milwaukie } \\
\text { Adding } 10 \text { stations over } 7.3 \\
\text { miles }\end{array}$ \\
\hline
\end{tabular}


Second, there is a well-documented history of gentrification in Portland's neighborhoods, and the area is now at the forefront of what Lees et al. (2008) have dubbed "fourth wave gentrification," which is driven by large investments from outside the neighborhoods and considered more likely to affect neighborhoods much further from the city center. Once a disparate array of prosperous and decaying neighborhoods, the disinvested urban core has been heavily gentrified, displacing low-income residents and racial minorities from the Pearl District downtown, North Portland, and the inner Northeast (Gibson 2007; Sullivan 2007; Boyle 2008). Considering the growing attractiveness of the area to college educated migrants (Jurjevich \& Schrock 2012), combined with the high rates of transit use noted above, gentrification along LRT lines further from the urban core is perhaps a greater possibility in Portland than elsewhere.

Table 2 provides a timeline for the MAX system. The Eastside Blue Line (EB), the first LRT line to be installed in the region, was built using federal transportation funds that were originally slated for the Mount Hood Freeway project - a major freeway initiative based on plans originating in the 1940s, which would have resulted in the destruction of 1,750 homes in SE Portland (Young 2005). News of the impending demolitions prompted strong grassroots opposition that hindered its implementation for decades and eventually brought the plan to a halt in 1974; the untouched development dollars were then redirected to build the EB MAX, earning Portland broad recognition as a sustainable city (Goodling, Green, McClintock 2015; Young 2005). 
The proposed Mount Hood Freeway was not the first major transportation project to cause controversy in Portland, but it was possibly the first to be defeated by grassroots organizing on the part of residents who would feel its impact. As part of the Federal Aid Highway Act of 1956, plans were drawn up for the construction of Interstate 5 and Highway 99, both of which would cut straight through the historically Black neighborhoods of North Portland, known as the Albina District. Despite contestation, that plan went through, demolishing 476 homes in the 1960s and dividing Oregon's largest African American community in the process (Gibson 2007). There are without a doubt many complex reasons why the efforts to keep the Mount Hood Freeway at bay succeeded and attempts to even mitigate the loss to community reaped by I-5 and Hwy 99 did not. However, from a political economy perspective it is explained in large part by the disproportionate economic and social power wielded by the opposition to Mount Hood Freeway, and the disproportionate exchange value associated with the 1,750 homes threatened in SE Portland compared to 476 homes in the long-disinvested communities of color in North and NE Portland.

The highway construction of the 1960s is just one of many examples of largescale urban development projects that displaced residents from Albina neighborhoods. Gibson (2007) notes that in the decades that followed, with construction of the Rose Quarter and Emanuel Hospital, accompanied and followed by disinvestment from absentee landlords and increasing tensions with law enforcement, the area was thoroughly prepared for the forces of gentrification by the 1990s. While the 
transformation of Albina up to that point was characterized by property demolitions and massive public works projects fueled by federal urban renewal programs, beginning in the 1990s those development trends shifted toward smaller-scale investments of private capital from "frontier gentrifiers" seeking profitable property investments (Gibson 2007).

From the 1990s onward, this re-investment of private capital increasingly was accompanied by targeted neighborhood revitalization efforts facilitated by public agencies such as the Portland Development Commission (Gibson 2007; Goodling et al. 2015). A key component of those efforts in Albina was the establishment of the interstate corridor urban renewal area (ICURA), which applied $\$ 30$ million of tax increment financing to develop the MAX Yellow Line (YL) - the only LRT in the region funded through an urban renewal program (Boyle 2008; TriMet 2005). In other words, the YL was installed under a program explicitly designed to raise property values, into a community that was at that time fervently combating gentrification. From 2000-2004 TriMet constructed and then began operation of the YL LRT facilities, which connect downtown Portland to the Portland Expo Center, with stations placed along the Interstate corridor that bifurcated the Albina community.

The potential impact of LRT development on the Albina community becomes even greater given Portland's status as the poster city of "smart growth" practices (Geller 2003), which prioritize high density housing, mixed use zoning, transit-oriented development, and highly walkable neighborhoods. Characteristics associated with smart growth, while highly desirable to a broad variety of urban residents, have spurred 
increasing market demand for single-family homes in these neighborhoods, which the supply-side is unable to satisfy due to a finite supply of those older homes of greatest desirability to gentrifiers, combined by planning policies necessitating higher density in new housing developments (Goodling et al. 2015). Goodling et al. (2015:13), suggests that the addition of "this direct transit route downtown and the abundance of quaint—and cheap-historic single-family homes lured legions more newcomers to Albina.” As a result, Albina neighborhoods are increasingly characterized by the predominantly white incoming residents and businesses that threaten to price-out long-time inhabitants (Sullivan and Shaw 2011), all under the auspices of "sustainable development" (Goodling et al. 2015).

When considered alongside the history of redlining and disinvestment in Albina, followed by a series of large-scale urban developments associated with the forced displacement of Black residents (Gibson 2007), and the direct public facilitation of housing market transformations associated with urban renewal and smart growth strategies - including the YL and the transit-oriented development associated with it North and Northeast Portland neighborhoods can be seen as embedded within a unique socio-historical context. Given this socio-historical neighborhood context, the gentrification of Albina is recognizable as a continuation of the narrative of that community, with freeway plans and bulldozers being replaced by LRT development, upper-middle class home renovation, and rising rents and property taxes as the driving 
forces of displacement. This makes the YL MAX of particularly great interest for the study of light rail and gentrification in the region.

\section{Literature Summary}

The research described above reveals that the bodies of literature on gentrification and on the neighborhood effects of transit development are both indisputably vast, while the intersection of those literatures is problematically limited. In both cases there is a considerable lack of consensus on preferred theoretical and operational definitions of gentrification. This consistent disagreement has been a major barrier to progress in this field of study. For example, Grube-Cavers and Patterson use spatial variables as well as a multi-item measure of gentrification, but that measure is based on a definition of gentrification as an event as opposed to a process, which is inconsistent with the most commonly cited definitions of gentrification as "the process by which higher income households displace lower income [households] of a neighborhood, changing the essential character and flavor of that neighborhood" (Kennedy and Leonard, 2001:5).

Another limitation of those studies is the simultaneous analysis of multiple metropolitan areas, which has consistently led to mixed findings. Although multi-city analysis improves one's ability to draw generalizable results, that advantage may be negated if heterogeneity between cities is great enough to make their comparison

problematic. For example, Kahn (2007) selected a control group of census tracts based on 
their being within 20 miles of the central business district $(\mathrm{CBD})^{10}$ in each of the 14 metropolitan areas analyzed. That selection criterion was the same for Portland as it was for Chicago, Los Angeles and Atlanta. As a result, analyses of 13 of the 14 cities controlled for variables measured in the surrounding urban area, while the Portland control group also included large rural populations located outside of the urban growth boundary (UGB), which did not exist elsewhere. Additionally, the finding that Portland did not have a significant effect of walk and ride station development on subsequent income or education levels may relate to the vastly different neighborhood types that the MAX system runs through on the east versus west sides of the region. By lumping them together and including all 4 MAX lines, which serve different purposes and types of neighborhoods, the unique effects of LRT development in specific neighborhoods along each line is lost to the analysis.

This study aims to make a contribution to the literature by measuring gentrification as a function of neighborhood SES and SES change, which is consistent with a large share of the methods reviewed. Additionally, as a continuous variable, this will provide indication not only of whether a neighborhood has gentrified, but also of the extent of gentrification that occurred between each time point. Furthermore, analysis will include consideration of the region as a whole as well as neighborhoods along each major LRT line individually, which will allow interpretation of neighborhood effects as

\footnotetext{
${ }^{10}$ CBD locations came from the 1982 Economic Census Geographic Reference Manual, based on "agglomerations of census tracts that surveyed local business leaders reported to represent the center of economic activity for a region” (Kahn 2007:158).
} 
opposed to regional effects. Lastly, this study will interpret findings through a theoretical framework - the urban growth machine as described by Logan and Molotch (1987) which allows for some degree of generalization from the findings and consideration of further explanations. 


\section{Chapter 3: Data and Methods}

Overview \& Justification

This study aims to fill an interdisciplinary gap in the literature, in which prior research pertinent to understanding the potential effects of LRT development on neighborhood socioeconomic change has largely focused on home values without inclusion of comprehensive demographic measures. On the other hand, research employing more comprehensive gentrification measures that account for changes in multiple dimensions of SES have rarely incorporated an empirical analysis of the role that transit plays in such processes. As such, the present study borrows methodological elements from both bodies of research.

In the former body of research, dominated by the fields of urban planning, economics and real estate, the primary focus is on transit development and other elements of the built urban environment, which are typically operationalized in the context of their spatial relationships with the use of geographic information systems (GIS). Since gentrification and transit are both spatially oriented in their impacts on neighborhood and community, this investigation has a similar basis in geographic variables computed in a GIS. Conversely, in the latter body of literature, coming largely from scholars in the field of sociology, gentrification is more often measured with multi-item SES constructs. Although transit may come up as a factor of neighborhood change in such works, it is typically not measured or analyzed explicitly. 
The present study bridges this clear methodological divide with an interdisciplinary approach, which draws on the strengths of various fields engaged in the production of knowledge relevant to the gentrification-transit link. The integration of spatial variables and analyses with demographic variables that are connected to gentrification theory addresses this potential link in more direct a manner than is seen in most prior research. As previously stated in the introduction, the research questions and hypotheses are as follows:

Research Questions

1. How has neighborhood SES changed in the Portland Metro region overall since the first MAX line was installed?

2. How has neighborhood SES changed in relation to different LRT developments since the first MAX line was installed?

3. To what extent is LRT development associated with gentrification in Portland Metro area neighborhoods?

Hypotheses

H1 Neighborhood SES will increase more in neighborhoods close to downtown than in those further away from downtown.

H2 Low-SES neighborhoods receiving new LRT infrastructure will increase in SES relative to the rest of the region following those stations opening for service. 


\section{H3 SES increases indicative of gentrification in newly transit-served}

neighborhoods will be greater in those with close proximity to new transit stations than in those further away.

This chapter breaks down the specific data and methods utilized. In sum, GISand census-derived data are combined to investigate (a) the general patterns of neighborhood SES throughout the region, and (b) the specific patterns of neighborhood SES associated with gentrification in particular neighborhoods along three different LRT lines before and after LRT development from 1980-2010. The analytical approach taken is thoroughly described in the Analysis and Findings chapter, but the analysis can be understood as consisting of three phases, summarized as follows:

\section{1) Descriptive statistics and GIS hot spot analysis (Getis-Ord Gi*) are used to} identify general trends of neighborhood SES throughout the study area as a whole and in each of the three 2-mile LRT subsamples from 1980 to 2010 - a period that saw the first LRT installation and multiple system expansions. More commonly utilized to track the spread of disease, the application of hot spot analysis for tracking crime rates is adapted in this study to map and analyze clusters of neighborhoods with especially high or low residential SES (Mitchell 2011). Together, these univariate and geospatial analyses provide an overarching context of neighborhood change around LRT development in relation to regional trends.

2) Correlations assess the extent and direction of potential linear relationships between LRT access and neighborhood SES as well as the rate of change in SES in three 
subsamples of census tracts along the EB, WB, and YL MAX. Findings from these bivariate analyses, combined with those from descriptive statistics and hot spot analyses, reveal SES trends indicative of gentrification in the YL subsample, but not in neighborhoods along EB or WB MAX lines.

3) OLS linear regression is performed on the YL subsample to determine the extent to which LRT development contributed to gentrification in those neighborhoods from 2000-2010, controlling for several other variables that are theoretically relevant to gentrification in the particular neighborhoods in question.

\section{GIS Data}

GIS methods employed in ArcGIS 10.3 were integral to operationalizing the concept of neighborhood LRT access, as well as selecting the full sample of census tracts (CTs) in the overall study area and the three LRT subsamples. An essential component of the GIS methods and data used involves the creation of CT housing centroids, which can be generally understood as the most centrally located housing unit in each CT. ${ }^{11}$ The sections below describe the use of GIS to calculate housing centroids, select samples, and compute new variables based on their spatial relationships. All GIS datasets utilized in this study were accessed from the Metro Government's Regional Land Information System (RLIS) and are listed in Table A-1 in Appendix A.

\footnotetext{
${ }^{11}$ An explanation of alternatives to housing centroids for sample selection - namely geographic centroids and population-weighted centroids - and why housing centroids were determined to be a superior approach, can be found in Appendix B.
} 


\section{Housing Centroids}

Housing centroids were calculated for each CT based on the distribution of housing units therein, with those housing units' counts and coordinates derived from two geographic datasets. First, Taxlots - a polygon dataset consisting of all known taxlots in the region, collected by local and county tax assessors and compiled by Metro as of February, 2010 - is used to establish a comprehensive basis of all potential housing locations in the region by the end of the study period. In addition to the location of housing, this dataset also identifies land use and zoning designations for each individual property at that time. Second, the multifamily housing inventory (MFHI) - a polygon dataset consisting of all known taxlots in the region known to contain more than one residence, collected by various organizations ${ }^{12}$ and compiled by Metro as of November, 2015 - is utilized to identify all properties containing multiple housing units, and specify the number of housing units (UNITS) represented by those taxlots, including properties designated for multifamily residential (MFR) as well as single family residential (SFR) land use. ${ }^{13}$

\footnotetext{
${ }^{12}$ The MFHI is based on at least 25 separate data sources, compiled and maintained by Metro beginning in May of 2010, and includes taxlot polygons of all condominiums, duplexes, apartments, mobile home parks, triplexes, retirement facilities, dormitories, and townhomes for which multiple dwellings share a common taxlot. MFHI records include, in addition to locational information, the name of the development and the number of housing units it contains.

${ }^{13}$ Since the organizations and agencies that contribute to the MFHI routinely identify previously undocumented multifamily properties, newer iterations of the MFHI always contain records of properties that were mistakenly omitted from previous versions. Although the newer iterations also contain records of recently added multifamily housing, their inclusion of the year each structure was built allows the omission of housing built after the study period, while retaining the housing that existed during the study period but was not documented as such until later.
} 
From the Taxlots dataset, all MFR and SFR properties were selected; from the MFHI, all properties built in 2010 or earlier were selected. Any selected Taxlots records overlapping ${ }^{14}$ with selected MFHI polygons were removed, and the remaining records were merged with those of the MFHI and given UNITS=1. These merged polygon features were then converted to points and input to the Central Feature Tool, weighted by the number of housing units represented by each point. The output from this tool (that is, central housing points for all CTs containing residential tax lots in 2010) indicates the locations of housing centroids. ${ }^{15}$

\section{Independent Variables: Neighborhood LRT Access}

The primary independent variables measure CT access to LRT in Portland, operationalized as the distance from housing centroids to the nearest LRT station along the EB, WB, and YL segments of TriMet's MAX system. ${ }^{16}$ These distances were

\footnotetext{
${ }^{14}$ MFR and SFR Records were selected only if their centroids were not located within any MFHI polygons. ${ }^{15}$ Central housing points were identified using the Central Feature Tool, which measures the Euclidean (straight-line) distance from each feature in an input dataset to every other feature in the dataset, sums those distances for each feature, and produces output of the one feature with the shortest cumulative distance to all others. The Central Feature Tool was run on the converted Taxlots/MFHI points, weighted by UNITS, with CT as the case field. Distance relationships were based on Manhattan distances, which use right angles similar to the directional turns made while navigating an urban street grid.

${ }^{16}$ Distances to Red Line and Green Line stations are not included in these analyses. The Green Line began operations in 2009, which was actually during data collection for the final census time point from 20062010, and therefore lacks the time element necessary to have had any influence on demographics in the final time point. The Red Line opened in 2001, but added only 5 new stations. One of these was added to a pre-existing LRT and bus transit center (Gateway/NE $99^{\text {th }}$ Ave), and 3 others are located in a single 10 square-mile CT that houses the Portland International Airport. Since the Red Line was developed primarily as transport to the airport and serves very few CTs that did not already have some LRT access from the prior lines, the impact of its stations on residential neighborhood outcomes is assumed to be especially minor and nuanced, and therefore beyond the scope of this project.
} 
measured in miles using Network Analyst, with a simple street network based on Metro's regional streets dataset from February, 2010. Due to the reliance on aggregate-level data, this measure of neighborhood LRT access using network distance from housing centroids to MAX stations is approximately as close as this study can get to a household-level measure of LRT access. ${ }^{17}$ LRT distance variables by MAX line are listed in Table A-2 in Appendix A.

Distance to Downtown

Distance to downtown (sometimes referred to as the central business district, or "CBD") has been a common control variable included in past studies, and is an important variable to include because proximity to downtown employment centers remains a common characteristic of gentrifying neighborhoods (Grube-Cavers and Patterson 2014; Kahn 2007; Lin 2002). Similar to the creation of the LRT access variables, distances from housing centroids to downtown was calculated in street network miles using ArcGIS Network Analyst. Downtown is operationalized as the geographic centroid of Multnomah County census tract 106, which is located in the middle of the downtown transit mall, near Portland City Hall.

\footnotetext{
${ }^{17}$ Census variables representing counts and proportions of different types of residents, households, families, etc. are only disseminated for public use after first being aggregated into various geographic units of analysis, which then cannot be validly used to describe the characteristics of the individual residents, households, and families that comprise them; and to do so would amount to an ecological fallacy.
} 


\section{Analytical samples}

The unit of analysis in this study is the $2010 \mathrm{CT}$, and the analytical sample is drawn from the 491 tracts in the Portland-Vancouver-Hillsboro metropolitan statistical area (MSA), which includes Clackamas, Multnomah, Washington, and Yamhill Counties in Oregon, and Clark, Columbia and Skamania Counties in Washington State. This is depicted in Figure 1, below.

Figure 1: Map: Portland-Vancouver-Hillsboro MSA (sampling frame)

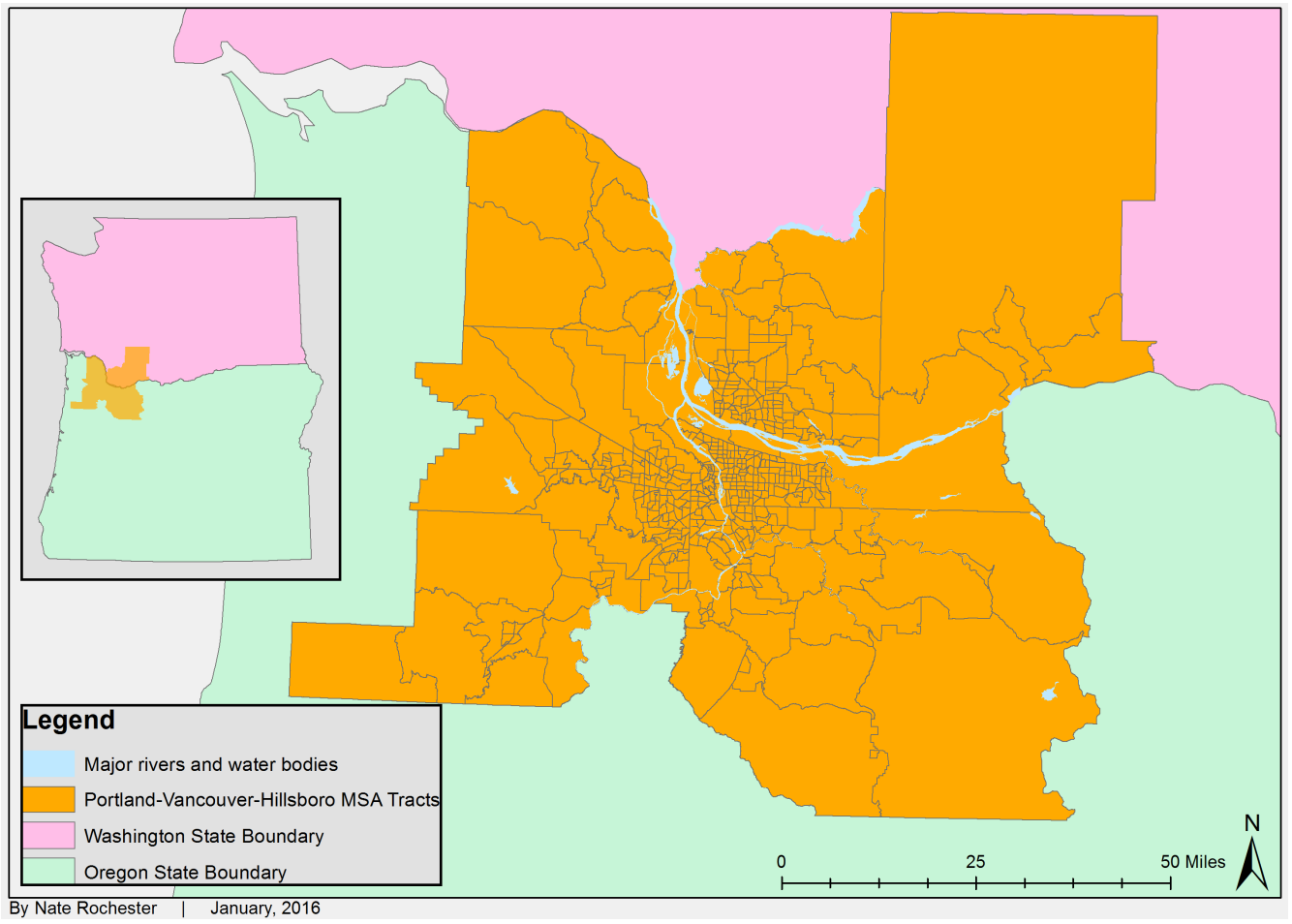

Full sample of ideal study area

Using the MSA as the sampling frame, 305 Oregon CTs in Clackamas,

Multnomah, and Washington Counties were selected for the full study area sample. The 
criteria for selection is that their housing centroids, as well as at least $20 \%$ of their geographic areas, ${ }^{18}$ are within the 2010 boundaries of the TriMet service area, Metro government jurisdiction, and the urban growth boundary (UGB). Using the Intersect Tool in ArcGIS, polygons of these three boundaries were combined into a single polygon representing the ideal study area. This ideal study area, along with housing centroids and sampled CTs (those with housing centroids and at least $20 \%$ of their geographic areas within the ideal study area boundary) are all depicted in Figure 2.

\section{Figure 2: Map: Full Sample of Study Area Census Tracts}

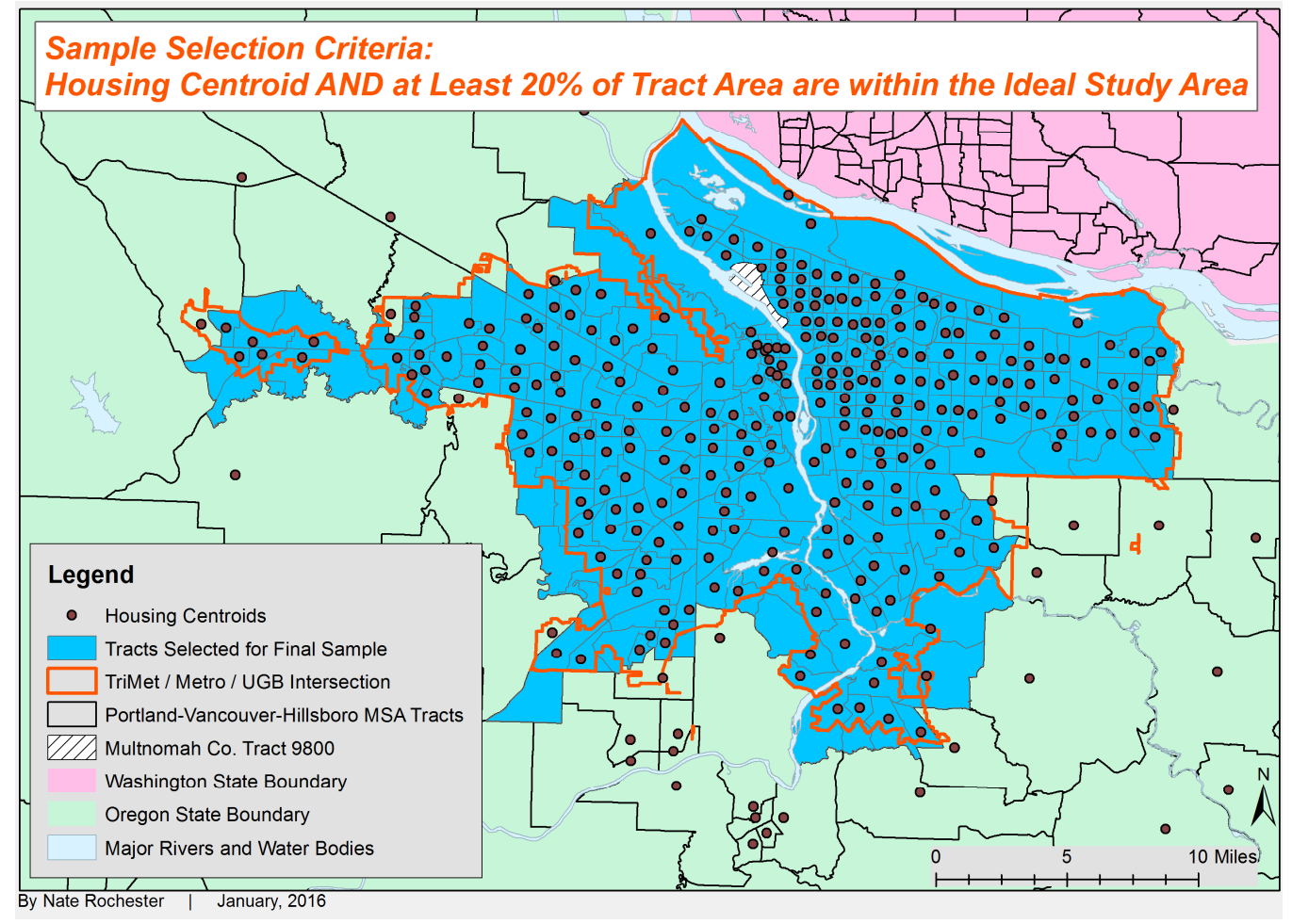

${ }^{18} 20 \%$ was selected as the minimum geographic area for inclusion to ensure that the study area does not include the especially large, mostly rural CTs at the edge of the three-boundary intersection. Since such tracts arguably play only a marginal role in current processes of urban growth, their significance to neighborhood dynamics in the early portion of the study period would likely have been negligible at best. 


\section{LRT subsamples}

Studies relating LRT development to property value changes have found that proximity to stations often has a positive effect on subsequent property values, but this is generally limited to properties located about half a mile from stations with a diminishing effect at greater distances (Mohammed et al. 2013). Compared to developed property values, vacant land values are generally found to have a greater and more consistently positive relationship to LRT proximity (Mohammed et al. 2013), with a study of land sales in the Portland region in relation to Westside Blue Line station locations finding that the influence persisted for land up to (and potentially exceeding) one mile away from those stations (Knaap et al. 2001). This suggests that studying the effects of LRT development on neighborhood outcomes should be limited to neighborhoods located along the LRT service corridors in question, and that any correlation between station distance and demographic outcomes at greater distances is likely a result of some other neighborhood characteristics not directly related to that infrastructure. For these reason, use of the full sample of CTs is limited to GIS hot spot analysis of the overall study area and as a comparison group for descriptive statistics of subsamples along each of three LRT lines.

Study area (full sample) CTs were selected for subsample inclusion if their housing centroids were less than 2 miles (network distance) from the nearest MAX station. These CTs were selected based on their distance to stations added along specific lines rather than distance to the nearest of any station operating at a given time (a) to 
account for analyses omitting measures of distance to Red Line stations, even though they were built and opened prior to the Yellow Line; and (b) to avoid conflating the demographic changes of neighborhoods that are not closely comparable in terms of baseline demographics or the time in the study period they received LRT development. ${ }^{19}$

Demographic Data and Methods

This study utilizes quantitative demographic data originally collected by the U.S. Census Bureau in the decennial Censuses of Population and Housing of 1980, 1990 and 2000, as well as the American Community Survey (ACS) 2006-2010 5-year estimates. Hammel and Wyly (1996:248) posit, "the U.S. census is the most comprehensive and comparable source of data on changes in urban neighborhoods, but the use of census variables to identify gentrification is highly problematic." This is partly because the aggregate nature of census data presents heightened risk of committing ecological fallacies, but also due to methodological changes in the study design used by the Census Bureau to collect and report these data from one census year to another (U.S. Bureau of the Census 2008). The population may be sampled differently, questions altered, replaced, or added, and geographical units of aggregation and reporting may also be

\footnotetext{
${ }^{19}$ Due to historical and demographic differences in the region's East-, West-, and North-side neighborhoods and populations, the effects of LRT development on demographic outcomes are expected to vary across the study area. In that case, a positive relationship along one line may be diluted by negative relationships elsewhere, or even produce misleading statistics suggestive of positive relationships where none exist. Another reason subsamples are based on proximity to stations along individual MAX lines is, even in the unlikely scenario of a geographically consistent relationship, time-series analysis is complicated by the fact that each MAX line being investigated was planned, developed, and opened for service during separate (though contiguous) decades.
} 
changed each time a new census is conducted. This means that census tracts - which are generally considered to be acceptable (though not ideal) as approximations of small neighborhoods - are often shifted somewhat in their boundaries from one census year to the next.

Just as each state is divided into counties, census tracts (CTs) are geographic subdivisions of each state's counties. CT boundaries generally follow visible geographic features (e.g., roads, railroad tracks, waterways), and encompass populations of 2,500 to 8,000 residents (U.S. Bureau of the Census 2000). When CT boundaries were first established, the Census Bureau sought to make them "as homogenous as possible with respect to population characteristics, economic status, and living conditions" (U.S. Bureau of the Census 2000:10). Thus, to maintain population size and homogeneity, CTs are subject to being split, consolidated, or a combination of both from one census year to the next in order to adjust for population growth, urbanization and other changes to the built environment, as well as fluctuations in population density. The resulting inconsistency across data time points presents one of the greatest obstacles to using census data to analyze neighborhood change over time (Logan, Xu, and Stults 2014:413). 
Demographic Dataset: Neighborhood Change Database (NCDB)

The Neighborhood Change Database

(NCDB: GeoLytics 2013) circumvents the

obstacle of shifting census boundaries by

presenting U.S. Census Bureau data from

1970 through 2010 all within $2010 \mathrm{CT}$

boundaries. The NCDB includes all tract-level

data for the entire United States from the

1970-2000 decennial censuses (including both

the enumeration-based "short forms" and the

sample-based "long forms" ${ }^{20}$ ), and the 2006-

2010 ACS. The NCDB standardizes prior

\section{Figure 3: Types of Census Tract \\ Changes}

Many to One (Combined)

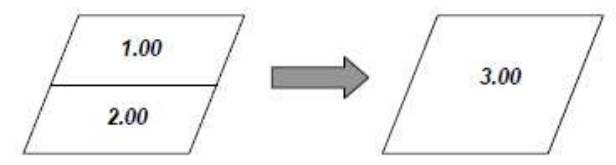

One to Many (Split)
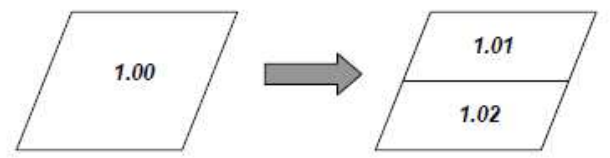

Many to Many
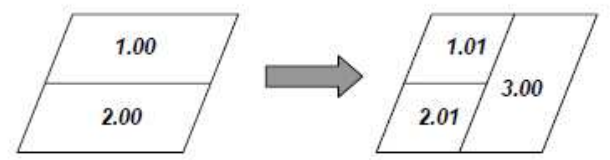

(Tatian 2003:4-2)

years' data to 2010 CT boundaries by taking advantage of the nested hierarchy of census

geographies. First, CT boundaries from earlier years were compared to 2010 boundaries

to determine which remained unchanged from previous years and to identify which of

\footnotetext{
${ }^{20}$ From 1940 through 2000, the U.S. Census of Population and Housing was conducted using two separate but related survey instruments. "Short form" refers to the instrument that is intended to be an enumeration that attempts to account for every member of the population, and therefore more closely fits the definition of a true census. As the name implies, this consists of relatively few questions relating to select characteristics of population (e.g., sex, age and race of all housing unit occupants) and housing (e.g., whether a home is rented or owned by the occupants). "Long form" refers to the instrument that asks, in addition to those from the short form, more detailed questions such as those pertaining to socioeconomic indicators, ancestry, disability, and specific characteristics of housing. Since the long form questionnaire takes substantially longer for people to fill out, it is distributed as a sampled survey to 1 out of every 6 housing units as opposed to being an enumeration (U.S. Bureau of the Census 1999). The data used in this study come predominantly from the census long form.
} 
three specific types of boundary change (see Figure 3) occurred in the rest. CTs that changed between census years were broken down into smaller geographic units such as census blocks and block groups, and population counts of the lower-level geographies were used to determine population-weighted proportions of earlier CTs that were later split into multiple 2010 CTs. In cases where an earlier CT could not be broken down into 2010 CT boundaries with this technique alone, population weighting was combined with area weighting based on street segments, resulting in a longitudinal dataset following a consistent panel of CT geographies over a forty-year period.

Despite its various weaknesses, ${ }^{21}$ as known approximations of the best data available, the NCDB has been utilized in many published works. Searching Google Scholar for "Neighborhood Change Database" at the time of this writing returned 674 results, including the NCDB Users' Guide (2002), which itself has been cited by 42 known publications. NCDB census variables used in this study are summarized in Table A-3 in Appendix A.

Dependent Variables: SES Index and SES Change

Due to the limitations of census data for tracking migration patterns across different census years, measurement of in-movers (gentrifier households) and out-movers

\footnotetext{
${ }^{21}$ Due to this reliance on population weighting and the reconfiguration of nested census geographies, NCDB data that is normalized to 2010 tract boundaries based on prior years' data collection can never be assumed to be as accurate as the data originally reported by the Census Bureau. This is particularly so in the context of margin of error, because although these would have originally amounted to very minor bias, they would be potentially compounded by re-aggregation from smaller geographical units, which happen to also have larger margins of error.
} 
(displaced households) is outside the scope of this project. Similarly, qualitative neighborhood characteristics are not adequately captured in census data and are thus not analyzed here. This leaves neighborhood SES as the primary factor of interest.

Operationalizing gentrification, as a measure of increased neighborhood SES from one census year to the next, is therefore dependent on an operational measure of neighborhood SES. This was accomplished with creation of the SES index - a construct that is calculated as the sum of three census-derived percentages,${ }^{22}$ relating to the educational attainment, occupation types, and income characteristics of census tract residents. These have been identified as highly relevant components of neighborhood SES based on the methods employed in prior studies [e.g., Bostic and Martin (2003), Freeman (2005), Gibbs Knotts and Haspel (2006), Grube-Cavers and Patterson (2014), Bates (2013), Owens (2012), and Delmelle (2015)], and their combination into a single index is an adaptation of the approach proposed by Ley (1986). The variables used to measure each of these SES components are each described below.

Educational attainment is operationalized with a variable for the percent of CT population ages 25 and older who have completed a bachelor's degree or higher (PCOL). This is computed from NCDB variables for number of CT residents age $25+$ in that category of educational completion (EDUC16), and total number of CT residents in the $25+$ age group (EDUCPP). Other than its use in the aforementioned prior studies,

\footnotetext{
${ }^{22}$ Percentage variables have the advantage of being standardized, which improves their compatibility for combining into a single construct.
} 
selection of this variable as an indicator of SES was also informed in part by the study by Jurjevich and Schrock (2012), which found that the Portland region attracted and retained young (ages 25-39), college educated migrants, while simultaneously declining in the inmigration of less-educated young people during the 1980 to 2010 period. The trend was found to be consistent despite periods of below average economic growth in the region, which suggests this demographic group has had especially ample opportunity to edge-out long-time, less educated residents in competition for jobs and housing.

Occupation type is operationalized with a variable for the percent of CT employed population age 16 and older working in professional or technical occupations, or as executives, managers, or administrators (PPROF). This variable was computed from the NCDB variables for the number of CT residents age 16+ employed in professional and technical occupations (OCC1), number employed as executives, managers and administrators (OCC2), and total number of civilian employed persons 16+ years old (INDEMP). ${ }^{23}$ Use of such occupational categories in operationalizing SES has direct precedent in the study of neighborhood ascent conducted by Owens (2012), which used the same very same variables also drawn from the NCDB. It also finds support in the works by Bostic and Martin (2003), which incorporated census data on managerial and

\footnotetext{
${ }^{23}$ Due to ongoing changes in the labor market and associated shifts in industry, these occupational categories differ to varying extents between census years. While 1990 occupational codes remain fairly similar to those used in the 1980 census, major changes were introduced in 2000 and then again in 2010. Despite changes to the specific occupations included in occupational categories, the categories themselves retain a level of conceptual consistency across years that was determined adequate for the purposes of this study. References to exhaustive lists of the occupations included in the categories used are provided in Table C-1 in Appendix C.
} 
administrative workers (but not professional or technical occupations), as well as GrubeCavers and Patterson (2014), which measures SES partially based on proportion of people in professional occupations using Canadian census data.

Lastly, income is operationalized as the percentage of $\mathrm{CT}$ families in an above average income category each year. Average annual family income for the study area is based on the median values of average income per family (FAVINC) in each census year for the full study area. That value was used as the break-point for income categories, and the sum total of all families in all income categories above that were divided by the total number of families in each $\mathrm{CT}$ to produce the new variable indicating percentage of higher-income families (PHFAMINC) ${ }^{24}$ Because neither average family income nor the income category variables are adjusted for inflation, there are a wide range of median incomes for the study area across census years, and therefore different income categories to be summed for each year (see Table A-4 in Appendix A).

Although the three SES component variables all individually have high face validity for measuring their respective dimensions of SES, it is important to also account for their validity and reliability for use together as a construct before relying on such a measure. Table 3 provides statistics from Pearson's correlations and Cronbach's alphas run using IBM SPSS (v. 23). Correlation coefficients are all statistically significant ( $p<$

\footnotetext{
${ }^{24}$ It is important to note that the Census Bureau's criteria for what constitutes a family is, at best, a less than ideal representation of all neighborhood inhabitants, and, at worst, may be considered a major limitation of this specific method of measuring neighborhood SES. This concern is considered in greater detail in the discussion chapter.
} 
.001 ) and range from a minimum of .719 to a maximum of .963 , indicating strong positive relationships between all three variables in every census year. This strong compatibility is further bolstered by Cronbach's alphas in all years being near or above .9, far exceeding minimum alpha standards. ${ }^{25}$ The SES index was therefore computed as the sum of CT values on all three percentages (see Table A-5 in Appendix A for detailed parameters of the SES index and its component variables).

Table 3: SES Index Construct Reliability Tests

\begin{tabular}{|c|c|c|c|c|}
\hline \multirow[b]{2}{*}{ Census Year } & \multicolumn{3}{|c|}{ Inter-Item Pearson's Correlations } & \multirow[b]{2}{*}{$\begin{array}{c}\text { Cronbach's } \\
\text { Alpha } \\
\end{array}$} \\
\hline & $\begin{array}{c}\text { PCOL } \\
x \\
\text { PPROF } \\
\end{array}$ & $\begin{array}{c}\text { PCOL } \\
x \\
\text { PHFAMINC } \\
\end{array}$ & $\begin{array}{c}\text { PPROF } \\
x \\
\text { PHFAMINC } \\
\end{array}$ & \\
\hline 1980 & $.936 * * *$ & $.719 * * *$ & $.749 * * *$ & .897 \\
\hline 1990 & $.949 * * *$ & $.779 * * *$ & $.833 * * *$ & .926 \\
\hline 2000 & $.963 * * *$ & $.775 * * *$ & $.826 * * *$ & .938 \\
\hline $2006-10$ & $.944 * * *$ & $.787 * * *$ & $.811 * * *$ & .935 \\
\hline
\end{tabular}

Data Source: Neighborhood Change Database (NCDB: Geolytics 2013) $* * * \mathrm{p}<.001$

Because the SES index is computed as the sum of three percentage variables, it is structurally bound to absolute minimum and maximum values of 0 and 3 , for the technical possibility of a CT with $0 \%$ or $300 \%$, respectively, on all three component variables. Higher index values therefore indicate neighborhoods of elevated SES, and lower values indicate low-SES neighborhoods. Although SES index - a static "snap-shot"

\footnotetext{
${ }^{25}$ Cronbach's alpha assesses the internal reliability between multiple items to ensure that they do in fact all measure a common concept and are therefore appropriate to combine as a single construct. Cronbach's alpha scores can range from 0 (indicating completely random dissimilarity between variables) to 1 (indicating perfect alignment between variables), with .6 to .7 generally regarded as the standard minimum for use in an index scale.
} 
of neighborhood SES in a given census year - is central to this study, changes in index values between time points is also highly relevant to the study of gentrification, which is in essence a process of socioeconomic change. To capture the extent of such change in neighborhood-level SES between census years, a new variable (SESCHANGE) was computed as the difference between adjacent time points in CT values for the SES index. Due to the added complexity of analyzing rates of change, analyses of SES change only accompany analyses of single year SES index values, as opposed to replacing SES index entirely as the dependent variable.

Because SES index values are technically limited to an absolute minimum of 0 and maximum of 3 , SES change is similarly bound by a range of -3 to 3 . However, just as it extremely unlikely (despite being technically possible) for a CT to have either $0 \%$ or $100 \%$ on all three component variables, it is exceedingly less likely still for a CT to have $100 \%$ on all three in one census year and then drop to $0 \%$ on all three in the subsequent census year (meaning SES change $=-3$ ) or vice-versa (meaning SES change $=3$ ). In reality it can be expected that SES index would have minimum and maximum values that may get near the potential extremes but never actually reach them, and that SES change would have a substantially narrower distribution.

It is very important to emphasize that neither SES index nor SES change values are indicative of gentrification in and of themselves - they should be interpreted within the context of the neighborhoods and times in which they are observed. SES change indicates the general extent of neighborhood ascent or decline in SES between two time 
points, so SES change $>0$ at time point $t$ can be considered to have undergone some degree of SES ascent since time point ( $t-1)$; and, conversely SES change less than 0 at time point $t$ can be considered to have undergone some degree of SES decline since time point $(t-1)$. However, due to a dearth of prior research measuring gentrification as an increase in the rate of change in a socioeconomic construct variable, SES change between census years will be kept only for descriptive purposes and the primary dependent variable in this study remains that of the SES index in individual years.

\section{Control Variables}

In addition to the three percentage variables used to measure SES, several other NCDB-based variables were used as controls in multivariate analyses. ${ }^{26}$ Control variables were selected for their relevance to neighborhood characteristics associated with urban growth and gentrification. These include the following:

- Race:

○ Population percent non-Hispanic Black (PNHBLACK);

- Population percent non-Hispanic white (PNHWHITE);

○ Population percent Hispanic (PHISP).

- Housing percent single family detached (PSFRDET);

- Population density (PopDensPSqM)

- Median Rent (AdjMDRENT)

- Distance to Downtown (DowntownMiles) ${ }^{27}$

\footnotetext{
${ }^{26}$ Details on the parameters for calculating NCDB-based control variables are listed in Table A-6 in Appendix A.

${ }^{27}$ Distance to downtown was previously described as part of the GIS data and methods.
} 
Race/ethnicity is of central importance to the study of gentrification. Though it is technically possible for gentrification to occur without a racial component, such processes of neighborhood change are much more commonly found with some amount of racial turnover. Many studies of gentrification have even included racial variables as explicit components of gentrification measures (e.g., Bostic and Martin 2003), and some scholars (e.g., Kirkland 2008) have lamented the lack of more research taking that approach. However, in a study of neighborhood changes in a region with an extremely white population, race/ethnicity variables are not expected to be consistent throughout all parts of the study area and are therefore reserved for analysis of descriptive statistics and for use as regression controls. Due to major differences in the way the Census Bureau asked questions about race in surveys and enumerations conducted in different years, race/ethnicity variables analyzed in this study will be limited to the percent of $\mathrm{CT}$ populations identifying as non-Hispanic white, non-Hispanic Black, and Hispanic. ${ }^{28}$ The percent of housing units identified as single family detached is first and foremost a measure of neighborhood housing type, but it is highly relevant to type of neighborhood in general and also relates to neighborhood desirability to potential gentrifiers. Lees et al. (2008) note that there has been a clear emphasis throughout the gentrification literature on the desirability of single-family freestanding houses -

\footnotetext{
${ }^{28}$ Beginning in 2000, the U.S. Census Bureau allowed respondents to their surveys to indicate multiple races. As a result, it is potentially problematic to compare race statistics across multiple census years. This study aims to mitigate the limitations associated with this change by including in each racial category all residents who selected that race alone or in combination with other races. Appendix $\mathrm{C}$ provides the original questions from the enumerations of 1980-2010.
} 
especially older houses - to individuals and families seeking to purchase and renovate properties for their own habitation. This variable is a correlate of other census measures related to neighborhood types. For example, neighborhoods with higher proportions of single-family homes would also be expected to have higher proportions of families with children, and lower proportions of renters.

Population density is particularly relevant to Portland due to the local initiative to reduce urban sprawl through mixed use zoning and high density housing development. The value of density is especially emphasized around LRT due to the trend toward transit oriented development, which has been associated with gentrification in other metropolitan regions (Kahn 2007).

Lastly, rent has been emphasized in the gentrification literature generally (Bates 2013; Gibbs Knotts and Haspel 2006; Lees et al. 2008; Owens 2010), as well as specifically in the literature on the urban growth machine (Logan and Molotch 1987; Molotch 1976; Molotch 1993; Rodgers 2009). Logan and Molotch (1987) discuss increased rents as an outcome of growth machines' success in exchange value pursuits, and a mechanism by which neighborhoods are cleared of low SES residents.

\section{Summary of Methods}

The preceding sections described how several GIS datasets were combined and utilized for this study. This includes calculation of housing centroids - that is, the housing unit in each CT that is most centrally located in relation to all other CT housing - and the operationalization of neighborhood access to LRT, which measure distance in miles 
along the regional street network from each CT's housing centroid to the nearest MAX station along the Eastside Blue, Westside Blue, and Yellow MAX Lines. GIS was further utilized to select the full sample of CTs that most accurately represent the study area, based on their inclusion within three regional boundaries, as well as three subsamples of CTs located within 2 miles (network distance) of LRT stations on the MAX lines of interest.

The Neighborhood Change Database (NCDB) is a longitudinal dataset based on census data from 1980 through 2010, standardized to 2010 tract boundaries, which this study utilized for variables pertaining to neighborhood characteristics in the Portland region. The NCDB was used to create the SES index and SES change variables, which measure neighborhood-level socioeconomic characteristics over time to approximate demographic changes indicative of gentrification. Lastly, NCDB-based variables relating to race/ethnicity, housing types, population density, and rental costs are included as controls in regression analyses. All analyses performed with these data are presented in the following chapter. 


\section{Chapter 4: Analyses and Findings}

Analytical Methods

The analytical approach utilized in this study follows three phases of inquiry.

These three phases incorporate univariate, bivariate, and multivariate analyses, respectively, alongside GIS mapping techniques that assist in the visualization of variables' geographic distributions as well as analysis of their relationships in a spatial context. Phase 1 includes descriptive statistics of the SES index by sample and census year to identify general region-wide trends over time and ensure variable distributions in all subsamples and time points are adequately normal for inclusion in subsequent analyses. Descriptive statistics are accompanied by choropleth maps ${ }^{29}$ depicting the spatial distribution of neighborhood SES across the region.

Phase 2 pairs Pearson's correlations with an explicitly geospatial statistic (GetisOrd Gi*, or "hot spot analysis") to identify general trends in neighborhood SES throughout the region as well as specific trends suggestive of gentrification. The Hot Spot Analysis Tool is a prepackaged tool in ArcGIS that detects local spatial autocorrelation using the Getis-Ord Gi* statistic ${ }^{30}$. While its most common applications are in

\footnotetext{
${ }^{29}$ According to the Encyclopedia of Human Geography, "choropleth maps depict data by symbolizing each enumeration or area unit with a shade of a color that represents a defined range or class of data" (Warf 2006:343)

${ }^{30}$ The Hot Spot Analysis Tool in ArcGIS calculates the Getis-Ord Gi* statistic. In this calculation, the value for a specified variable is summed between each feature of the input dataset and all of its neighboring features. If the summed values of a feature and its neighbors differs substantially enough compared to the summed values of all features, it is depicted as a statistically significant hot or cold spot, depending on if the local sum is above or below its expected value. For the purposes of this project, the input features were
} 
epidemiological research, this method of visualizing concentrations of particular characteristics has also been very successfully deployed for crime analysis, and more recently in demography and the mapping of socioeconomic variables using census data (Mitchell 2011). Although not widely utilized for sociodemographic analysis, it has been suggested as an especially useful, if underappreciated method of exploratory analysis to inform more targeted subsequent analyses (Grubesic and Murray 2001).

The Hot Spot Analysis Tool, was utilized to produce hot spot maps depicting statistically significant clustering of CTs with especially high or low values on the SES index in each census year as well as SES index change between consecutive census years. Time-series hot spot maps depicting clustering of CTs with high or low values of SES and SES change from 1980 to 2010 reveal significant and substantive patterns throughout the region and study period. However, the hot spot approach does not, in and of itself, directly assess the influence of LRT development on that change.

To that end, Pearson's correlations measured the relationships between LRT distance and SES index values in each census year as well as between LRT distance and SES change in each interval between census years. Correlation is an appropriate choice of bivariate analysis for this study because (a) all of the variables of primary interest are interval-ratio in level; and (b) significant correlations suggest linearity, which satisfies an important assumption of OLS linear regression. However, as Waldo Tobler (1970: 236),

CTs, and neighbors of a given CT were conceptualized as any other CT with which it shared a corner or edge. 
once famously proclaimed as the 'first law of geography', "everything is related to everything else, but near things are more related than distant things" which suggests that full sample correlations would produce misleading results. ${ }^{31}$ Because of this general understanding of spatial relationships, combined with property value studies finding that the effects of LRT diminish greatly with distance, analyses were limited to local subsamples of CTs within 2 miles of the stations in question. Together, hot spot maps of the full study area and Pearson's correlations of LRT subsamples gave clear indications of gentrification occurring in relation to Yellow Line stations, which directed the focus of OLS regression analysis (phase 3).

Phase 3 of analysis builds on the prior findings with several OLS linear regression models of the SES index regressed on LRT distance, holding control variables constant. These multivariate analyses focus specifically on the Yellow Line subsample. Similar to the decision to measure bivariate relationships with Pearson's correlations, selection of OLS was motivated largely by the level of measurement of the dependent and primary independent variables. Additionally, regression is in line with the hedonic price models utilized in property value studies, which similarly aim to assess the effects of LRT access on a variable that has generally increasing values throughout the study area.

\footnotetext{
${ }^{31}$ If near things are more related than are distant things, neighborhoods that are especially far from LRT station locations would be expected to have very different levels of SES than neighborhoods that are close to those locations, regardless of whether or not the actual stations have been built. In this sense, it should be assumed that any correlation between SES and LRT distance for CTs beyond a certain distance is spurious.
} 


\section{Descriptive Statistics}

This section presents descriptive statistics, including mean, median, standard deviation and range, which were used to measure central tendency and distribution of all key variables. Together, these statistics identify the most general trends in neighborhood SES throughout the region, how SES and other neighborhood characteristics changed over the study period, and how such changes may have differed between the three LRT subsamples in comparison to the full study area. Additionally, these statistics were instrumental in assessing variable distributions for their conformity to a normal bellshaped curve, ${ }^{32}$ which is assumed of variables analyzed in OLS models.

\section{LRT distance}

Table 4 lists descriptive statistics related to the primary independent variables of CT distance to light rail, by LRT subsample. Street network distance was measured in miles from the housing centroid of each CT (described in methods chapter) to the nearest LRT station along the MAX line associated with the CTs respective subsample. For example, of the $75 \mathrm{CTs}$ located less than 2 miles from Eastside Blue Line stations, mean distance is 1.152 miles, and median distance is 1.165 miles, which indicates a slight but non-problematic, negative skew. Similarly, the Westside Blue Line $(\mathrm{N}=50)$ and

\footnotetext{
${ }^{32}$ Assessment of variable distributions was made primarily through a comparison of mean and median values, with a large difference between the two indicating asymmetry. This was accompanied by visual assessments of histograms produced for each variable. Although this assessment was made for every variable included in regression models, it is not discussed explicitly for all variables, and unless otherwise noted all variables used in multivariate analyses can be assumed to have adequately normal distributions.
} 
Yellow Line ( $\mathrm{N}=43)$ subsamples also have minor differences between mean and median distances to WB and YL stations, respectively, which suggests their distributions have slight levels of skew that should not prove problematic for subsequent analyses.

Table 4: Descriptive Statistics: LRT Distance by Subsample

\begin{tabular}{lcccc}
\hline Subsample & $\boldsymbol{N}$ & Mean $($ S.D. $)$ & Med & Range \\
Eastside Blue Line & 75 & $1.152(0.503)$ & 1.165 & 1.938 \\
Westside Blue Line & 50 & $1.040(0.537)$ & 1.021 & 1.939 \\
Yellow Line & 43 & $1.044(0.554)$ & 0.973 & 1.813 \\
\hline
\end{tabular}

Data Sources: GIS shapefiles accessed from the Regional Land Information System (RLIS), including those for MAX station locations (lrt_stop), for creating housing centroids (tract2010, taxlots, and MFHI); and for calculating network distances between the two (streets).

Measures of central tendency are all near 1 and ranges are all near 2, which should be expected since the subsamples are based on proximity within 2 miles of stations on these particular MAX lines. However, in the context of subsequent analyses it is valuable to know based on medians that each subsample consists of a roughly $50 / 50$ split of CTs that are less than 1 mile versus 1-2 miles from LRT stations along its associated MAX line. LRT subsamples are depicted in the maps of Figures 4, 5, and 6.

\section{SES index}

Figures 4 through 6 present cartographic depictions of SES index for the full study area in each census year, with subsample areas outlined census years following their associated MAX lines opening for service. For example, Figure 4 depicts 1980 SES index values for the region with no subsample outlines because the first MAX line (EB) 
didn't open until 1986. Conversely, 1990 SES index is depicted in Figures 4 and 5 with the EB subsample outlined because the EB MAX was operating at that time.

Some very general patterns can be discerned with careful inspection of each map, but these are limited in analytical power and mostly serve exploratory purposes. For example, there is a noticeable increase in SES in North Portland and the inner east side throughout the study period, while patches of CTs in the furthest east and west parts of the region remained relatively low in SES. While this indicates a potential trend to explore in subsequent analyses, the confidence of such an observation on its own is problematized by at least two factors. First, choropleth maps such as these rely on the use of ordinal categories (classes) of values, ${ }^{33}$ meaning changes in CT values that are not large enough to push it into a different category are not represented in the map. Second, it appears that SES generally increased in the region overall, including in LRT subsamples, throughout the study period. Together, these factors suggest the importance of univariate analysis of descriptive statistics, which is addressed in Table 5.

\footnotetext{
${ }^{33}$ In Figures 4-6, SES index categories are based on the quintile distribution of SES index for the full study area across all census years. In other words, SES index values for every CT at every time point $(305 \times 4=$ 1220 observations) were ordered smallest to largest and then split up into 5 groups, each containing an equal number of observations $(1220 / 4=244)$. The value ranges associated with these groups were then used to define common categories of SES index for all the individual time points.
} 

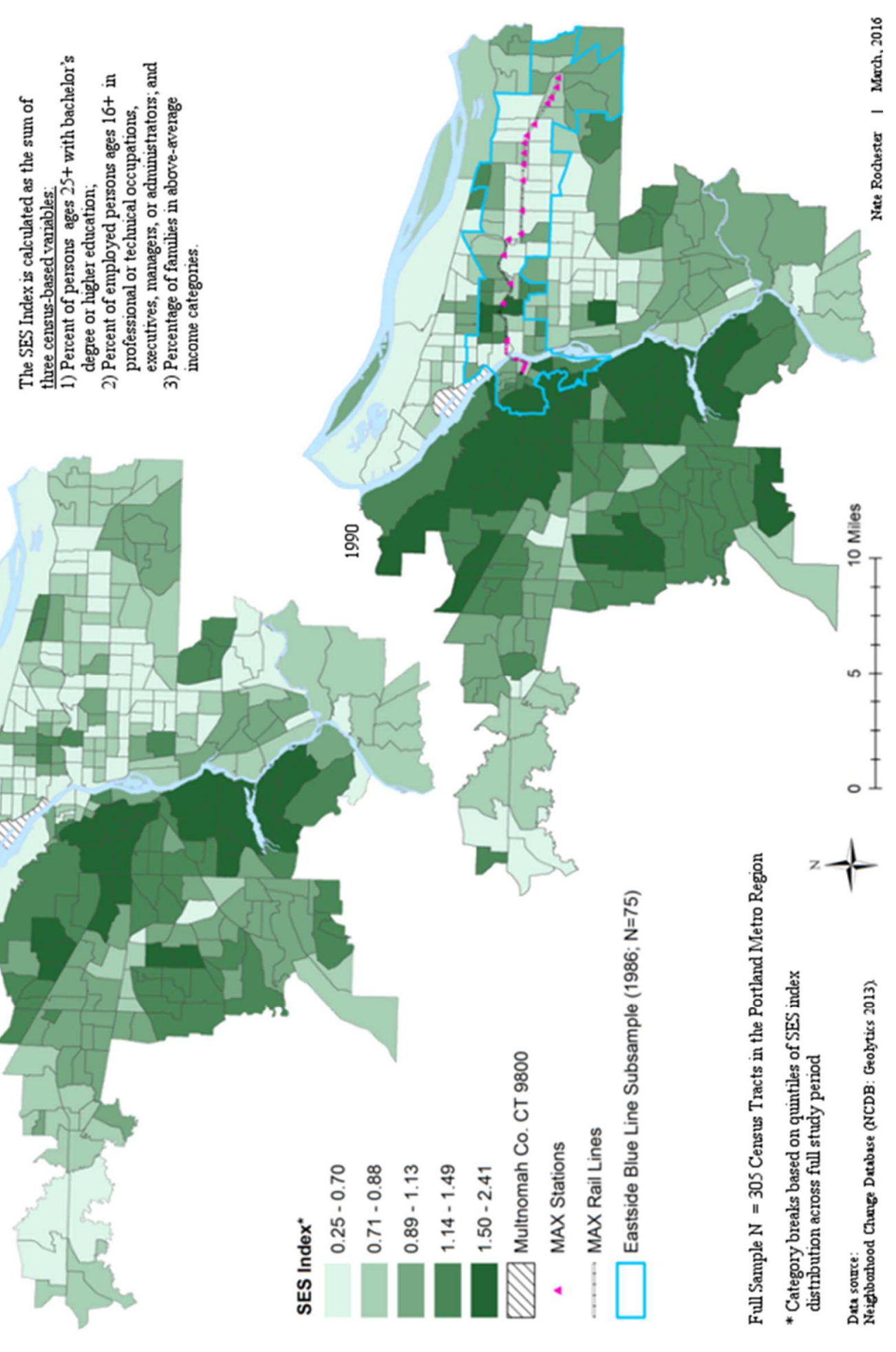

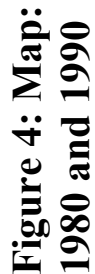



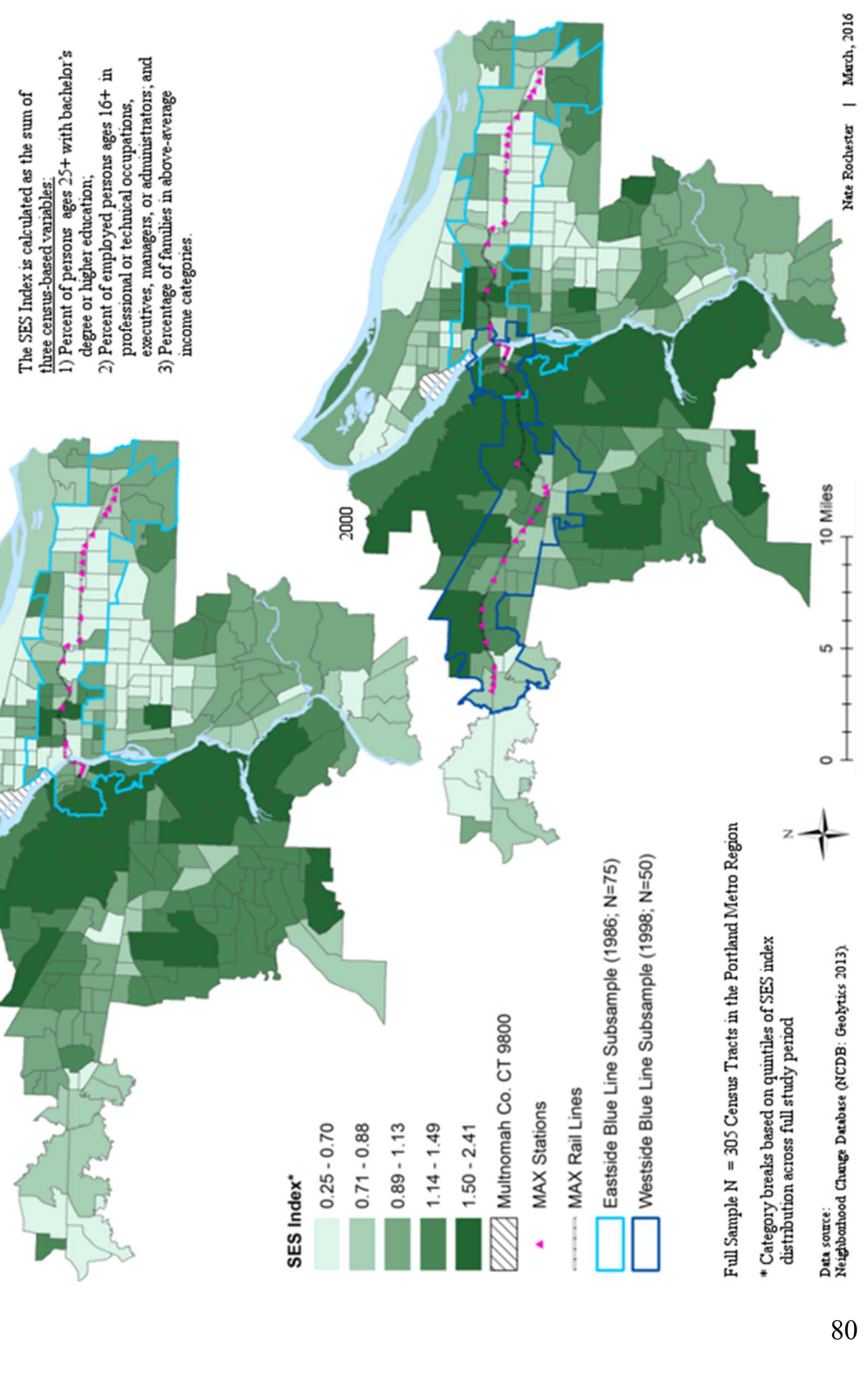


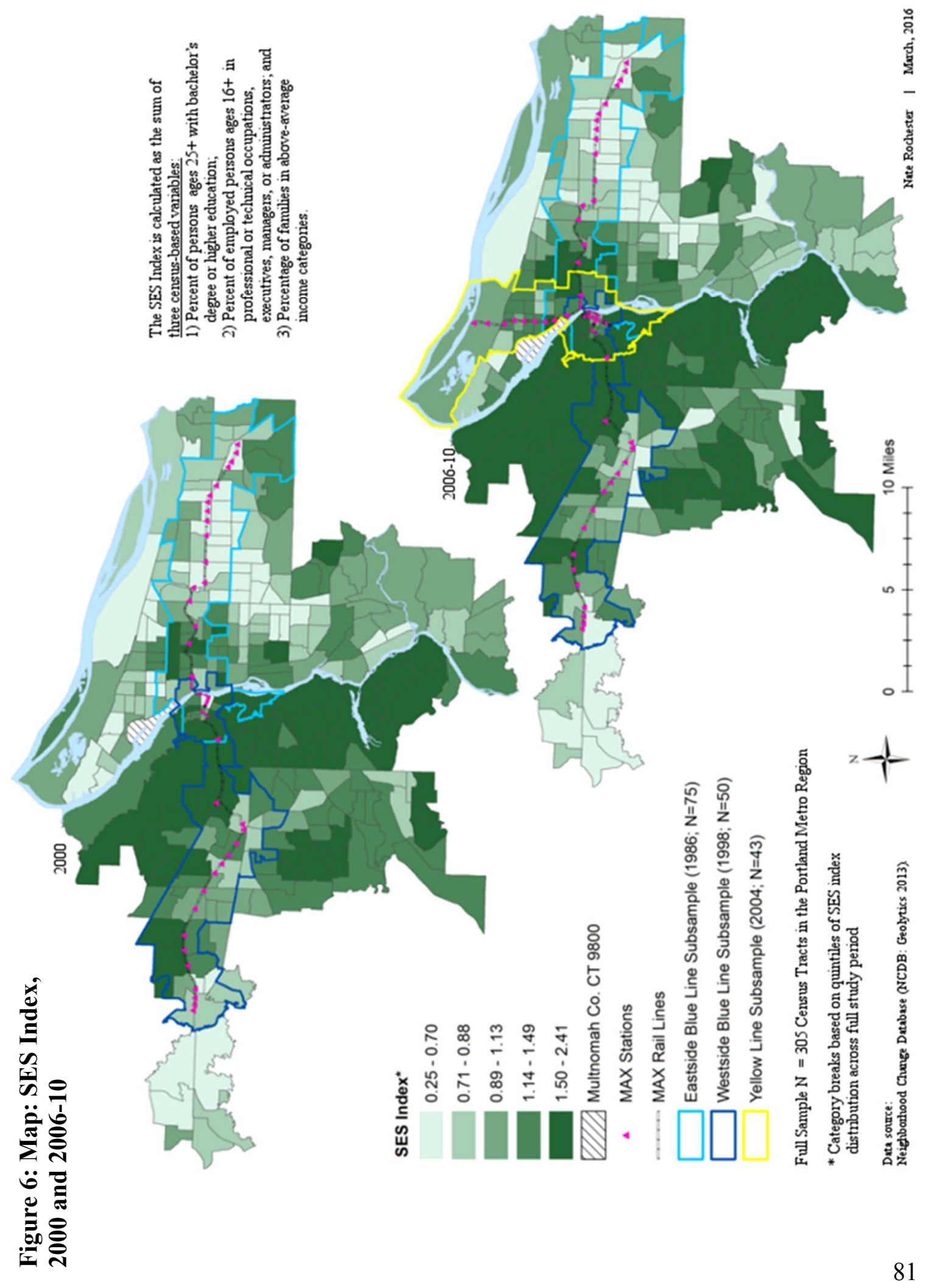




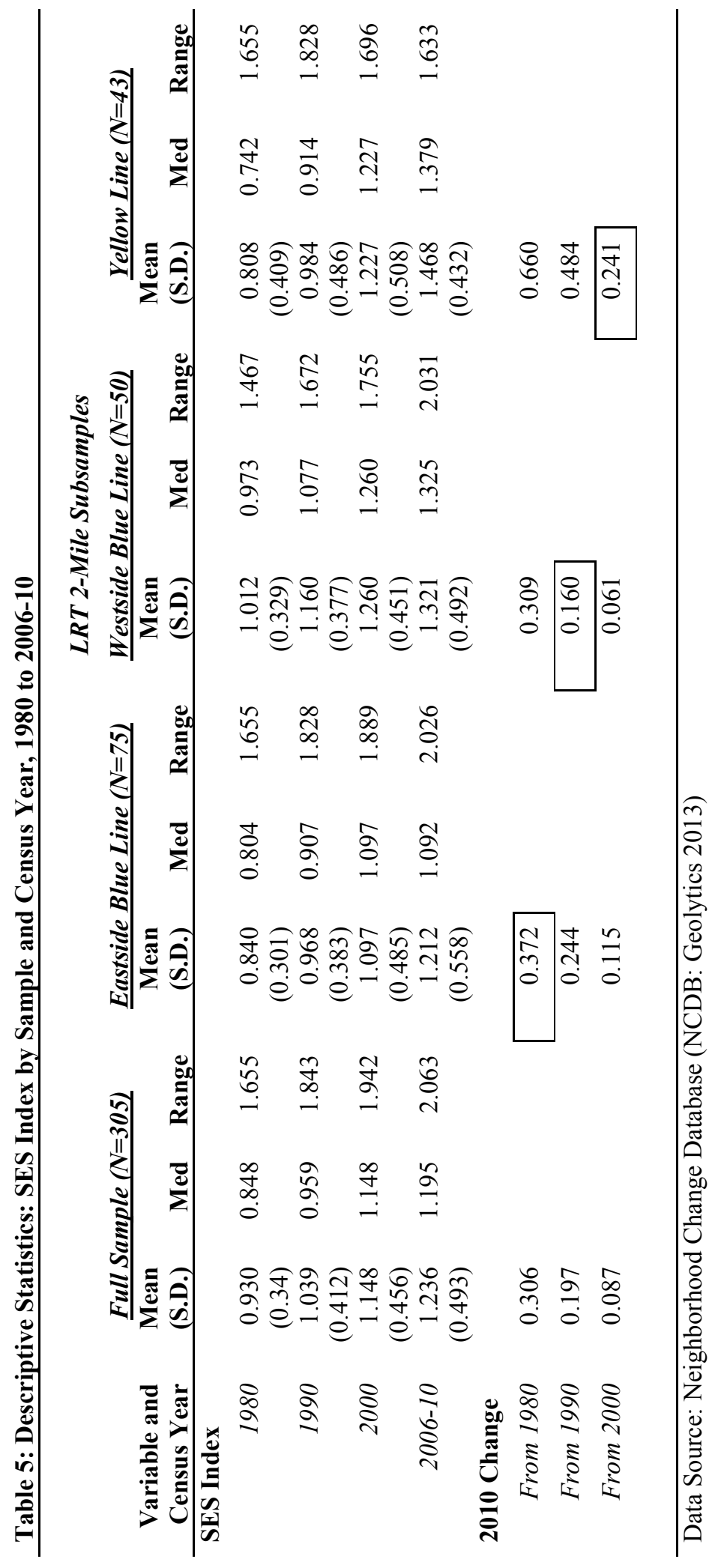


Table 5 provides descriptive statistics of the SES index for the full sample and the three LRT subsamples in each census year from 1980-2010, which reveal some trends and suggest others to be explored further in subsequent analyses. First, in the full sample and all subsamples, SES index mean and median both increased consistently throughout the study period, which confirms the observation from choropleth maps of region-wide ascent in neighborhood SES. In the full sample as well as both Blue Line subsamples this increase in average SES was accompanied by a consistent increase in range and standard deviation, which suggests socioeconomic inequality between neighborhoods increased in the region overall and along those two MAX lines specifically from 1980 to 2010.

The Yellow Line subsample departs from this trend. In CTs within 2 miles of Yellow Line stations, SES index range and standard deviation both increased from 1980 to 1990 , followed by an increase in standard deviation (but not range) from 1990 to 2000 . Then during the period from 2000 to 2010, during which Yellow Line infrastructure was built and opened for service, both statistics decreased, even as mean and median values continued increasing. The co-occurrence of increasing mean and median along with decreasing range suggests that SES increase affected neighborhoods at the low- as well as high-end of the distribution. This is also apparent in the previously noted observations from choropleth maps that low-SES areas persisted in the furthest east and west reaches of the region while the inner core neighborhoods more consistently increased in SES.

Table 5 also provides the amount of change in mean SES index values for each sample from 1980, 1990, and 2000 to the end of the final time point in 2010. The 
subsample values with boxes drawn around them correspond to mean SES index change from the time point prior to development of their respective MAX lines to the 2006-10 census year. For example, this indicates that from 1980 to 2010, mean SES index along the Eastside Blue Line (which opened in 1986) increased by .372 index points, which is .066 points (i.e., 6.6 summed percentage points) greater than the amount of change for the overall region (.306). Conversely, from 1990 to 2010, during which time the Westside Blue Line was developed and opened for service, CTs within 2 miles of those stations increased in mean SES index by only .16 index points, which is .037 less than the change for the region (.197).

Once again, the Yellow Line subsample stands out in these comparisons, with a change in mean SES index from 2000 to $2006-10$ of .241 - substantially greater (by .154 index points) than the region-wide change (.087) between the same two time points. This disproportionate increase in the mean SES index of CTs close to Yellow Line stations compared to the rest of the region is suggestive of gentrification taking place in those neighborhoods at that time. However, as Figure 7 illustrates, these gentrification trends are apparent in the Yellow Line subsample going at least as far back as the interval between the 1990 and 2000 census years. Figure 7 indicates that Yellow Line neighborhoods were increasing in SES more rapidly than the region as a whole throughout the study period, but that the difference became especially stark during 1990 to 2000 interval, and continued that trajectory of change from 2000 to 2010 . 
Figure 7: Mean SES Index by Sample and Census Year, 1980-2010

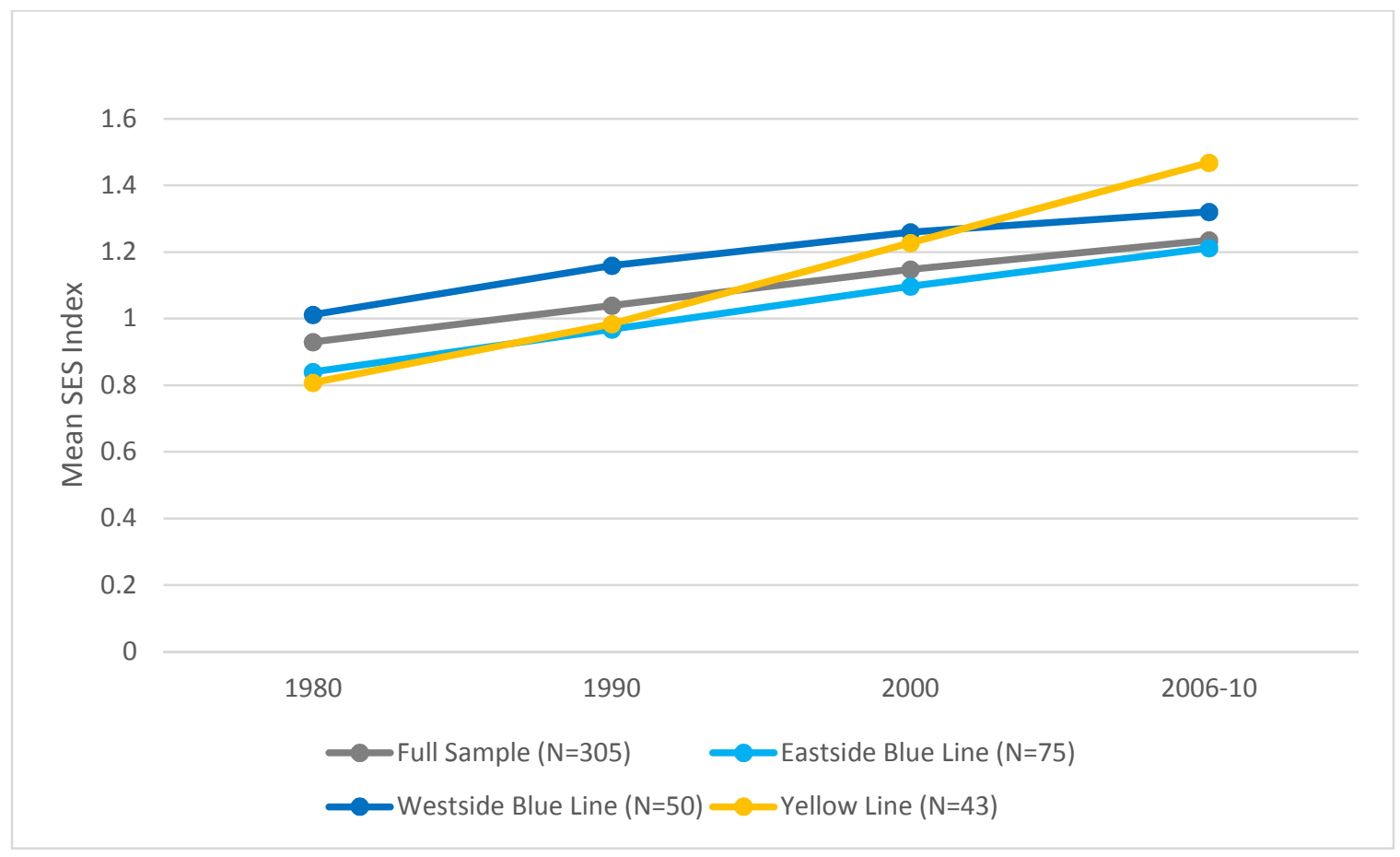

That trend is made even more apparent in Figure 8, which depicts rate of change in mean SES index values for each subsample in comparison to the full region sample. Yellow Line neighborhoods, which began the study period in 1980 with the lowest mean SES index value of all samples (0.808), consistently increased more than the region as a whole in every subsequent census year. This is in line with Figure 7, which shows that by 2000, the YL subsample SES index mean surpassed that of the full sample, and by 2010 was the highest of any sample. The EB subsample also increased more in SES index mean than did the region as a whole, but the margin between them is considerably smaller, and at no point did the EB subsample surpass the region in mean SES index. Conversely, WB neighborhoods began the study period as the highest SES in the region and had the second greatest amount of change from 1980 to 1990 (.149, with the YL 
subsample having the greatest change of .176). However, the WB subsample then consistently had the lowest amount of change in the two subsequent census year intervals.

Figure 8: Mean SES Index Change by Sample and Census Year Interval, 1980-2010

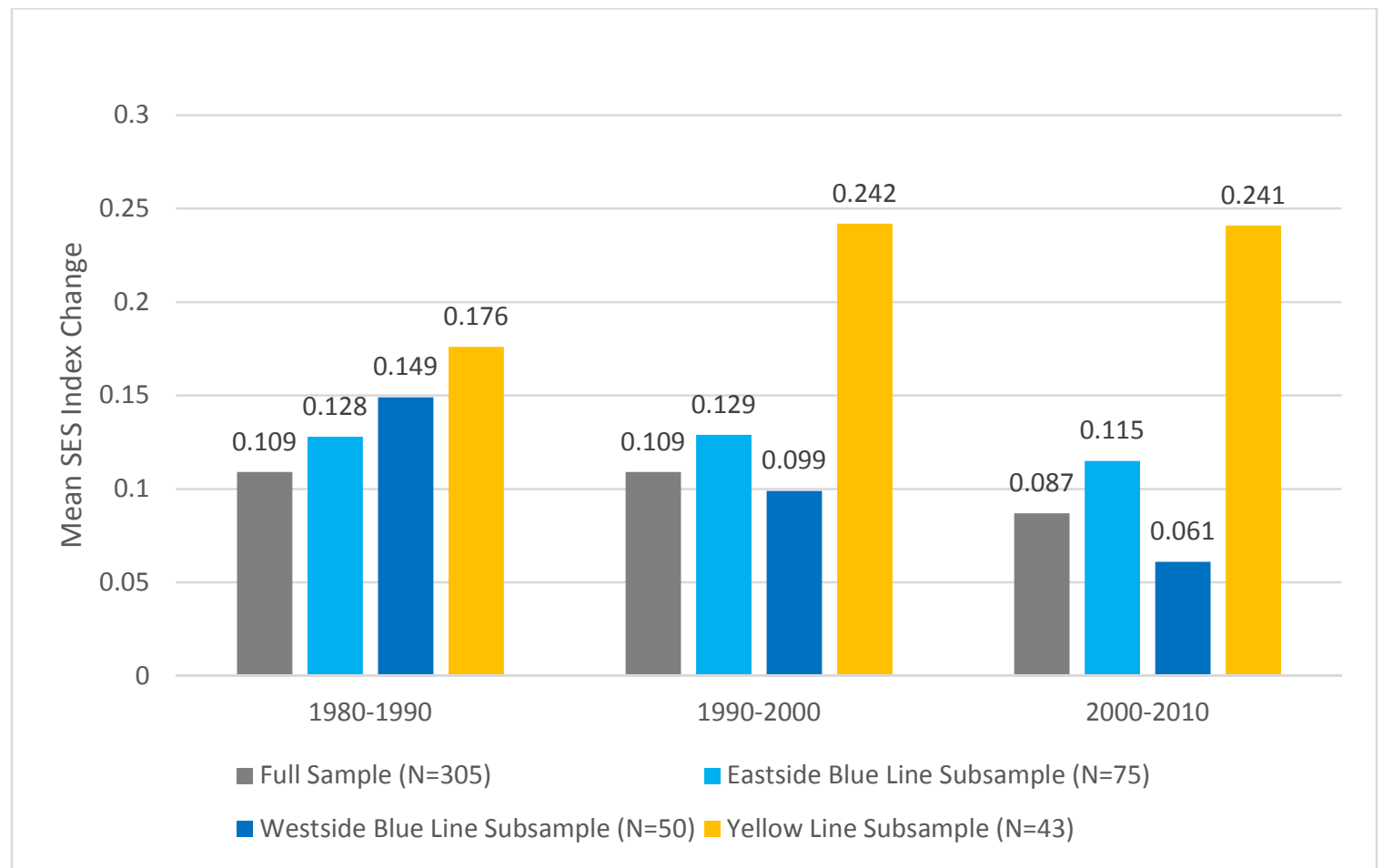

In summary, univariate findings from descriptive statistics and choropleth maps

of neighborhood SES indicate that the overall region experienced SES increases

throughout the study period, but that the magnitude of such increases were not consistent between neighborhoods in different parts of the region. On average, EB neighborhoods began the study period with below average SES, and then consistently increased more than the overall region in every subsequent census year, but still remained below average in 2010. This mixed finding, when considered alongside the choropleth maps in Figures 4-6, suggests that the relationship between LRT access and neighborhood SES likely 
varies within the EB subsample. Conversely, WB neighborhoods had high levels of SES in all census years, and also increased in SES substantially less than the region as a whole between those census years. The former finding suggests that WB neighborhoods should not be considered eligible for gentrification, and the latter suggests there may even be a negative relationship between LRT access and neighborhood ascent on the west side that may be illuminated in bivariate analyses.

In contrast to the first two MAX lines, YL neighborhoods began the study period with the lowest SES on average, but then consistently had greater increases in SES than the rest of the region and ended the study period with the highest average SES. Since this meets the gentrification eligibility criterion of neighborhoods being initially low-income or working class, it provides strong evidence of gentrification in CTs within 2 miles of YL station locations. However, it also indicates that gentrification was occurring in those neighborhoods before LRT development began, which begs the question of how much SES index change during those latter two intervals is associated with proximity to station locations. This question is addressed in correlations and hot spot analyses.

\section{Control variables}

Analysis of control variables is divided between descriptive statistics that potentially affect neighborhood level SES, which are listed in Table 6, followed by choropleth maps that track changes in the distribution of race/ethnicity over the study period. These variables are to be used as controls in regression analysis of any subsample(s) that exhibit evidence of gentrification in relation to LRT development. 
Table 6 indicates that CTs in the YL subsample are, on average, considerably closer to downtown (2.6 miles) than are the EB or WB subsamples (5.8 and 7.9 miles, respectively), or the full sample (8.4 miles). Close proximity to downtown has often been noted as a risk factor for gentrification (Kennedy 2001; Lees et al. 2008). This proximity is likely also related to the high population density and low percentage of single family houses because the high demand for housing and limited supply of real estate so close to downtown drives entrepreneurs and developers, in partnership with public planning organizations, to maximize the number of units built on a given parcel in pursuit of exchange values.

Median rent is an especially appropriate census variable to represent the imperative to maximize exchange values. CTs throughout the entire region increased in rent over the study period, but the YL subsample started out with considerably lower median rents than the rest on average, with a 1980 mean of $\$ 616$, compared to $\$ 715$ in EB neighborhoods, $\$ 779$ in WB neighborhoods, and $\$ 792$ for the region overall. ${ }^{34}$ However, by the final time point the mean value for YL subsample median rent, while still lower than that of other samples, was considerably closer to the other samples.

\footnotetext{
${ }^{34}$ Monetary values are adjusted for inflation to 2010 dollars.
} 


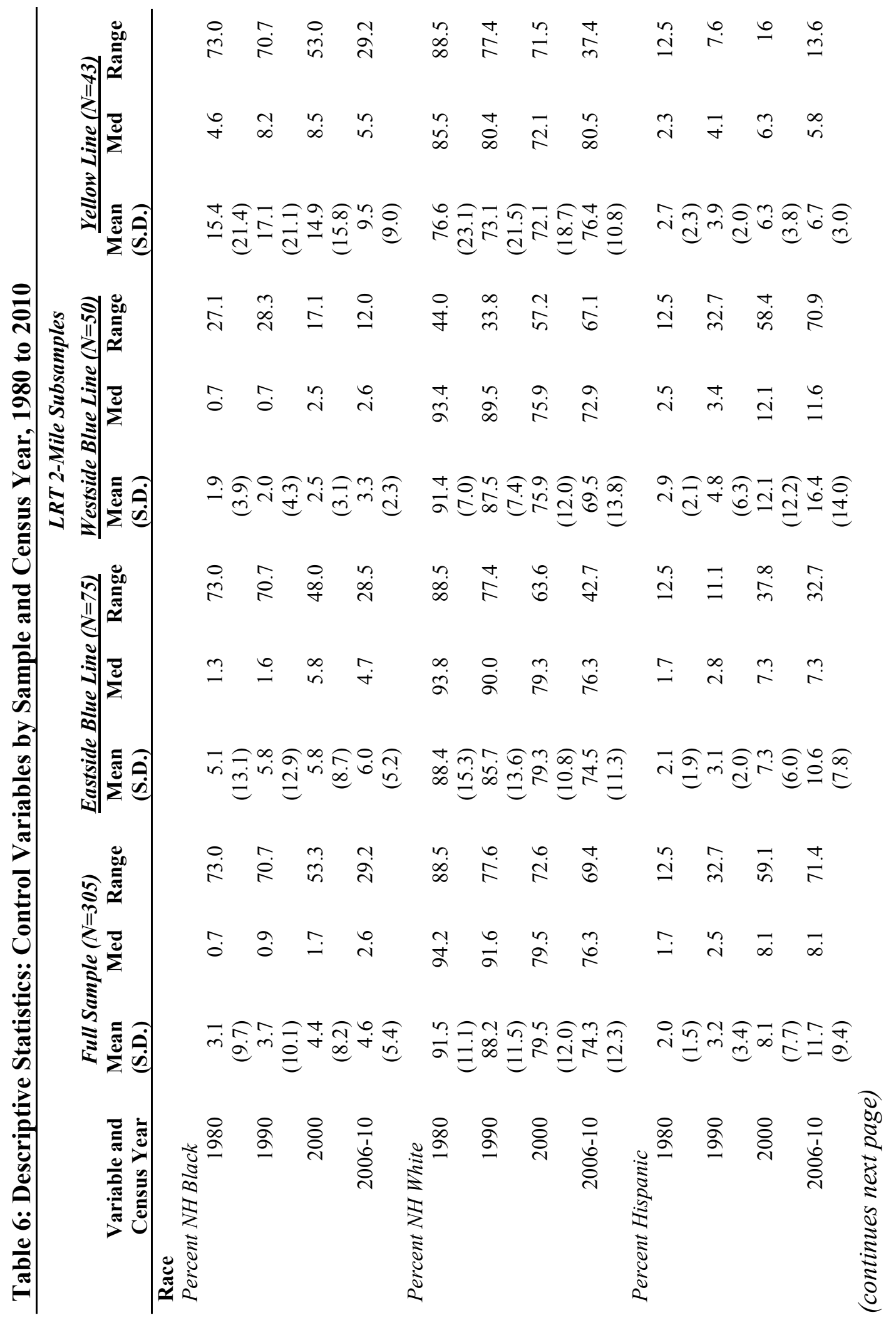




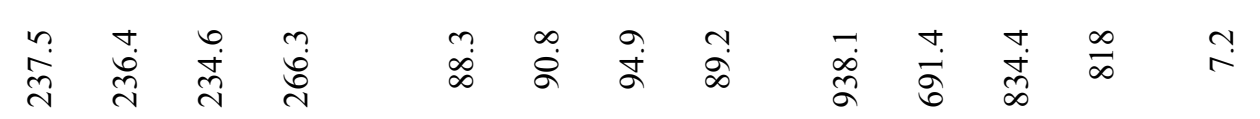

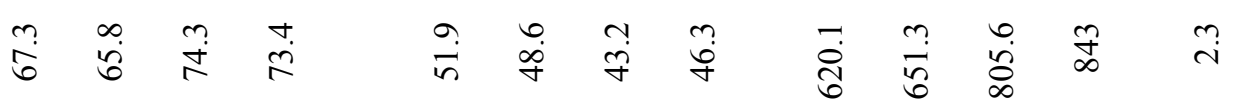

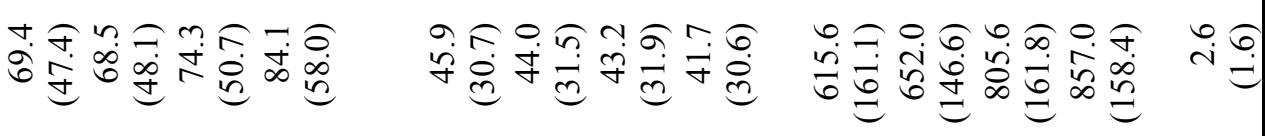

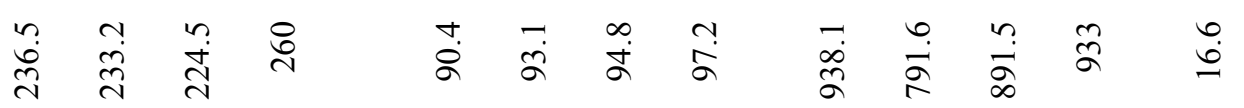

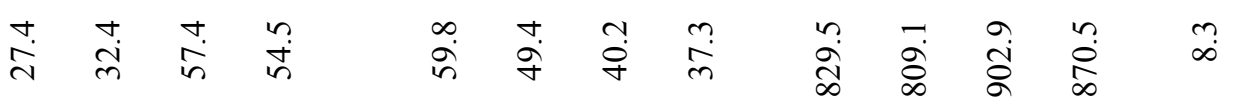

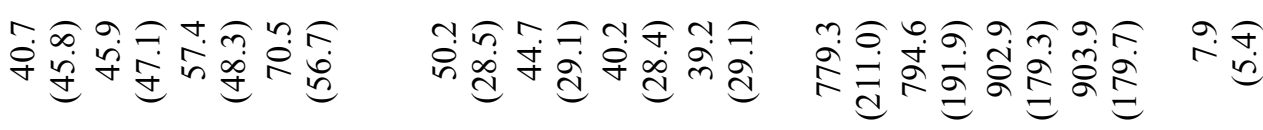

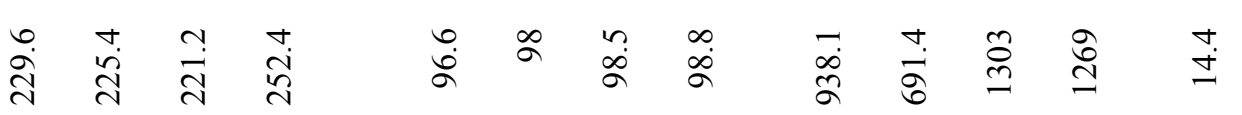

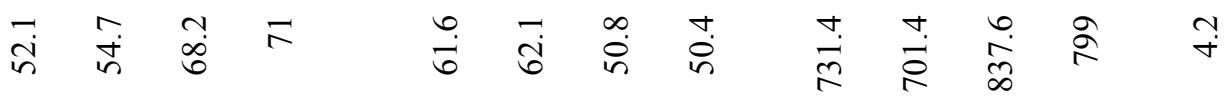

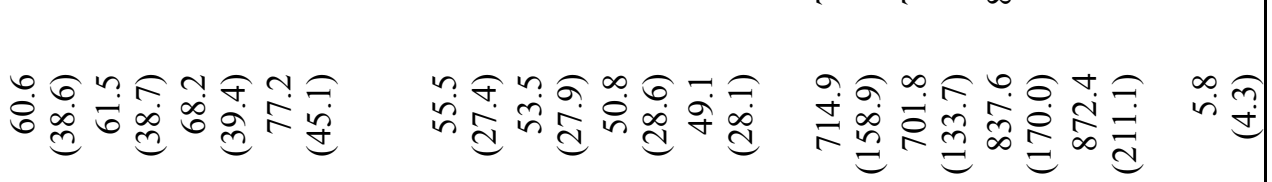

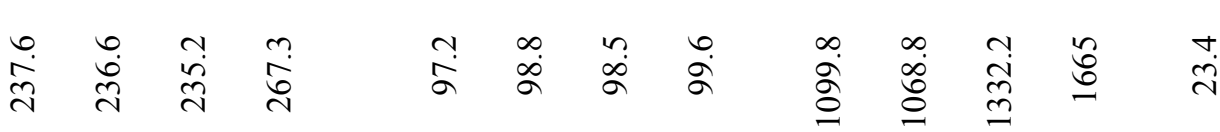

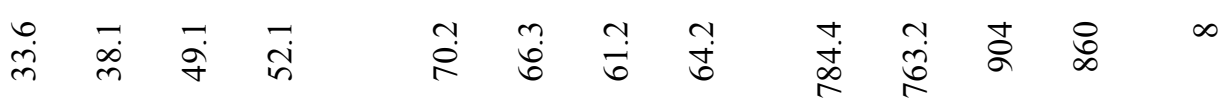

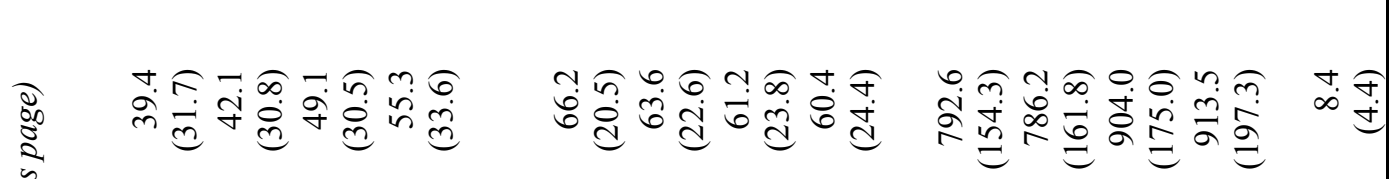

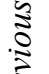
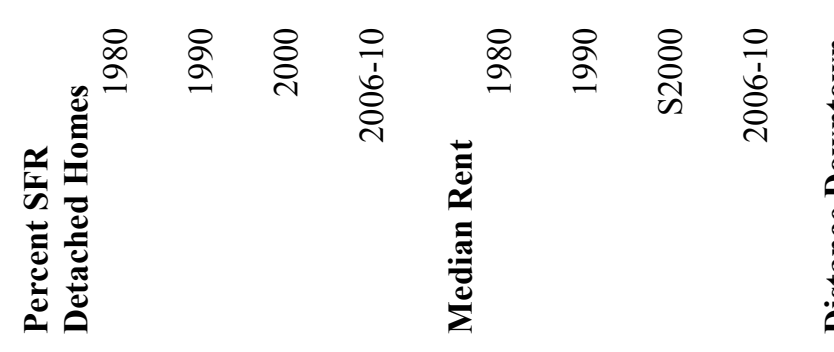
The race/ethnicity variables indicate, as expected, that the YL subsample contains the largest proportions of non-Hispanic Black residents in every census year, with nonHispanic whites on average composing the vast majority of the population in every sample and every census year. It is important to note that the Black population share in the YL subsample decreased over the study period, and by the final time point was only slightly greater than the EB subsample, which increased slightly. This may relate to displacement of Black residents from North Portland and their relocation to the eastern reaches of the region, but that cannot be confirmed by the descriptive statistics in Table 6 . Similarly, it is interesting to note that the WB subsample, which has had the most consistently high SES in the region, shows the greatest increase in Hispanic population share, topping out at an average of $16.4 \%$ in $2006-10$, but again, descriptive statistics alone can only prompt speculation rather than confirm it. For a clearer understanding of shifts in race/ethnicity, choropleth maps are highly beneficial.

Figures 9 and 10 depict the spatial distribution of the non-Hispanic Black population in 1980 and 2010, respectively. Since the census bureau only recorded one race for each resident in the 1980 and 1990 censuses, but allowed multiracial responses ("mark one or more") in 2000 and 2010, direct comparison between these should not be relied upon as the sole analysis of change. To mitigate this limitation, 2000 and 2010 values represent the percentage of residents identifying as non-Hispanic and Black, either alone or in combination with one or more other races. With this limitation in mind, it is clear that noteworthy changes in the distribution of the Black 

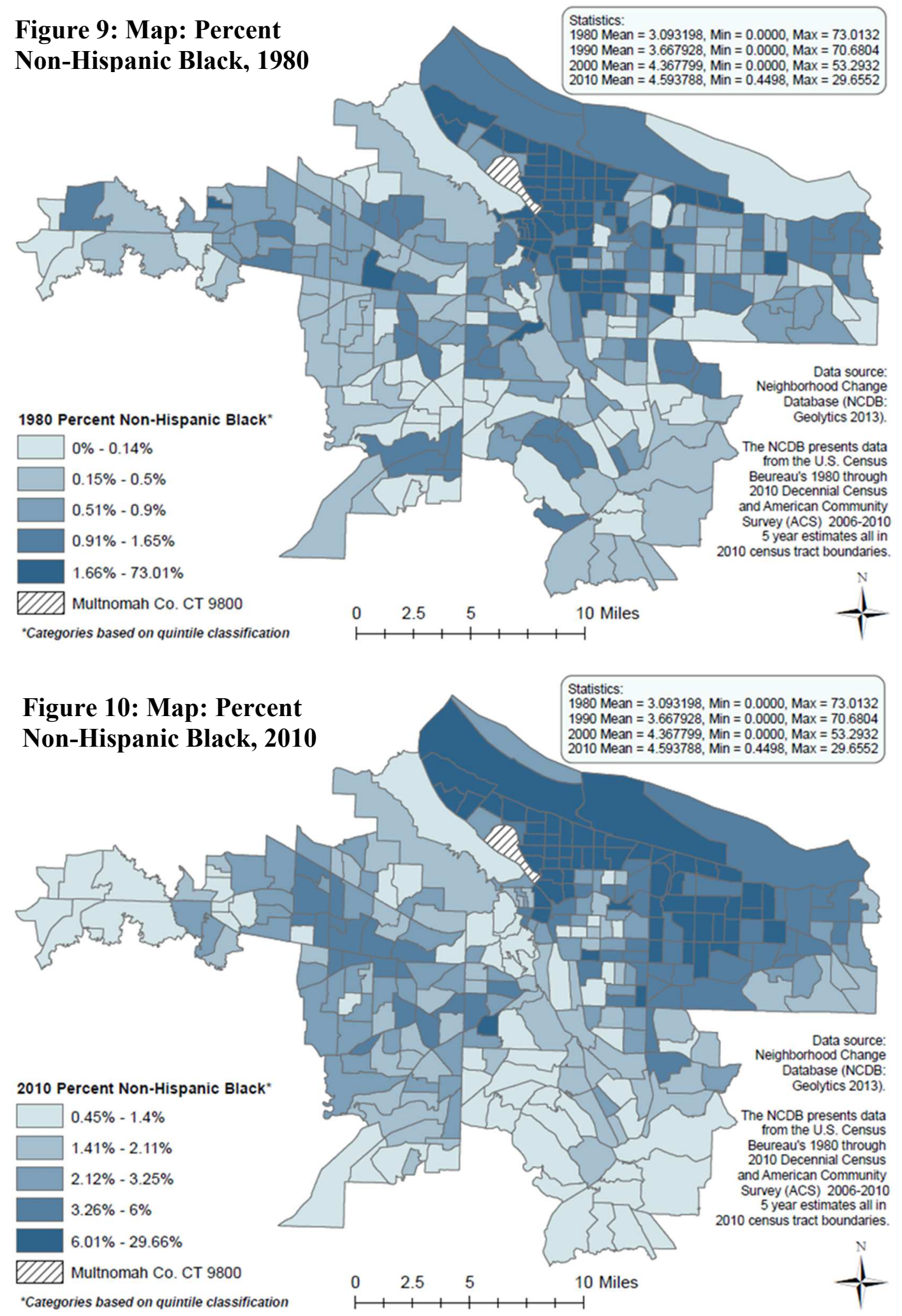
population occurred during the study period - specifically there appears to be an increase in the eastern portion of the region, and a slight decrease in many North and NE Portland neighborhoods. Hence, for a clearer depiction of change between year, the difference between 1980 and 1990 CT percentages of non-Hispanic Blacks are mapped in Figure 11, and differences between 2000 and 2010 in Figure 12.

Figure 11 shows that the Black population in proportion to CT population increased in North, NE, NW, and downtown Portland by 1.3 to 14.1 percentage points. Conversely, neighborhoods of decline in their proportion of Black residents during the 1980s appear to be dispersed with no clear patterns. However, change in percent non-

Figure 11: Map: Change in Percent Non-Hispanic Black, 1980 to 1990

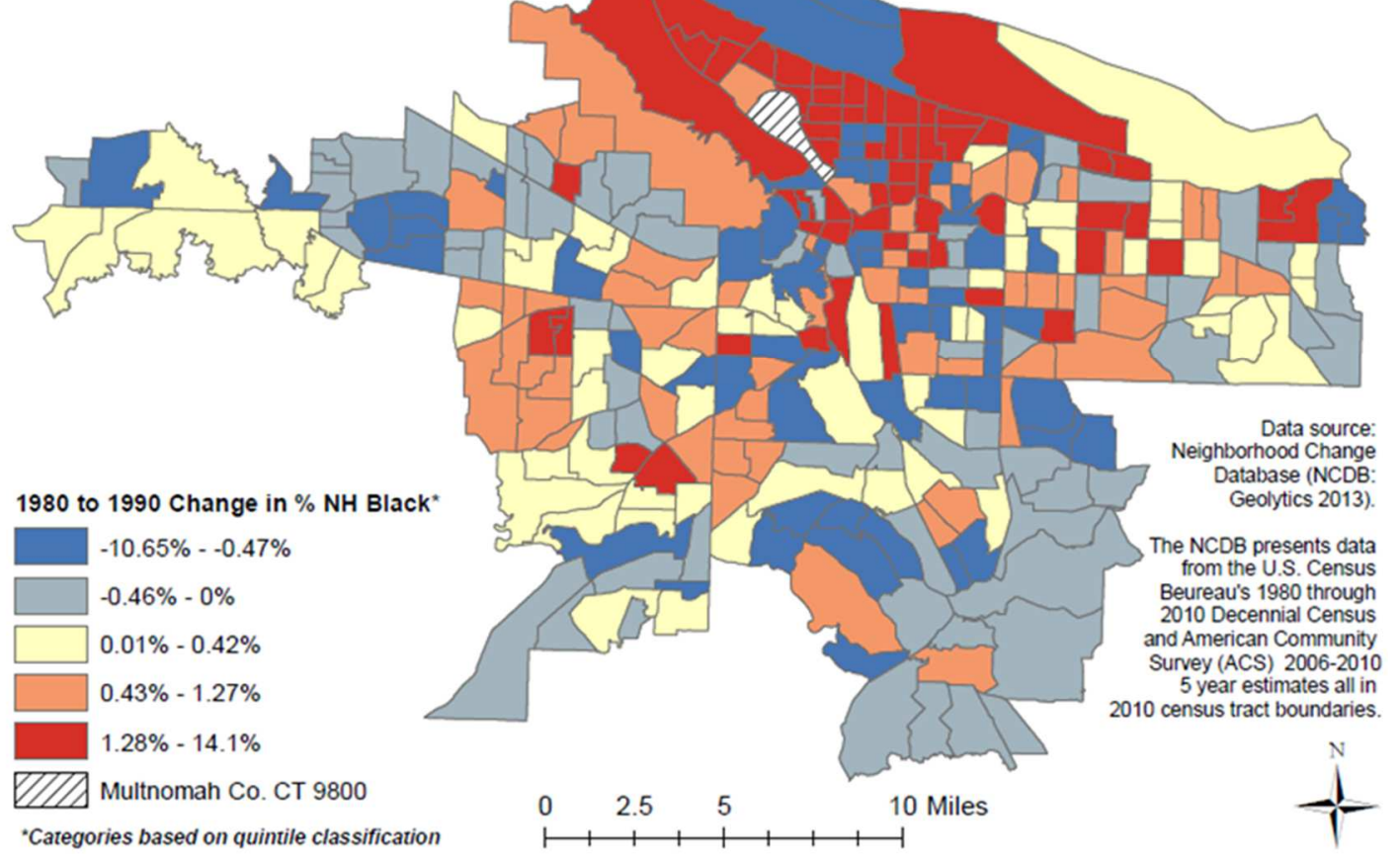


Hispanic Black from 2000 to 2010, as depicted in Figure 12, follows a clear trend that is arguably the opposite of 1980 to 1990 change. Increases are seen almost exclusively east of Portland in the suburb of Gresham, with some smaller clusters of increase in the suburbs west of Portland. At the same time, a solid block of decreasing Black populations covers the majority of North, NE, and SE Portland. As an aggregate measure, while not a definitive indicator of displacement, this is at the very least highly suggestive of the displacement of Black residents.

Figure 12: Map: Change in Percent Non-Hispanic Black, 2000 to 2010

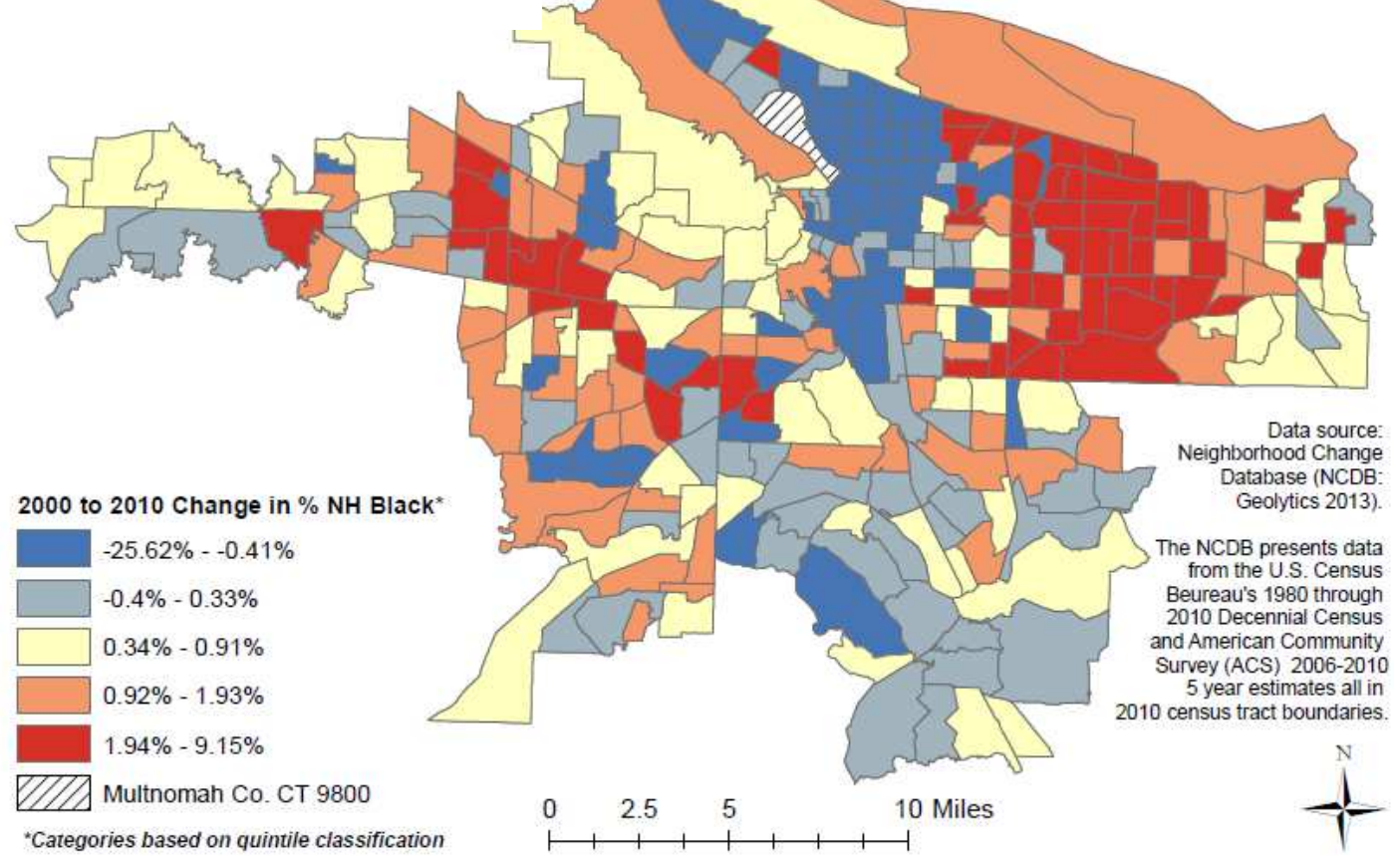


Similarly, Figures 13 and 14 depict the distribution of the region's Hispanic population in 1980 and 2010, respectively. Although questions about Hispanic origin did not change between census years as did the race questions, ${ }^{35}$ it is important to note that the region's overall Hispanic population did increase substantially during the study period. This is reflected in the quintile ranges in that the lowest quintile range in 2010 has an upper bound value exceeding that of the $4^{\text {th }}$ quintile in 1980 . With this in mind, note that the higher proportion CTs in 1980 were located downtown, the inner eastside, and in the westernmost suburbs. By 2010, high Hispanic proportions were almost entirely in the furthest east and west suburbs, with relatively low proportions in Portland city proper.

\footnotetext{
${ }^{35} \mathrm{Hispanic} /$ Latino is considered an ethnicity and has consistently been reported separate of race questions in all census years in the study period. See Table C-2 in Appendix C for the original questionnaire questions.
} 
Figure 13: Map: Percent Hispanic,
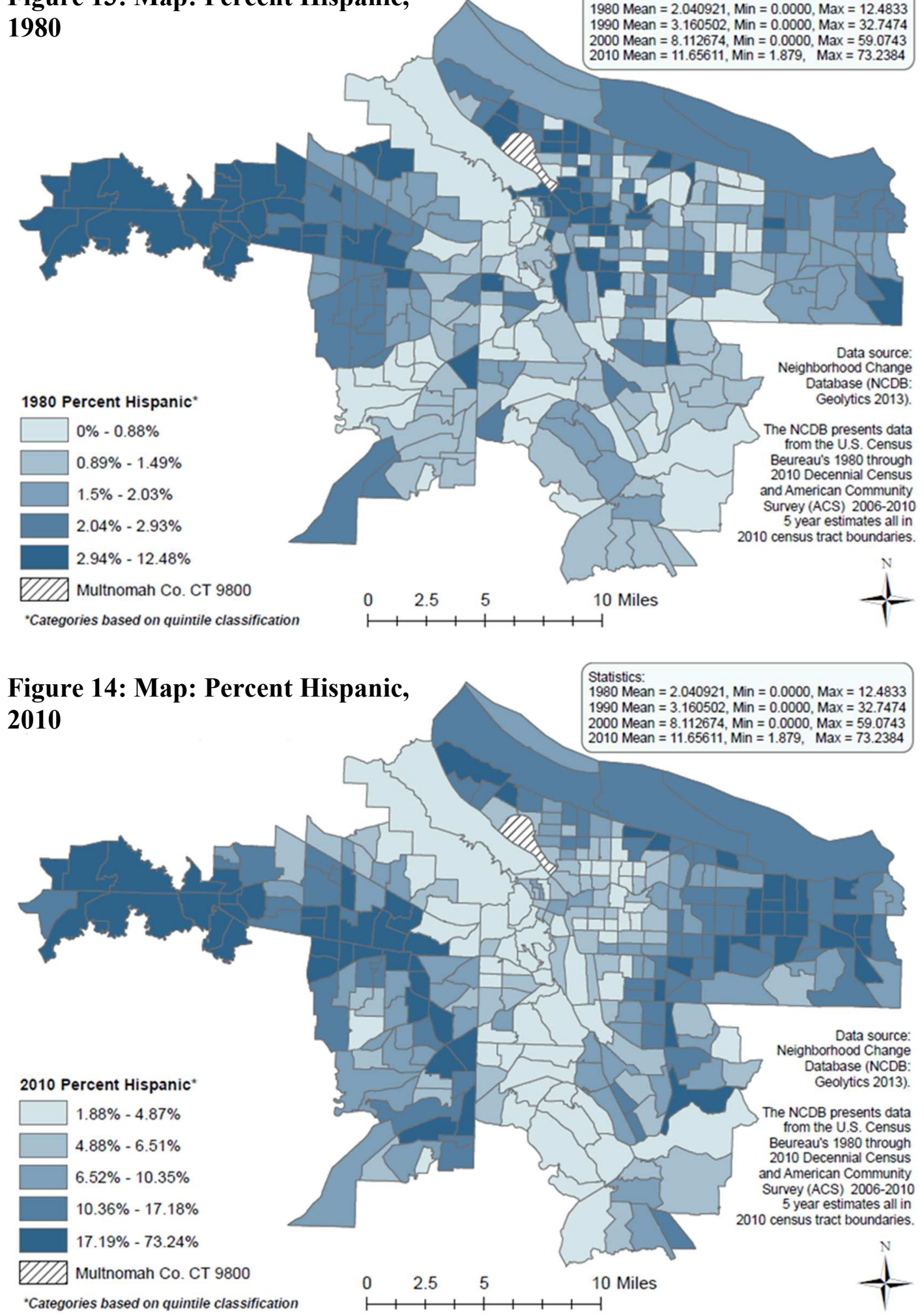
Figure 15 depicts change in Hispanic populations from 1980 to 1990, with increases of 2-29\% mainly in those westernmost CTs, sections of the eastern suburb of Gresham, as well as in North Portland, appearing to cluster in several CTs that are in the interstate corridor where the Yellow Line would eventually be installed. There is little in the way of specific trends of decreasing Hispanics during this period, but again, note that there is actually very little decrease in the Hispanic population in any neighborhood because the population overall was increasing throughout the 1980s.

Figure 16 indicates that neighborhoods west of Portland experienced large increases in Hispanic populations from 1990 to 2000. This coincides with the construction of the WB MAX from 1993 to 1998, which runs through the same

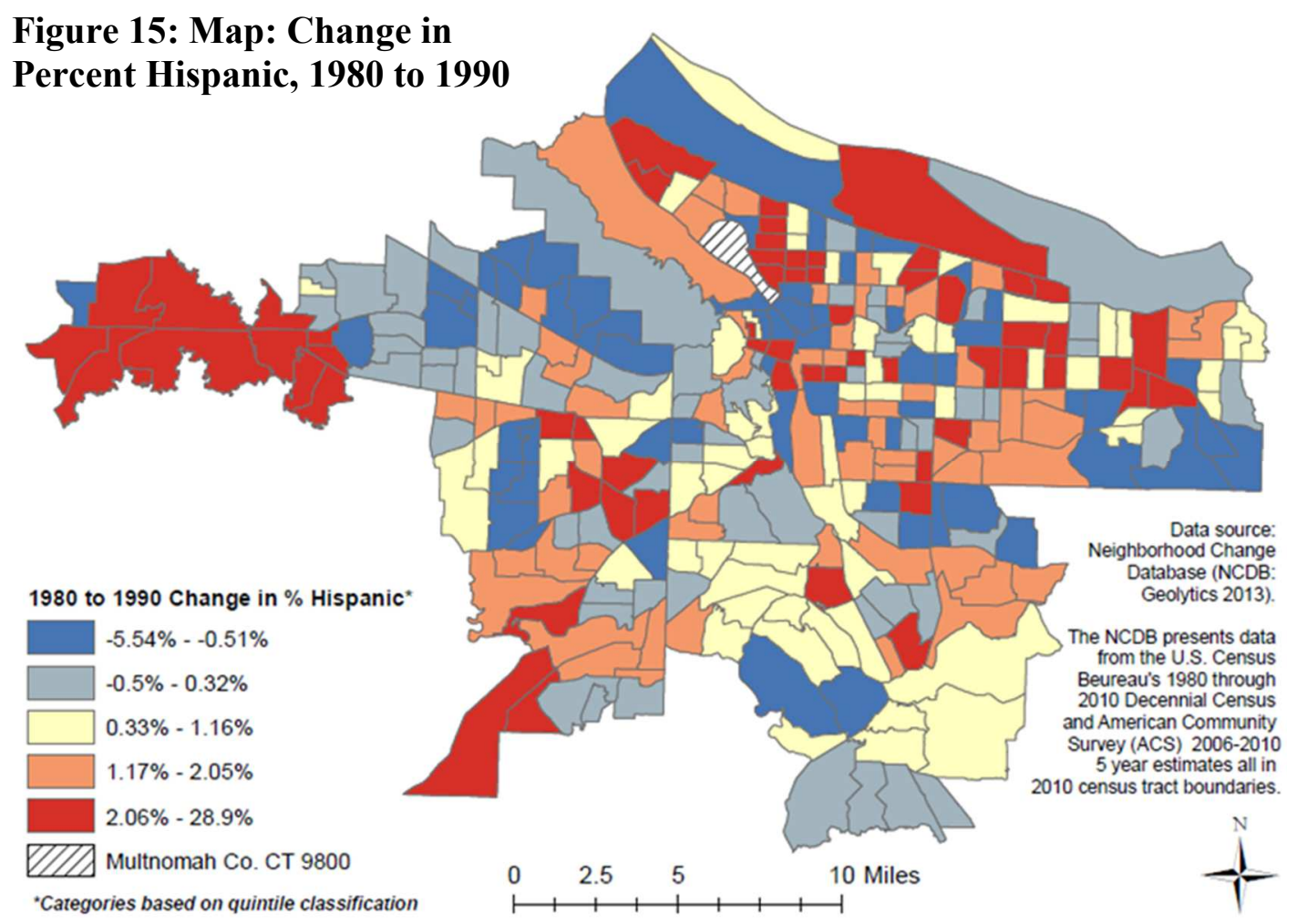


neighborhoods. The increase in Hispanic populations east of Portland also continued from the prior decade - a trend that Figure 17 depicts as further intensifying from 2000 to 2010.

It is evident in Figure 17 that by the final time interval in the study period a clear regional divide had formed in the spatial distribution of Hispanic population movement. While the Hispanic populations of most neighborhoods within Portland city proper in the center of the region either decreased or increased only a fraction of a percentage point, the neighborhoods of surounding suburbs to the east, southeast, west, and southwest of Portland saw Hispanic populations increase substantially.

Figure 16: Map: Change in Percent Hispanic, 1990 to 2000

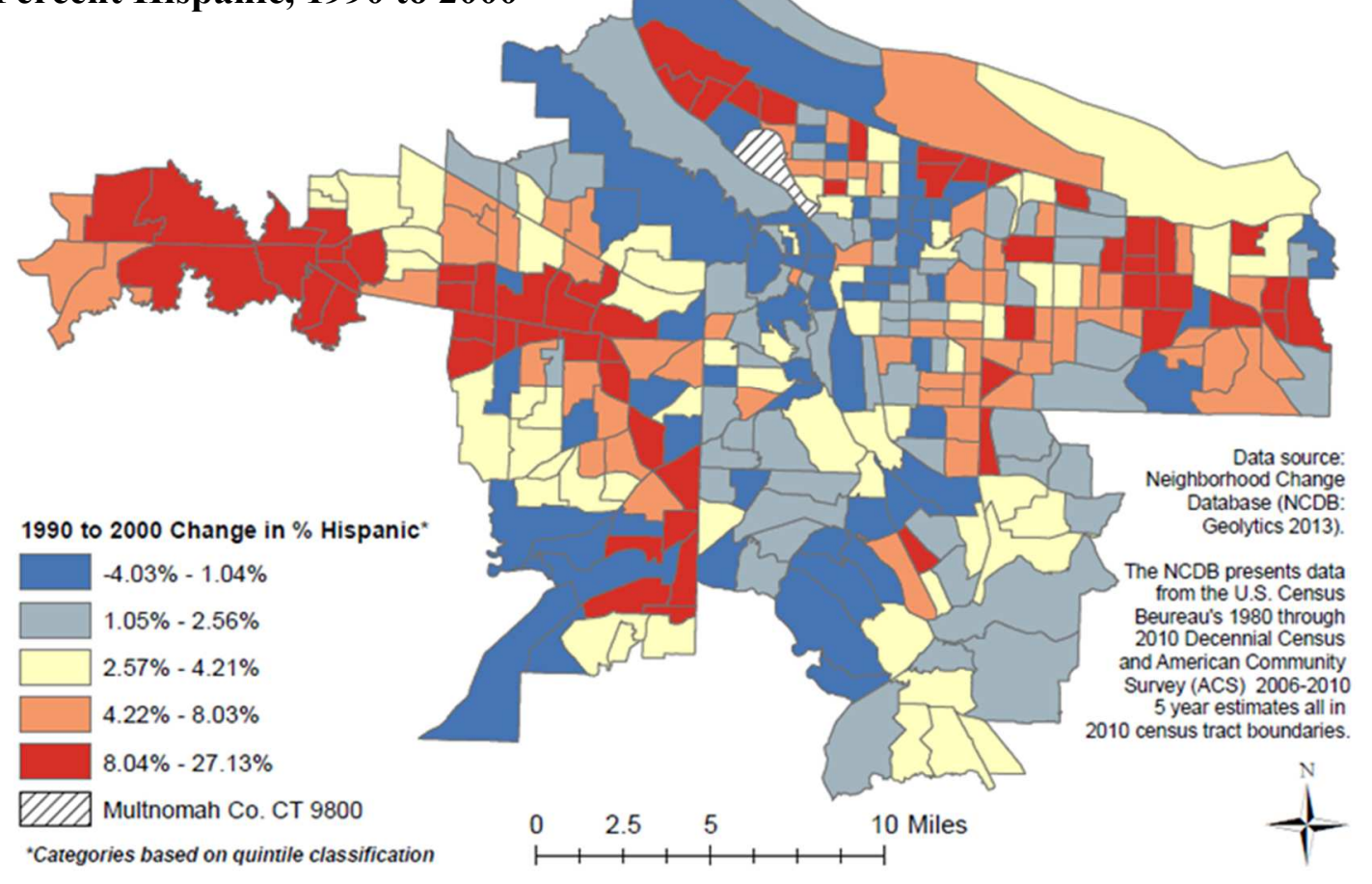




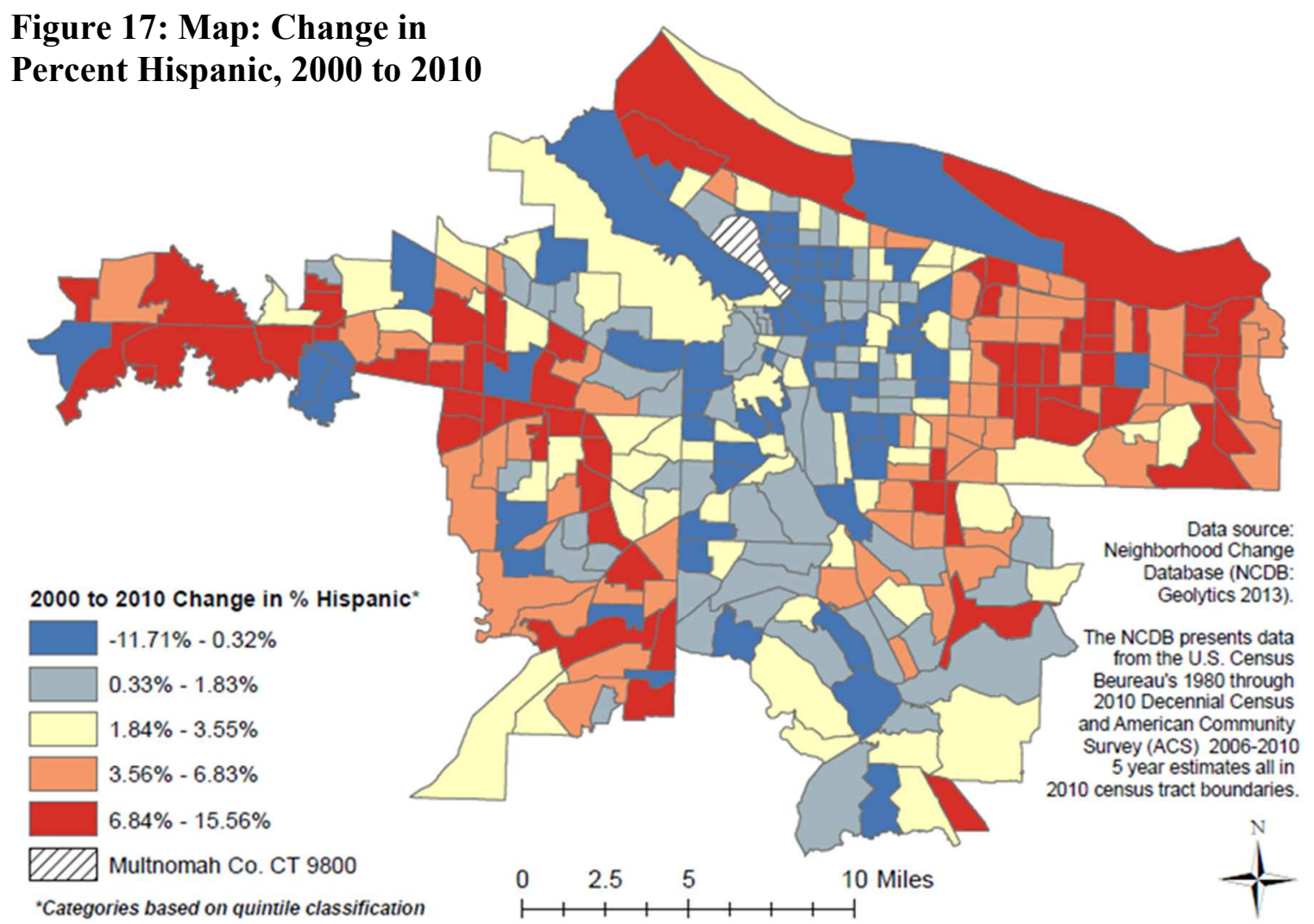

Hot Spot Analysis

SES index and SES index change were analyzed using the Hot Spot Analysis Tool in ArcGIS (v. 10.3), which utilizes the Getis-Ord Gi* statistic. Getis-Ord Gi* is a localized measure of spatial autocorrelation that identifies statistically significant clustering of high values ("hot spots") and low values ("cold spots") for a given variable. This involves comparing the sum of every neighborhood of CTs on that variable to the 
sum of all CTs in the sample on the same variable. ${ }^{36}$ A CT with a neighborhood sum that is significantly higher or lower than would be expected in a random distribution is identified as the focal point of clustering. Should that CT have a neighboring CT that is also a focal point for clustering then together they comprise a small cluster. The statistical significance of a given cluster then depends on the number of CTs comprising it.

Figures 18, 19 and 20 depict the results of hot spot analyses of SES index alongside SES index change for census years 1980 to 1990,1990 to 2000 , and 2000 to 2006-10, respectively. In these maps, Darker shades of red represent greater statistical significance (i.e., lower p-values) of high clustering, and darker shades of blue indicate greater statistical significance of low clustering. A $90 \%$ confidence interval was used as the upper-bound alpha threshold, meaning CTs are only shaded to indicate being part of hot spots or cold spots if there is at least $90 \%$ statistical certainty that their clustering is not merely a product of chance. All of the hot spot analyses in this study were run using the full sample in order to better understand neighborhood change throughout the region.

Figure 18 depicts the outputs from the Hot Spot Analysis Tool run on the SES index in 1980 and 1990, as well as SES index change in the interval between those census years. The 1980 and 1990 hot spot maps both depict an apparent eastern/western divide in the region. The western portion of the region in 1980 contained large and highly

\footnotetext{
${ }^{36}$ This analysis was set to conceptualize a given CT's "neighborhood" as consisting of itself and any other CTs with which it shares an edge or corner. That is, the Hot Spot Analysis Tool calculated neighborhood sums for each CT by adding its SES index and SES change values to those of all the adjacent CTs that share some part of its boundary.
} 
significant clusters of high SES neighborhoods in areas west and southwest of downtown, extending into the suburbs in those directions as well as further south-southwest of Portland city proper. Conversely, low-SES neighborhoods in 1980 and 1990 were clustered predominately in (a) the eastern portion of the region along $82^{\text {nd }}$ Avenue and Interstate 205 and expanding southeastward; and (b) in all of North Portland and much of inner NE, extending across the river and claiming two west side downtown CTs.

Although the general east/west divide of 1980 persisted in 1990, some notable changes are apparent in comparing the two individual years; these differences are emphasized in the hot spot map of 1980 to 1990 SES change. The low SES clustering downtown - both east and west of the river - disappeared, which corresponds with the same area in the SES change map showing significant clustering of SES increase in downtown CTs, expanding into the NW, SW, and inner eastside Portland neighborhoods nearest to downtown. Clustering of high SES change values extended east along the EB MAX line, which opened for service during that period, and reached as far as the NE $60^{\text {th }}$ Ave MAX station. However, beginning a short distance (two MAX stops) eastward at the Gateway Transit Center, and continuing to the easternmost station, the EB MAX line runs through a large cluster of cold spot neighborhoods that experienced especially little 


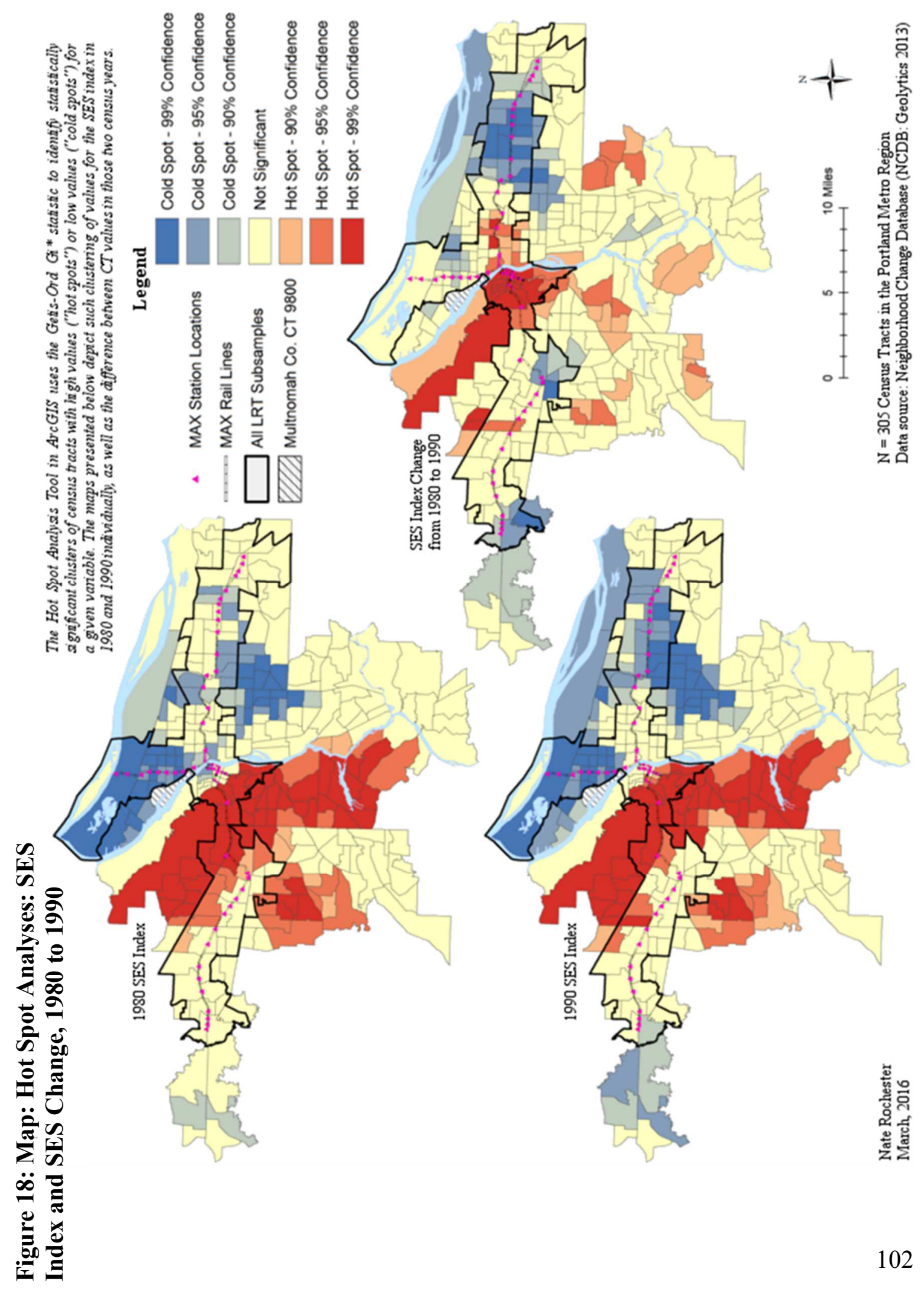


increase or even decrease in SES index values during the same period. ${ }^{37}$ This intensification of low SES clustering in the furthest east suburbs is mirrored in the westernmost suburbs and may suggest those areas amount to what Bates (2013) refers to as "landing zones" for the displaced.

It is apparent in Figure 19 that the trends of 1980 and 1990 largely continue in 2000; however, there are some key differences to note. Most notably, the first instance of high SES index clustering anywhere on the east side began taking shape in 2000 in central NE Portland neighborhoods near EB stations. A potential link between EB development and the ascent of NE neighborhoods is suggested by the majority of high SES clustering on the eastside being within the EB subsample. The 1980 to 1990 eastside clustering of high SES index change expanded in the 1990 to 2000 interval into areas of NE Portland that had in the previous decade still included cold spots of change, and this likely relates to the simultaneous weakening of low SES clustering in North Portland.

\footnotetext{
${ }^{37}$ Because hot spot analysis identifies high and low clusters based on CT values relative to the rest of the region, low clustering represented as "cold spots" does not necessarily indicate decreasing SES. As previously reported in Table 5, every time interval between census years is characterized by SES change with a positive mean and median, meaning there is overall increase in SES index values throughout the region during the study period. This means low clustering of SES change could very well indicate areas where neighborhood SES is increasing according to this measure, but at a lower rate of change than the rest of the region.
} 


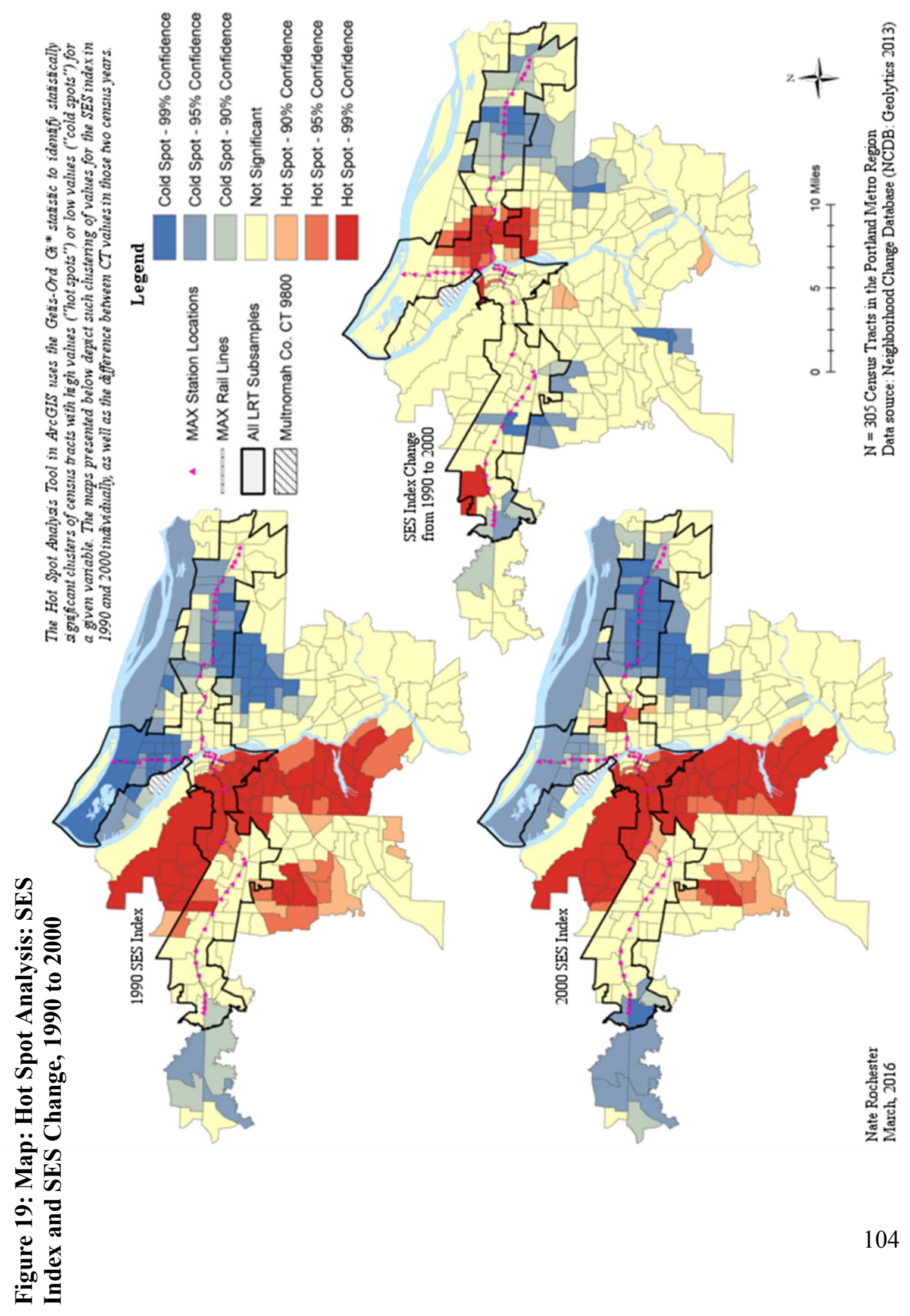


However, relating the neighborhood ascent of N/NE Portland is problematized by the growing clusters of low SES and SES change seen along the eastern half of the EB MAX throughout and surrounding the easternmost suburb of Gresham. Similarly, the 2000 SES index hot spot map also depicts intensification of low SES clustering in the western suburbs of Forest Grove and Hillsboro, including around multiple stations at the terminal end of the WB MAX, which had been operating for about a year at that time. The juxtaposition of both high and low clustering of SES index and SES index change along the same LRT lines suggests the effects of LRT development on neighborhood SES, if any, is complex and likely includes other mediating and moderating relationships.

Figure 20 illustrates that many SES clustering patterns of 1980 through 2000 not only continued, but became increasingly pronounced in the final decade of the study period. From the hot spot map of the 2006-10 time point it is apparent that all clustering of low SES index values had disappeared entirely from North Portland and the Interstate corridor, where YL MAX stations had recently opened for service. This is emphasized in the hot spot map of 2000 to 2006-10 SES index change, which depicts high clustering throughout all of North Portland as well as large swaths of NE and SE Portland neighborhoods like not seen in prior census year intervals. The final time point therefore represents the culmination of trends that were previously identified in hot spot analyses over the entire study period, which together amount to the strongest evidence yet of a link between LRT development and gentrification in North Portland. 


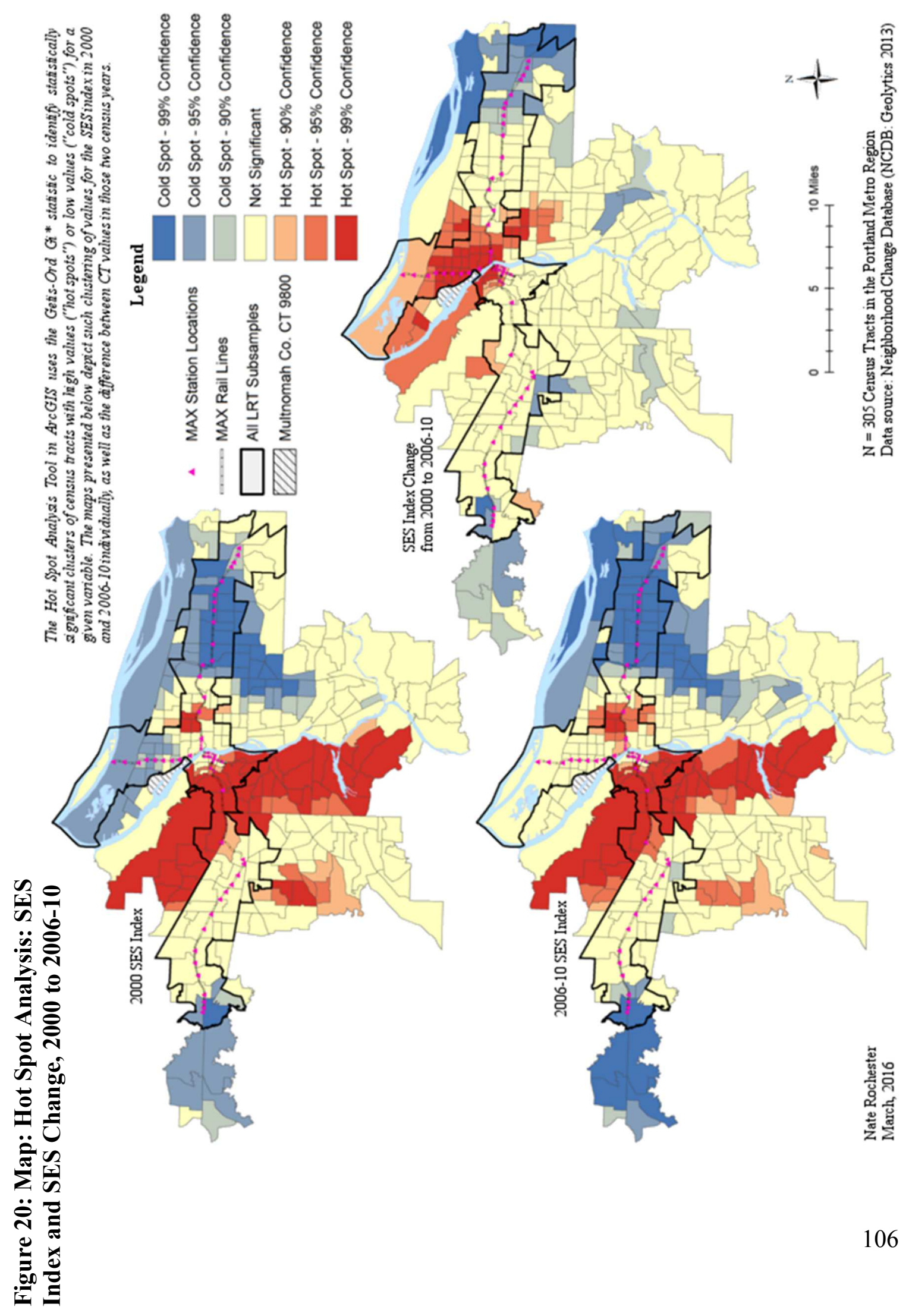


This is supported by three factors. First, North Portland neighborhoods, including CTs located parallel to where YL MAX would later be installed, comprised low SES change clustering in the 1980 to 1990 interval. That pattern, resulting from multiple adjacent CTs either decreasing in SES or increasing to a substantially lesser extent than average in the region, is indicative of disinvestment processes that are theorized to precede reinvestment and subsequent gentrification (Logan and Molotch 1987). Second, high clustering of SES change occurred during the 1990 to 2000 interval in NE Portland, including in CTs that comprised low clusters of change in the prior decade, but did not reach the CTs closest to YL station locations. This suggests that although gentrification processes were already underway in that general area they had not significantly affected YL neighborhoods in 2000. Third, although statistical significance of low SES clustering was beginning to weaken in 2000, it was still present and significant in this part of the YL subsample in 2000, indicating that those neighborhoods were eligible to undergo gentrification as defined for this study. Finally, the high clustering in SES change from 2000 to 2006-10 includes virtually every CT containing a YL station.

\section{Pearson's Correlations}

CTs in each subsample were analyzed for bivariate relationships between distance to their respective MAX stations and SES index in each census year, as well as change in SES index between census years. Pearson's correlation was selected as the bivariate analysis method because SES index and LRT distance are both interval-ratio level variables. These analyses are limited to subsamples of CTs within 2 miles of stations 
along individual lines because the effect of LRT development on neighborhood change is thought to be local in reach. Each MAX line is analyzed only in the subsample associated with it, with correlations run for years before and after stations were installed. Correlation coefficients corroborate prior findings from univariate and cluster analyses that suggest neighborhood access to new LRT infrastructure was likely an exacerbating factor in the gentrification of North Portland.

Table 7 lists coefficients and significance levels for Pearson's correlations by subsample and census year. A statistically significant $(\mathrm{p}<.01)$ but weak positive correlation was found in EB neighborhoods between distance to EB station locations and SES index in all census years. This indicates that both before and after the 1986 grand opening of the EB MAX, the neighborhoods closest to station locations were characterized by generally lower levels of SES than neighborhoods just slightly further away but still within 2 miles of those locations. Since the strength and direction of relationship between LRT distance and SES index is approximately the same in the time point prior to EB MAX station development (1980) as in the census years after the stations were built and operating (1990, 2000 and 2006-10), the findings from the EB subsample fail to identify an effect of Eastside Blue Line development on neighborhood SES. 
Table 7: Correlations: LRT Distance with SES Index and SES Change, by

Subsample and Census Year, 1980 to 2010

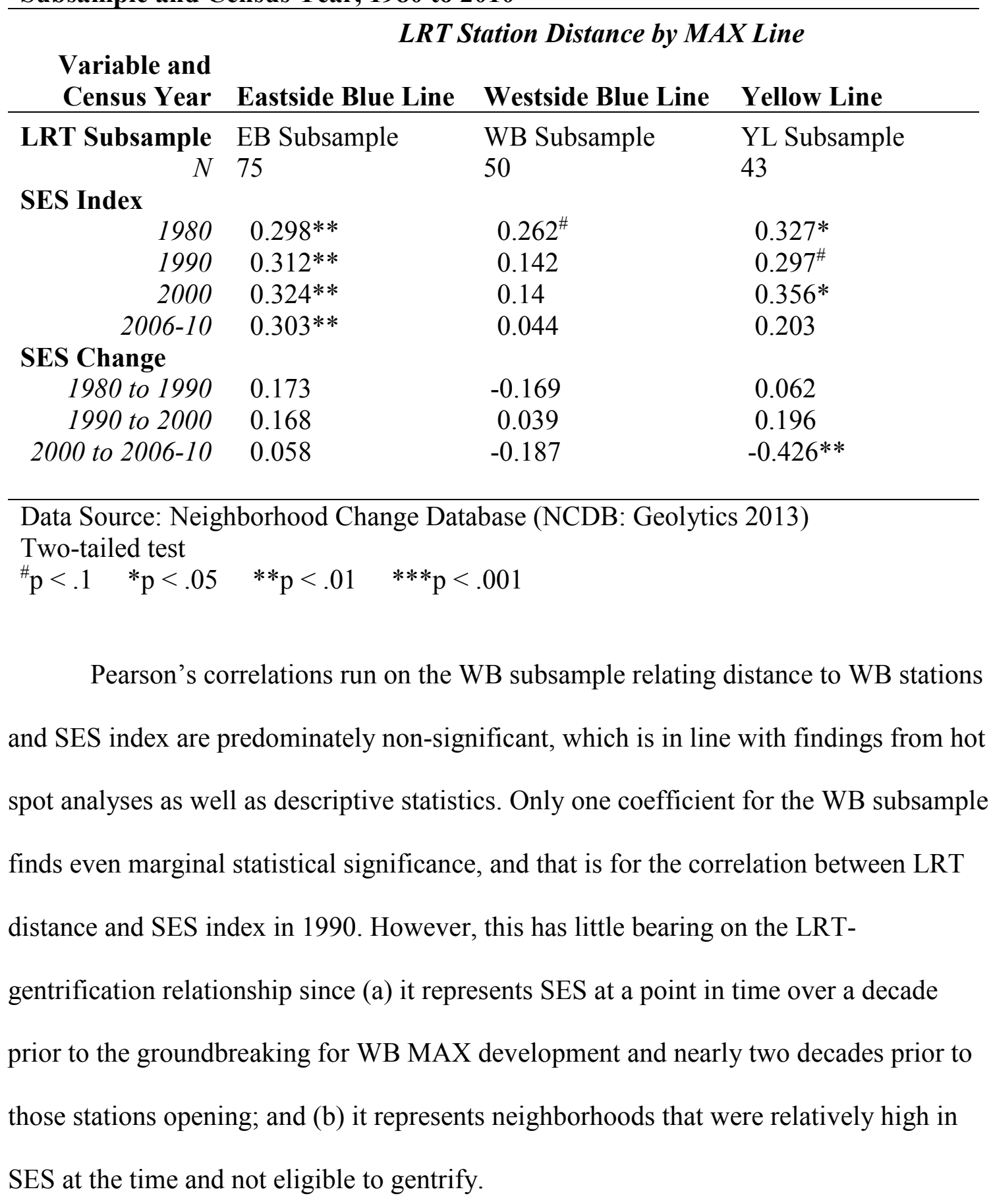


The YL subsample correlations are particularly interesting and provide evidence of the relationship between YL MAX development and North Portland gentrification that mirrors and improves upon findings from hot spot analyses. Correlations between YL distance and SES index reveal statistically significant and moderate-strength positive coefficients in $1980(\mathrm{r}=.327 ; \mathrm{p}<.05), 1990(\mathrm{r}=.297 ; \mathrm{p}<.1)$, and $2000(\mathrm{r}=.356 ; \mathrm{p}<$ .05) indicate that CTs within 2 miles of YL station locations tended to increase in SES the further away they were from those locations. However, this relationship lost all linear strength and statistical significance in 2006-10, coinciding with the construction of those stations and beginning of Yellow Line MAX service. This also coincides with the only statistically significant correlation coefficient between LRT distance and SES change of any subsample. In the YL subsample, the difference in SES index between the 2000 and 2006-10 census years is strongly negatively correlated $(\mathrm{r}=-0.426 ; \mathrm{p}<.01)$ with distance to YL stations. In other words, YL CT's with housing centroids located closer to YL stations experienced greater increase in SES after those stations were built and opened than did CTs further away but still within 2 miles.

No statistically significant relationships are found between distance to yellow line station locations and SES change from 1980 to 1990, or from 1990 to 2000. However, from 2000 to 2006-10 - the time interval during which Yellow Line stations were built and services began - the correlation coefficient relating distance to yellow line stations with SES change suddenly switched directions and increased sharply in strength The consistently positive correlation coefficients of local subsamples in the SES index 
throughout the study period suggests that the CTs closest to Yellow Line stations were lower in their socioeconomic status than other CTs in the area, and the strong negative correlation between distance from those stations and SES change during the time interval in which the stations were built indicates such rapid increase in SES during the relatively short period that few if any explanations other than gentrification come to bear on it.

\section{Multivariate Analyses: OLS Linear Regression}

Based on descriptive statistics, correlations, and hot spot analyses, the only subsample that consistently displayed SES trends characteristic of gentrification around LRT was that based on YL stations. ${ }^{38}$ Multivariate analyses are therefore limited to the YL subsample. Several OLS models regressed SES index and SES change on YL station distance, controlling for downtown distance and census control variables from the prior time point ${ }^{39}$ Results, presented in Tables 8 and 9, indicate a positive relationship between LRT development and gentrification in simple regressions as well as with control variables. In SES index analyses this finding is supported by substantial weakening in strength and significance of the YL distance coefficient in the final time point. In SES change analyses it is supported by the stability of that coefficient between models.

\footnotetext{
${ }^{38}$ Although multiple CTs in the EB subsample also demonstrated some evidence of neighborhood ascent following development of that MAX line, the relationship of those changes to EB station locations is highly variable across the subsample. Additionally, since relatively few of the EB CTs that showed evidence of SES increase had previously been characterized by especially low SES, much of the neighborhood ascent in downtown Portland and the inner east side does not meet the disinvestment criterion for gentrification established at the beginning of this study.

${ }^{39}$ For ease of interpretation, SES index and SES change values were multiplied by 100 to be in percentage point units (as opposed to decimal proportions), and adjusted median rent values were divided by 100 to be in units of $\$ 100$.
} 
Table 8 lists regression coefficients, standard errors, and significance levels for OLS models of SES index as measured in 1990, 2000, and 2010, regressed on distance to YL station locations and control variables as measured in 1980, 1990, and 2000, respectively. Models 1, 3, and 5 regress SES index on LRT distance alone, whereas Models 2, 4, and 6 add in the control variables. The main intention of these analyses is to determine if the findings from Pearson's correlations continue to be evident when controls are added.

The results of simple regressions reflect the findings from Pearson's correlations. For example, F-statistics indicate overall statistical significance in all of the models except Model 5, which is in line with the correlation previously run between YL distance and 2006-10 SES index. Similarly, regression coefficients for YL distance, when it is the only predictor variable, correspond in strength and significance with correlation coefficients for the same years: there is a stronger relationship between YL distance and SES index in 2000 than in 1990, and a non-significant coefficient in 2006-10. Adjusted R-squared values follow the same trend, with about $6.6 \%$ of SES index variation being explained by YL distance in $1990,10.6 \%$ in 2000 , and only $1.8 \%$ in $2006-10$. This suggests that from 2000-2010, when the YL MAX was constructed and opened, neighborhoods closest to YL stations, which in previous years had significantly lower SES than those further away, increased in SES to such an extent that the relationship lost statistical significance. 


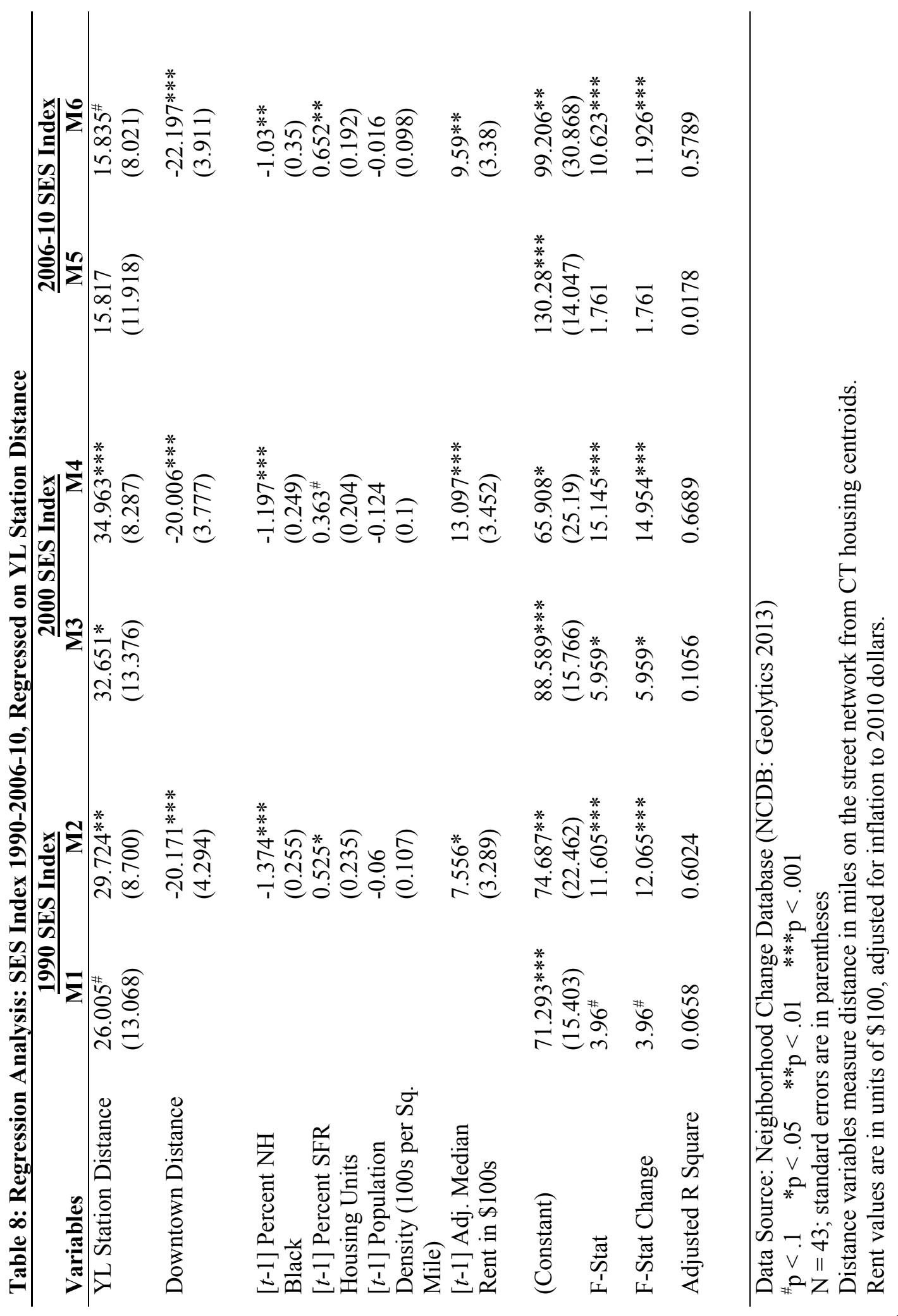


The addition of control variables illuminates some important changes in these trends that provide further evidence of gentrification in relation to LRT development. First, adding controls results in a statistically significant change in the F-statistic for all three census years, accompanied by substantial increases in adjusted R-squares. When all control variables are held constant, the models explain about $60 \%, 67 \%$, and $58 \%$ of the variation in SES index in 1990, 2000, and 2006-10, respectively. Second, and most importantly, the inclusion of controls in modeling 2006-10 SES index (Model 8) resulted in a significant $\mathrm{F}$-statistic $(\mathrm{F}=10.623 ; \mathrm{p}<.001)$, and a marginally significant $\mathrm{YL}$ distance coefficient of $15.8(\mathrm{p}<.1)$. This coefficient indicates that neighborhood SES in 2006-10 is predicted to be almost 16 points greater with each additional mile from the nearest $\mathrm{YL}$ station, all else being equal. Although the coefficient remains positive, it is substantially lower than the corresponding coefficient in 2000, which predicted about 35 points increase in SES index for every mile from YL stations. This trend is indicative of a positive relationship between LRT development and neighborhood socioeconomic ascent.

Coefficients for the downtown distance variable indicate, as expected, that CTs further from downtown were expected to have lower neighborhood SES in 1990, 2000, and 2006-10. The strongest effect is found in the final time point, which indicates that for every mile of distance between a neighborhood and downtown, SES index in 2006-10 is expected to decrease by over 22 points, holding all else constant. That is a sizable increase in impact compared to about 20 points in 1990 and 2000. Such a change likely 
relates to gentrification in YL neighborhoods, and is reflected in the choropleth maps in Figures 4-6, which depict neighborhood SES along that north/south corridor as being more-or-less evenly distributed in 1990, then slightly higher in values but still relatively evenly distributed in 2000 , and then notably higher close to downtown and lower in the northernmost neighborhoods in 2006-10. This is consistent with the priority of urban growth machines towards the pursuit of exchange values through land use intensification (Logan and Molotch 1987), achieved through the high density, mixed zoning around transit stations associated with transit oriented development (Geller 2003).

With regard to race, an almost perfect 1:1 negative relationship is found between percent non-Hispanic Black population in 2000 and SES index values in 2006-10, with each one percent increase in a CT's 2000 non-Hispanic Black population associated with a 1.03-point decrease in 2006-10 SES index, all else being equal. Looking at previous years, this appears to follow a trend of a gradually decreasing negative association between black population share and subsequent neighborhood-level SES. In 2000, SES index values were estimated to decrease 1.2 points for each percentage point increase in 1990 PNHBLACK, and 1990 SES index values are estimated to be 1.4 points lower for each one-point increase in 1980 PNHBLACK, holding constant all other variables.

Rather than indicating social mobility in Portland's African American population due to rising incomes and educational and occupational attainment throughout the study period, this finding likely relates to McKenzie's (2013) finding that the geographic distribution of Portland's Black population became increasingly dispersed during the 
2000s. Both findings correspond to the declining Black population in this subsample of neighborhoods that is evident in Table 6. As Blacks have been displaced from gentrifying North/NE neighborhoods, those households have been replaced by relatively affluent white households, and as a result the negative relationship between Black population share and subsequent SES has gradually decreased. This is in line with the emphasis of the urban growth machine theory on the "recycling" of racial minority neighborhoods to serve growth coalition interests (Logan and Molotch 1987), and is generally consistent with the socio-historical context of Albina as a regional "catch-all" for displacementinducing urban policy (Gibson 2007).

Rent coefficients indicate that for neighborhoods within 2 miles of YL station locations, 1990 SES index values are estimated to increase by about 7.6 points for every $\$ 100$ increase in 1980 rent, all else being equal. The figure nearly doubles in the following census year to an estimated 13.1 points increase in 2000 SES index values for every $\$ 100$ of median rent in 1990, and then comes down again to a 9.6-point increase in 2006-10 SES index for each $\$ 100$ of median rent in 2000. All dollar amounts are adjusted for inflation to 2010 dollars, and the trend indicates that the relationship between rent and subsequent SES in North/NE Portland neighborhoods, while consistently positive, has fluctuated in magnitude over the study period.

A possible explanation for 1990 rents having a greater positive impact on 2000 neighborhood SES than 2000 rents have on 2006-10 SES may be that wealthier newcomers to the area between 1990 and 2000 favored the neighborhoods along the 
eastern side of the subsample that had higher SES (and therefore higher rents) to begin with; whereas from 2000 to 2006-10 gentrifying households ventured further into the neighborhoods closer to YL stations that were still characterized by relatively low rents and low SES populations. In this context, the fact that the smallest coefficient is for the 1990 SES index regressed on 1980 median rent simply reflects that at the 1980 and 1990 time points, prior to the onset of gentrification trends in the area during the 1990s, neighborhood SES and rents were both depressed throughout the subsample, meaning most households were comparably low SES and would have sought housing with the lowest possible rent. This explanation is consistent with the hot spot analyses depicted in Figures 18 through 20, as well as descriptive statistics in Table 6.

Table 9 presents two OLS models that regress 2000 to 2006-10 SES change on YL station distance. This census year interval, during which YL stations were built and opened, is the period in which SES change had the most consistently high clustering around YL stations in hot spot analyses, and also the only interval in which any subsample had a significant correlation between SES change and YL distance. As in the SES index regressions of Table 8, the first model (M7) is a simple bivariate regression with YL distance as the sole independent variable, and the second model (M8) adds control variables corresponding to the 2000 census year. M7 has overall model significance $(\mathrm{F}=9.066 ; \mathrm{p}<.01)$, and the adjusted $\mathrm{R}$-square indicates that without controlling for any other variables, distance to YL stations explains about $16 \%$ of the variation in SES change $(\mathrm{r}=.1611)$. The regression coefficient $(-16.834)$ indicates that 
SES index is predicted to increase by nearly 17 points in the final time interval for every mile nearer a neighborhood is to a YL station.

With the addition of control variables in M8, the coefficient becomes slightly weaker at -14.1 , but remains statistically significant $(\mathrm{p}<.01)$. This indicates that neighborhoods are predicted to increase in their SES index values by just over 14 points

Table 9: Regression Analysis: SES Index Change 2000 to 2006-10, Regressed on YL Station Distance

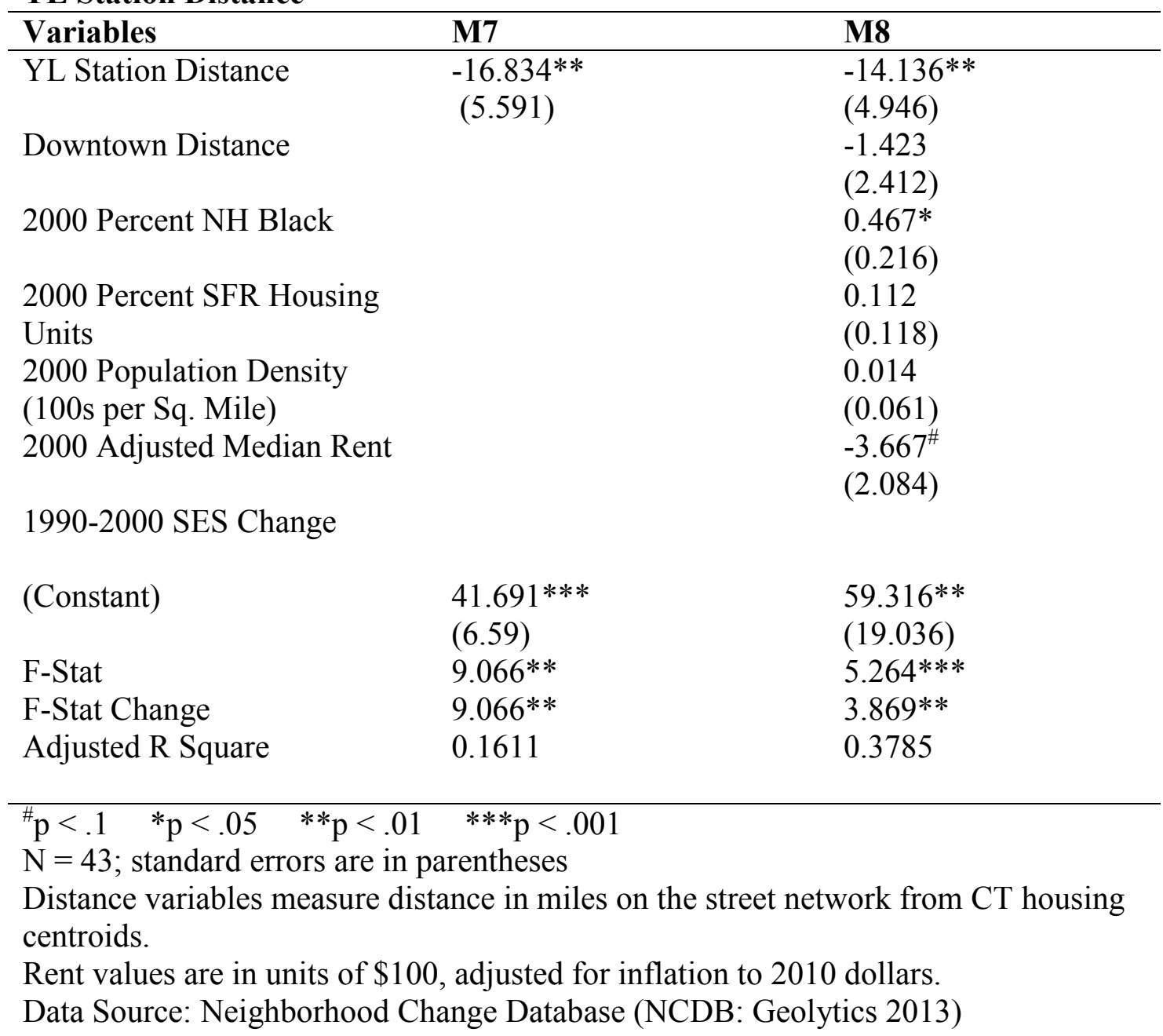


with every mile of increased proximity to YL stations, all else being equal. This especially large coefficient provides the strongest evidence so far of the connection between LRT development and gentrification. Holding control variables as constant, M8 maintains a statistically significant model fit $(\mathrm{F}=5.264 ; \mathrm{p}<.001)$, and the adjusted $\mathrm{R}$ square increases to .3785 , meaning the model as a whole explains nearly $38 \%$ of variation in SES change.

Unlike the regressions modeling SES index in 1990, 2000 and 2006-10, distance to downtown is not significantly related to SES change from 2000 to 2006-10. However, percent non-Hispanic Black in 2000 is a statistically significant predictor of SES change from 2000 to $2006-10$, with $95 \%$ certainty that the relationship found is real and not a product of chance $(\mathrm{p}<.05)$. M8 indicates that every one percent of a CT's 2000 population representing non-Hispanic Black residents is associated with an increase of about a half-point (0.467) in SES index change in the final time interval, holding all else constant. In other words, neighborhoods with non-Hispanic Blacks accounting for a higher percentage of their population in 2000 are estimated to increase more in SES between 2000 and 2006-10.

Although a half-point change on the SES index may seem like a small figure on its surface, note that control variable descriptive statistics reported in Table 6 indicate a range of 53 in the distribution of PNHBLACK in 2000 for the YL subsample. In other words, all else being equal, a CT with a 53\% non-Hispanic Black population in 2000 is predicted to increase by nearly 25 points in SES index in the period from 2000 to 2006- 
10. This finding, accompanied by the fact that neighborhoods in the subsample overall decreased in Black populations during that period, provides very strong evidence of gentrification and displacement, and further supports the findings of McKenzie (2013) regarding the increasingly dispersed distribution of Black neighborhoods.

Rent has a marginally significant negative relation to SES change $(p<.1)$, meaning neighborhoods with lower rents in 2000 are expected to increase the most in SES index from 2000 to 2006-10. More specifically, the regression coefficient (-3.667) indicates that a $\$ 100$ lower median rent in 2000 (adjusted to 2010 dollars) is associated with a predicted increase of about 3.7 points in SES index during the final time point interval. Taken together, these coefficients indicate that SES change in the final census year interval of the study period is greatest for neighborhoods that began the decade with large Black populations, low rents, and close proximity to transit stations. This is highly consistent with the urban growth machine theory, which emphasizes the priority of growth coalitions to facilitate economic growth through targeted investments that increase exchange values in neighborhoods with previously low exchange values, large low income or minority populations, and potentially strategic location within the city (such as being close to the urban core). 


\section{Chapter 5: Discussion and Conclusion}

This study reveals patterns throughout the Portland metropolitan region that are indicative of residential neighborhood segregation as well as gentrification along lines of race and socioeconomic class during the period from 1980 to 2010. Key findings relating to research questions and hypotheses are discussed in detail below.

H1 Neighborhood SES will increase more in neighborhoods close to downtown than in those further away from downtown.

Hot spot analyses indicate that the study period began with high SES neighborhoods concentrated on the west side of Portland, and low SES neighborhoods concentrated in North, NE, and East Portland. Conversely, downtown consisted of both lower and higher SES neighborhoods, separated by a middle-class mix. Over the three decades that followed, neighborhood changes throughout the region were characterized by a general trend of centralization of higher SES residents in neighborhoods close to the urban core, and the simultaneous marginalization of lower SES residents to suburban neighborhoods along the region's eastern and western fringe. Based on these most general findings, I therefore reject the null hypothesis that there is no difference in SES change between neighborhoods closer to or further away from downtown. 


\section{H2 Low-SES neighborhoods receiving new LRT infrastructure will increase in SES relative to the rest of the region following those stations opening for service.}

Descriptive statistics indicate that development of the Yellow Line and, to a lesser extent, the Eastside Blue Line, is associated with increases in neighborhood SES in their respective subsamples exceeding the rate of SES change for the region as a whole following the opening of those lines. However, since the rate of SES change in the EB subsample was only marginally greater than for the region overall, and choropleth maps and hot spot analyses depict a mix of both high- and low-SES neighborhoods along that line, the relationship is not considered further for EB neighborhoods. Descriptive statistics for the WB subsample finds that that is has consistently contained high-SES neighborhoods compared to regional averages, and that, if anything, WB development may have actually contributed to SES decline in those neighborhoods, they too are not considered any further.

YL neighborhoods, on the other hand, show clear patterns of SES increase following LRT development based on descriptive statistics, and this is strengthened by the findings from choropleth maps and hot spot analyses Additionally, the relationship between increasing SES and LRT proximity is demonstrated statistically in bivariate and multivariate analyses. I therefore find partial support for Hypothesis 2 and reject the null hypothesis that low SES neighborhoods along the Yellow Line did not increase in SES following those stations opening for service. 
H3 SES increases indicative of gentrification in newly transit-served neighborhoods will be greater in those with close proximity to new transit stations than in those further away.

SES increases indicative of gentrification in newly transit served neighborhoods were observed in the YL subsample, but not in the EB or WB subsamples, and bivariate and multivariate analyses were performed to assess the effect of LRT proximity on YL neighborhood SES change. Pearson's correlations (Table 7) reveal that in 1980, 1990 and 2000, YL neighborhoods generally decreased in SES the closer they were to YL station locations. However, in 2006-10 - following those stations' 2004 opening - that relationship was no longer statistically significant. Conversely, in correlations between YL distance and SES change, no significant relationship was found in any time interval prior to YL development, but in the interval from 2000 to 2006-10, a strong and statistically significant negative correlation was found, indicating that neighborhood SES increase during that period was greater the closer a CT was to a station. Further support for hypothesis 3 comes from the regression analysis of OLS Model 8 (Table 9), which regresses SES change on YL distance and several control variables, and finds that in the time interval during which YL stations were built and opened, all else being equal, SES index values are estimated to have increased at a greater rate in CTs with shorter distances to YL stations. 
Although in a general sense it is possible that SES increase in low-SES neighborhoods could be due to forces other than gentrification, the extent of neighborhood change observed near YL stations is sufficient to preclude most alternative explanations. Furthermore, descriptive statistics and choropleth maps of population by race and ethnicity provide additional evidence of residential displacement from those communities. As neighborhood SES increased in YL neighborhoods, Hispanic and nonHispanic Black population shares were declining, presumably as those residents were departing (i.e., displaced, "priced out" or voluntarily moving) from the area for suburbs to the west and east, respectively. Taken together, these findings amount to strong evidence that LRT development influenced neighborhood demographic and socioeconomic changes indicative of gentrification and displacement in the YL subsample, and that neighborhood proximity to YL stations is positively related to the extent of socioeconomic change experienced in those neighborhoods. Hence, finding empirical support for hypothesis 3, I reject the null hypothesis that the extent of gentrification-related SES change in newly transit-served neighborhoods is not related to neighborhood proximity to transit stations.

\section{Neighborhood Contexts}

The relationship between LRT development and neighborhood SES appears to be distinct in each LRT subsample, relating to the particular socio-historical contexts of their respective neighborhoods. In other words, the impact of LRT on neighborhood change is seen as contingent not only on neighborhood-level SES and other demographic 
characteristics prior to infrastructure development, but also upon more nuanced qualities of those neighborhoods and the communities they contain. ${ }^{40}$ Those qualities correspond to their histories of political mobilization and marginalization, as well as their implementation of urban development projects before, after, and concurrent to the introduction of LRT.

For example, at the beginning of the study period, the YL subsample was characterized by neighborhood segregation along lines of race and social class following decades of public disinvestment, and discriminatory housing policies, and urban renewal projects that functioned to clear out Black neighborhoods to be recycled for the benefit of the region's continued growth. As a result of that socio-historical context, combined with narrowly focused revitalization efforts and urban development policies prioritizing "smart growth" strategies, gentrification trends in the YL subsample - which began in the 1990s - accelerated rapidly in response to LRT development. ${ }^{41}$

Conversely, the WB subsample began the study period as especially affluent, with a history of low-density neighborhoods and predominantly white, middle and uppermiddle class populations. Given that context, it is understandable that LRT development

\footnotetext{
${ }^{40}$ There is an implied distinction here between neighborhood, as the geographic space in which people live and go about their daily routines, and community, referring to the people themselves, their shared values and identification with the neighborhood, and their abilities to organize as a group in relation to the city or region.

${ }^{41}$ Since it is evident that such patterns began in nearby neighborhoods prior to LRT development, it is most likely that LRT development, rather than instigating the gentrification process in North Portland, had the effect of exacerbating and speeding up processes of gentrification and displacement that had already begun and may have eventually reached those neighborhoods anyway.
} 
on Portland's west side was not associated with neighborhood ascent. To the contrary, WB neighborhoods appear to have declined in SES throughout the study period.

In contrast to both YL and WB neighborhoods, SES trends in the EB subsample appear to be heterogeneous, due in part to differences in SES change between the urban core and the easternmost suburb of Gresham. Because EB neighborhoods are divided between the central city and a distinctly working class suburb, their socio-historical contexts are not consistent, and their response to LRT development is similarly uneven. While hot spot analyses of SES change suggest some EB neighborhoods close to downtown experienced socioeconomic ascent following LRT development, in East Portland and Gresham neighborhoods nearest to EB stations, SES is seen to have started low and remained low regardless of the addition of this major transit amenity. As a result of this more complex relationship, SES change in EB neighborhood is not significantly related to EB distance - positively or negatively - at any point in the study period.

\section{Portland's Urban Growth Machine}

Similar to the variability between different metropolitan regions found by Kahn (2007) and Grube-Cavers and Patterson (2014), these findings indicate that the sociodemographic neighborhood outcomes following LRT development also vary between large subsections of neighborhoods within a single region. Kahn's (2007) finding that Portland neighborhoods near park and ride stations decreased in home values and college educated population shares was notably out of line with the findings from the other cities analyzed. While my analysis did not explicitly account for different station 
types, Kahn (2007) notes that suburbs, which are lower in residential density and therefore less appropriate for the walk and ride variety, would be expected to have more park and ride stations. Given that dynamic, it is worth noting that hot spot maps and descriptive statistics do indicate that Portland suburbs - especially on the eastside consistently declined in SES relative to the rest of the region throughout the study period.

Bringing this back to the theory of the urban growth machine, it must be acknowledged that any manifestation of neighborhood ascent or decline does not amount to some autonomous force of neighborhoods. To the contrary, neighborhood socioeconomic change is the outcome of the concerted efforts of growth actors within a political economy of place. In this context, it can be argued that North and NE Portland neighborhood ascent amounted to "planned gentrification" in the interest of growth.

This is best exemplified by the fact that the MAX Yellow Line was an explicit component of targeted urban renewal, in which TriMet utilized tax increment financing to access $\$ 30$ million of funding to go towards the rail development (TriMet 2005). As a result of this strategy, gaining community buy-in was not only an essential part of project planning, but was also literally a component of the funding mechanism itself. ${ }^{42}$ After all, as Logan and Molotch emphatically argue, "the most durable feature in U.S. urban planning is the manipulation of government resources to serve the exchange interests of local elites, sometimes at the expense of one another and often at the expense of local

\footnotetext{
42 This is because tax increment financing funds are recaptured from the increase in property taxes associated with increased property values, which result from such neighborhood revitalization efforts.
} 
citizens" (Logan and Molotch 1987:178). If residents opt to stay in a gentrifying neighborhood despite a loss of affordability from increased property taxes and rents, as well as the loss of community from the displacement of longtime local businesses and lower-income households, growth elites are appeased because capital continues to enter the neighborhood, and indeed the city and region, from outside developers. Conversely, if a community member decides to capitalize on increased home equity as a result of neighborhood improvements - including but not limited to LRT - growth elites are also appeased because the market for land is controlled by supply-side actors, and the demand-side is insatiable (Logan and Molotch 1987).

However, just as Logan and Molotch (1987) note that growth coalitions' efforts to draw large employers to their region does not truly "create jobs" but actually "distributes jobs" that would otherwise have been distributed in a neighboring region, efforts to attract higher SES residents to a gentrifying neighborhood has the effect of distributing neighborhood SES. In this context, the redistribution of neighborhood SES is evident in the various public and private investments, as well as policies surrounding growth and development, enacted in neighborhoods throughout the region. For example, the Yellow Line was developed as part of urban revitalization efforts, meaning it was framed as an investment in a previously disinvested neighborhood. The addition of LRT to North Portland was accompanied by numerous commercial developments, improvements to public space, and community involvement efforts that, while marketed to residents as use value oriented, was designed explicitly to increase exchange values. As the findings of 
this study demonstrate, those efforts have been a success for the neighborhoods, but not necessarily for the communities or their longtime residents.

Conversely, Eastside Blue Line development, as previously described, was framed by the controversy surrounding the Mount Hood Freeway, and the rebranding of Portland as a pioneer in sustainable planning practices. Although it too was installed in low SES neighborhoods, East Portland and Gresham, being so distant from downtown, did not have the same intrinsic capacity for reuse as did the more centrally located ICURA neighborhoods, so accompanying investment never materialized. In other words, the rent gap was not sufficiently large to draw increased investment to those neighborhoods. As a result, both use and exchange values in those furthest east neighborhoods suffered, and the redistribution of neighborhood SES adhered to the previously described pattern of centralization and marginalization.

\section{Limitations}

An overarching limitation of this study is the reliance on aggregate quantitative data. The lack of precision associated with census data presents a geospatial limitation in operationalizing light rail access in that even the CTs with the closest proximity to MAX stations are very likely include many households that are beyond what most people consider reasonable walking distance. Other studies have addressed this issue by analyzing census block groups instead of CTs, but this would likely raise more limitations than it would settle because there is no longitudinal dataset comparable to the NCDB that uses block groups, and even if such a dataset were available, the much 
smaller sample size at that scale (particularly in census data collected after 2000) makes for a problematically high margin of error.

A related limitation, also having to do with the reliance on census data, is in the operationalization of gentrification. Most importantly, the data at my disposal do not account for displacement, but only aggregate change in SES. Hypothetically, a CT could experience what appears to be neighborhood ascent through displacement of low-SES incumbent residents by relatively high-SES in-movers, when in fact it was simply the original residents experiencing socioeconomic mobility through success in their educations, occupations, and incomes. One way to potentially address this limitation is with the inclusion of a census variable indicating how many households reported having a different residence five years prior, but that is only a partial solution and requires the addition of variables that are not available for all years of the NCDB.

Similar shortcomings were encountered with other variables that are normally available for census data accessed directly from the Census Bureau, but are not included in the NCDB. Possibly the most problematic of those limitations (and indeed, potentially the most provocative) relates to the use of family income as a component of the SES index. This is because the census uses a very specific definition of what constitutes a family, as "two or more people (one of whom is the householder) related by birth, marriage, or adoption residing in the same housing unit" (U.S. Bureau of the Census 2016). In other words, the measure does not account for the income of single-person households, unrelated roommates, unmarried couples, or any number of other possible 
arrangements that do not involve marriage of other familial relations. Besides the failure to account for non-family incomes, this is recognized as a potentially inequitable limitation due to the possibility of further marginalizing same-sex couples and perhaps other people with non-traditional family or living arrangements. However, despite these limitations, the variable was selected because (1) it is theoretically important that the SES index account for income; (2) to be compatible with the other two measures combined into the SES index, income needed to be represented as a percentage variable, which required counts of households in particular income brackets; and (3) the NCDB does not include CT counts of the number of households in particular income categories for all census years under investigation, but it does provide this for different levels of family income.

Lastly, the approach taken in this study does not directly demonstrate all the machinations of the growth machine, only that the findings are consistent with predictions of growth machine. Because the growth machine theory is concerned largely with the motivations of actors, which is not readily available data, its application here is based primarily on the outcomes of growth coalition pursuits.

Despite the stated limitations, the present study is strengthened by the use of multiple measures and types of analyses to validate findings and ensure that findings are robust. Such a practice is appropriate for any study attempting to bridge a gap in the literature, because to a certain extent it delves into uncharted waters. 


\section{Implications for Gentrification Research}

This study bridges a gap in urban neighborhood research, in which the intricate role of transportation in processes of neighborhood change has been too little explored. The approach taken in this study is an attempt develop improved quantitative and geospatial methods of measurement, while remaining engaged with theoretical explanations of neighborhood change. To this end, cartographic depiction is a powerful tool for understanding gentrification as a process of neighborhood change. The methodology used - particularly the innovation of CT housing centroids as points from which neighborhood distances are measured, and the application of hot spot analysis to track neighborhood SES over time - is a potential contribution to advancing the study of gentrification in general. In this context, this research can be seen as one answer to the decades-old call for a 'geography of gentrification' (Lees 2000) as well as for a more spatially oriented sociology (Gieryn 2000).

\section{Directions for future research}

Further advancement in the study of gentrification will be best achieved through mixed methods research that incorporates quantitative and qualitative components. On the qualitative side, an improved understanding the gentrification processes requires getting to know the individuals and organizations involved, including those on the 'urban frontier' as well as the players behind the scenes. This means learning about the lived experiences of displacement, the challenges of incumbent residents in gentrifying neighborhoods, and those of gentrifiers hoping to integrate into a new community. It also 
means glimpsing the perspective from inside the growth machine through data collection from elected officials and other public figures involved in the management of urban growth in the region.

On the quantitative side, a continuation of this thesis as a $\mathrm{PhD}$ dissertation would do well to incorporate updated census data from the most recent release of the ACS. Improvements should be made to the multivariate analysis methods to be more robust to the non-normally distributed variables and smaller sample sizes that are often involved in census data analysis. With these and similar methodological improvements, regression analysis can illuminate the extent of moderation that distance to downtown has on gentrifying effects of neighborhood access to the EB MAX, as well as the Green Line, which would require updated census data. Lastly, the role of urban revitalization programs in gentrification and displacement should be explicitly considered in analyses of neighborhood change. This may be best addressed through GIS analysis combined with interviews - for example, with representatives of city agencies such as the Portland Development Commission.

Lastly, in the findings pertaining to the general pattern of neighborhood SES change throughout the study area, I describe the pattern as a combination of centralization of high SES neighborhoods and marginalization of low-SES neighborhoods. While the former has very direct relevance to gentrifying areas, the latter is only indirectly related and therefore not discussed much at all in this study. However, in future research it would be highly valuable to examine the characteristics of neighborhoods along the region's 
margin that decreased in SES over the study period. Sometimes referred to as "landing zones" of displaced residents (Bates 2013), these areas are further removed from employment centers and other resources for daily living, and a closer investigation of the conditions there would reflect further on the equity implications of this particular pattern of neighborhood socioeconomic segregation. If such an analysis were performed, it is logical to expect findings that are the inverse of those for the YL subsample in the present study. 


\section{References}

Al-Mosaind, Musaad A., Kenneth J. Dueker, and James G. Strathman. 1993. "Light-Rail Transit Stations and Property Values: A Hedonic Price Approach.”

Transportation Research Record 1400(1) 90-94.

Atkinson, Rowland, and Gary Bridge, eds. 2004. Gentrification in a global context. New York: Routledge/Taylor \& Francis Group.

American Public Transportation Association. 2007. " A Profile of Public Transportation Passenger Demographics and Travel Characteristics Reported in On-Board Surveys." Retrieved March 5, 2015

(http://www.apta.com/resources/statistics/Documents/transit_passenger_character istics_text_5_29_2007.pdf).

American Public Transportation Association. 2014. "Public Transportation Ridership Report: Fourth Quarter 2013." Retrieved March 5, 2015 (http://www.apta.com/resources/statistics/Pages/RidershipArchives.aspx).

Bajic, Vladimir. 1983. "The Effects of a New Subway Line on Housing Prices in Metropolitan Toronto." Urban Studies 20(2):147-158.

Bates, Lisa K. 2013. "Gentrification and Displacement Study: Implementing an Equitable Inclusive Development Strategy in The Context of Gentrification." City of Portland Bureau of Planning and Sustainability. Retrieved Jan. 10, 2015 (www.portlandoregon.gov/bps/article/454027)

Bostic, Raphael W., and Richard W. Martin. 2003. "Black Home-Owners as a Gentrifying Force? Neighbourhood Dynamics in the Context of Minority HomeOwnership." Urban Studies 40(12):2427-2449.

Bowes, David R., and Keith R. Ihlanfeldt. 2001. "Identifying the Impacts of Rail Transit Stations on Residential Property Values." Journal of Urban Economics 50(1):1-25.

Boyle, Indrani. 2008. "Measuring Gentrification in the Interstate Corridor Urban Renewal Area." Institute of Portland Metropolitan Studies.

Bullard, Robert D. 1997. Just Transportation. Stony Creek, CT: New Society Publishers.

Bullard, Robert D. 2003. "Addressing Urban Transportation Equity in the United States." Fordham Urban Law Journal 31(1):1183.

Checker, Melissa. 2011. "Wiped Out by the "Greenwave": Environmental Gentrification and the Paradoxical Politics of Urban Sustainability." City \& Society 23(2):210229.

Cervero, Robert, and Michael Duncan. 2004. "Neighbourhood Composition and Residential Land Prices: Does Exclusion Raise or Lower Values?" Urban Studies 41(2):299-315.

Chen, Hong, Anthony Rufolo, and Kenneth J. Dueker. 1998. "Measuring the Impact of Light Rail Systems on Single-Family Home Values: A Hedonic Approach with Geographic Information System Application." Transportation Research Record: Journal of the Transportation Research Board 1617(1):38-43. 
Danyluk, Martin, and David Ley. 2007. "Modalities of the New Middle Class: Ideology and Behaviour in the Journey to Work from Gentrified Neighbourhoods in Canada." Urban Studies 44(11):2195-2210.

Davidson, Mark, and Loretta Lees. 2005. "New-Build 'Gentrification' and London's Riverside Renaissance.” Environment and planning 37(7):1165-1190.

Debrezion, Ghebreegziabiher, Eric Pels, and Piet Rietveld. 2007. "The Impact of Railway Stations on Residential and Commercial Property Value: A Meta-Analysis." The Journal of Real Estate Finance and Economics 35(2):161-180.

Delmelle, Elizabeth C. 2015. "Five Decades of Neighborhood Classifications and their Transitions: A Comparison of Four US Cities, 1970-2010." Applied Geography 57(1):1-11.

Diaz, Roderick B. 1999. "Impacts of Rail Transit on Property Values." American Public Transit Association Rapid Transit Conference Proceedings.

Dominie, W. 2012. "Is Just Growth Smart Growth. The Effects of Gentrification on Transit Ridership and Driving in Transit Station Area Neighborhoods." Report for the Bus Riders Union.

Dueker, Kenneth J., and Martha J. Bianco. 1999. "Light-Rail-Transit Impacts in Portland: The First Ten Years." Transportation Research Record 1685(1):171-180.

Eckerd, Adam. 2011. "Cleaning Up Without Clearing Out? A Spatial Assessment of Environmental Gentrification." Urban Affairs Review 47(1):31-59.

Florida, Richard. 2006. "The Flight of the Creative Class: The New Global Competition for Talent." Liberal Education 92(3):22-29.

Formoso, Diana, Rachel N Weber, and Marc S Atkins. 2010. "Gentrification and Urban Children's Well-Being: Tipping the Scales from Problems to Promise." American Journal of Community Psychology 46(3-4):395-412.

Foster, Edward. 2010. "The Pecuniary Value of Commuting Time." Eastern Economic Journal 36(3):391-397.

Freeman, Lance. 2005. "Displacement or Succession? Residential Mobility in Gentrifying Neighborhoods." Urban Affairs Review 40(4):463-491.

GeoLytics. 2013. Neighborhood Change Database (NCDB) 2010 Tract Data for 197080-90-00-10. E. Brunswick, NJ: GeoLytics, Inc.

Ghose Rina. 2004. "Big Sky or Big Sprawl? Rural Gentrification and the Changing Cultural Landscape of Missoula, Montana." Urban Geography, 25(6):528-549. DOI: $10.2747 / 0272-3638.25 .6 .528$

Gibbs Knotts, H., and Moshe Haspel. 2006. "The Impact of Gentrification on Voter Turnout*." Social Science Quarterly 87(1):110-121.

Gibson, Karen J. 2007. "Bleeding Albina: A History of Community Disinvestment, 19402000." Transforming Anthropology 15(1):3-25.

Gieryn, Thomas F. 2000. "A Space for Place in Sociology." Annual Review of Sociology 26(1):463-496. 
Goodling, Erin, Jamaal Green, and Nathan McClintock. 2015. "Uneven Development of the Sustainable City: Shifting Capital in Portland, Oregon." Urban Geography 36(4):504-527.

Grube-Cavers, Annelise, and Zachary Patterson. 2014. "Urban Rapid Rail Transit and Gentrification in Canadian Urban Centres: A Survival Analysis Approach." Urban Studies DOI: 10.1177/0042098014524287.

Grubesic, Tony H., and Alan T. Murray. 2001. "Detecting Hot Spots Using Cluster Analysis and GIS." Proceedings from the Fifth Annual International Crime Mapping Research Conference, December 1-4, Dallas, TX.

Hackworth, Jason, and Neil Smith. 2001. "The Changing State of Gentrification." Journal of Economic \& Social Geography 92(4):464-477.

Hammel, Daniel J., and Elvin K. Wyly. 1996. "A Model for Identifying Gentrified Areas with Census Data." Urban Geography 17(3):248-268.

Hess, Daniel Baldwin, and Tangerine Maria Almeida. 2007. "Impact of Proximity to Light Rail Rapid Transit on Station-Area Property Values in Buffalo, New York." Urban Studies 44(5):1041-1068.

Jurjevich, Jason R., and Greg Schrock. 2012. "Is Portland Really the Place Where Young People Go to Retire? Migration Patterns of Portland's Young and CollegeEducated, 1980-2010." Metropolitan Knowledge Network, Institute of Portland Metropolitan Studies and the Population Research Center. Retrieved Jan. 10, 2015

(http://mkn.research.pdx.edu/wpcontent/uploads/2012/09/JurjevichSchrockMigrat ionReport1.pdf)

Kahn, Matthew E. 2007. "Gentrification Trends in New Transit-Oriented Communities: Evidence from 14 Cities That Expanded and Built Rail Transit Systems." Real Estate Economics 35(2):155-182.

Knaap, Gerrit J., Chengr Ding, and Lewis D. Hopkins. 2001. "Do Plans Matter? The Effects of Light Rail Plans on Land Values in Station Areas." Journal of Planning Education and Research 21(1):32-39.

Kennedy, Maureen, and Paul Leonard. 2001. Dealing with Neighborhood Change. Washington DC: Brookings Institution.

Kilpatrick, John, Ronald Throupe, John Carruthers, and Andrew Krause. 2007. "The Impact of Transit Corridors on Residential Property Values." Journal of Real Estate Research 29(3):303-320.

Kirkland, Elizabeth. 2008. "What's Race Got to do with it? Looking for the Racial Dimensions of Gentrification." Western Journal of Black Studies 32(2):18.

Lees, Loretta. 2000. "A Reappraisal of Gentrification: Towards a 'Geography of Gentrification'." Progress in Human Geography 24(3):389-408.

Lees, Loretta. 2003. "Super-gentrification: The case of Brooklyn heights, New York city." Urban Studies 40(12):2487-2509.

Lees, Loretta, Tom Slater and Evlin K. Wyly. 2008. Gentrification. New York: Routledge/Taylor \& Francis Group. 
Ley, David. 1986. "Alternative Explanations for Inner-City Gentrification: A Canadian Assessment." Annals of the Association of American Geographers 76(4):521-535.

Lin, Jeffrey. 2002. "Gentrification and Transit in Northwest Chicago." Journal of the Transportation Research Forum 56(4):175-191.

Logan, John, and Harvey Molotch. 1987. Urban Fortunes: The Political Economy of Place. Berkeley, CA: University of California Press.

Logan, John R., Zengwang Xu, and Brian Stults. 2012. "Interpolating US Decennial CT Data from as Early as 1970 to 2010: A Longitudinal CT Database." Professional Geographer 66(3):412-420.

McKenzie, Brian S. 2013. "Neighborhood Access to Transit by Race, Ethnicity, and Poverty in Portland, OR." City \& Community 12(2):134-155.

Miller, Rupert G Jr. 2011. Survival analysis. John Wiley \& Sons: New York.

Mitchell, Stephen. 2011. "Using GIS to Explore the Relationship between Socioeconomic Status and Demographic Variables and Crime in Pittsburgh, Pennsylvania." Papers in Resource Analysis 13(1):1-11. Saint Mary's University of Minnesota University Central Services Press. Winona, MN.

Mohammad, Sara I., Daniel J. Graham, Patricia C. Melo, and Richard J. Anderson. 2013. "A Meta-Analysis of the Impact of Rail Projects on Land and Property Values." Transportation Research Part A: Policy and Practice 50(1):158-170.

Molotch, Harvey. 1976. "The City as a Growth Machine: Toward a Political Economy of Place." American Journal of Sociology 82(2):309-332.

Molotch, Harvey. 1993 "The Political Economy of Growth Machines." Journal of Urban Affairs 15(1):29-53.

Owens, Ann. 2012. "Neighborhoods on the Rise: A Typology of Neighborhoods Experiencing Socioeconomic Ascent." City \& Community 11(4):345-369.

Pollack, Stephanie, Barry Bluestone, and Chase Billingham. 2010. "Maintaining Diversity in America's Transit-Rich Neighborhoods: Tools for Equitable Neighborhood Change." Dukakis Center Publications 3(1). http://hdl.handle.net/2047/d20001161

Revington, Nick. 2015. "Gentrification, Transit, and Land Use: Moving Beyond Neoclassical Theory." Geography Compass 9(3):152-163.

Rodgers, Scott. 2009. "Urban Geography: Urban Growth Machine.” Pp. 1-21 in International Encyclopedia Of Human Geography, edited by Rob Kitchin and Nigel Thrift. Oxford, UK: Elsevier.

Smith, Neil. 1979. "Toward a Theory of Gentrification: A Back to the City Movement by Capital, Not People." Journal of the American Planning Association 45(4):538548.

Smith, Neil. 1987. "Gentrification and the Rent Gap." Annals of the Association of American geographers 77(3):462-465.

Smith, Neil. 1998. "Gentrification." Pp. 198-199 in The Encyclopedia of Housing, edited by Willem Van Vliet. Thousand Oaks, CA: Sage Publications. 
Sullivan, Daniel Monroe, and Samuel C. Shaw. 2011. "Retail Gentrification and Race: The Case of Alberta Street in Portland, Oregon." Urban Affairs Review 47(3):413432.

Sullivan, Daniel Monroe. 2007. "Reassessing Gentrification Measuring Residents' Opinions Using Survey Data." Urban Affairs Review 42(4):583-592.

Schwirian, Kent P. 1983. "Models of Neighborhood Change." Annual Review of Sociology 9(1):83-102.

Tatian, Peter A. 2003. Data Users' Guide: Neighborhood Change Database (NCDB) 1970 - 2000 Tract Data Long Form Release. Washington, DC: The Urban Institute.

Tobler, Waldo R. 1970. "A Computer Movie Simulating Urban Growth in the Detroit Region." Economic Geography 46(1):234-240.

TriMet. 2005. "Interstate MAX DBE \& Workforce Story: Overcoming Barriers to Inclusion." Tri-County Metropolitan Transportation District of Oregon. Retrieved March 15, 2015 (https://trimet.org/pdfs/business/DBE_Workforce_Story.pdf)

U.S. Bureau of the Census. 1999. "The Long and Short of it." Retrieved Feb 2, 2015 (http://www.census.gov/dmd/www/pdf/d3239a.pdf)

U.S. Bureau of the Census. 2000. "Geographic Areas Reference Manual." Retrieved June 20, 2015 (https://www.census.gov/geo/reference/garm.html)

U.S. Bureau of the Census. 2008. "A Compass for Understanding and Using American Community Survey Data: What General Data Users Need to Know." Retrieved June 22, 2015

(https://www.census.gov/content/dam/Census/library/publications/2008/acs/ACS GeneralHandbook.pdf)

Wardrip, Keith. 2011. "Public Transit's Impact on Housing Costs: A Review of the Literature." Insights from Housing Policy Research. August, pp. 1-12.

Warf, Barney, ed. 2006. Encyclopedia of human geography. Thousand Oaks, CA: Sage Publications.

Yago, Glenn. 1983. "The Sociology of Transportation." Annual Review of Sociology 9(1):171-190.

Young, Bob. 2005. "Highway to Hell." Willamette Week, March 9.

Zuk, Miriam, Ariel H. Bierbaum, Karen Chapple, Karolina Gorska, Anastasia LoukaitouSideris, Paul Ong, and Trevor Thomas. 2015. Gentrification, Displacement and the Role of Public Investment: A Literature Review. San Francisco, CA: Federal Reserve Bank of San Francisco. 


\section{Appendix A: Tables and Figures}

Table A-1: Geographic Datasets Used

Dataset Name (RLIS Shapefile) RLIS Archive Source

2010 Census Tracts - Portland-Vancouver-Hillsboro Current

MSA - identified by 11-digit FIPS code (tract2010.shp)

Taxlots (taxlots.shp)

Multifamily Housing Inventory (MFHI;

February, 2010

multifamily housing inventory.shp)

Metro Regional Government Boundary (metro.shp)

November, 2015

Urban Growth Boundary (ugb.shp)

February, 2010

TriMet Service Area Boundary (transit_district.shp)

February, 2010

TriMet MAX Stations (1rt_stop.shp)

February, 2010

TriMet MAX Rail (lrt_line.shp)*

February, 2010

Streets (streets.shp)

February, 2010

February, 2010

Major Rivers and Water Bodies (mjriv_fi.shp)*

February, 2010

Data Source: Metro Regional Land Information System (RLIS)

*Indicates shapefiles used for cartographic purposes only

Table A-2: Independent Variables: Neighborhood LRT Access by MAX Line

\begin{tabular}{ll} 
Variable Name & Description \\
\hline MAX_Distance_EB & $\begin{array}{l}\text { Street Network miles from housing centroid to nearest } \\
\text { MAX station along the Eastside Blue Line }\end{array}$ \\
MAX_Distance_WB & $\begin{array}{l}\text { Street Network miles from housing centroid to nearest } \\
\text { MAX station along the Westside Blue Line }\end{array}$ \\
MAX_Distance_YL & $\begin{array}{l}\text { Street Network miles from housing centroid to nearest } \\
\text { MAX station along the Yellow Line }\end{array}$ \\
\hline
\end{tabular}

Dataset: Streets and TriMet MAX Stations shapefiles

Data Source: Metro Regional Land Information System (RLIS) 
Table A-3: Original NCDB Census Variables Used

\begin{tabular}{|c|c|}
\hline Variable & Description \\
\hline TRCTPOP\# & Total population \\
\hline SHRNHW\# & Proportion of non-Hispanic/Latino White population \\
\hline SHRNHB\# & $\begin{array}{l}\text { Proportion of non-Hispanic/Latino Black/African American } \\
\text { population }\end{array}$ \\
\hline SHRHSP\# & Proportion of Hispanic/Latino population \\
\hline EDUC16\# & $\begin{array}{l}\text { Persons } 25+\text { years old who have a bachelors or } \\
\text { graduate/professional degree }\end{array}$ \\
\hline EDUCPP\# & Persons $25+$ years old \\
\hline OCC1\# & $\begin{array}{l}\text { Persons } 16+\text { years old employed in professional and technical } \\
\text { occupations }\end{array}$ \\
\hline $\mathrm{OCC} 2 \#$ & $\begin{array}{l}\text { Persons } 16+\text { years old employed as executives, managers, and } \\
\text { administrators (excluding farms) }\end{array}$ \\
\hline INDEMP\# & Civilian employed persons $16+$ years old \\
\hline WRCNTY\#D & Workers $16+$ years old reporting place of work \\
\hline FAVINC\#D & Total number of families. \\
\hline FAVINC\# & $\begin{array}{l}\text { Average family income per family in year\# (not adjusted for } \\
\text { inflation) }\end{array}$ \\
\hline [Income Cat.] & $\begin{array}{l}\text { *Annual family income categories above sample median } \\
\text { FAVINC\#. }\end{array}$ \\
\hline MDGRENT\# & $\begin{array}{l}\text { Median gross rent of specified renter-occupied housing units } \\
\text { paying cash rent }\end{array}$ \\
\hline YTHPOP\# & Persons $18-24$ years old \\
\hline FEM34\# & Females $30-34$ years old \\
\hline FEM44\# & Females $35-44$ years old \\
\hline MEN34\# & Males 30-34 years old \\
\hline MEN44\# & Males 35-44 years old \\
\hline OCCHU\# & Total occupied housing units \\
\hline RNTOCC\# & Total renter-occupied housing units \\
\hline OWNOCC\# & Total owner-occupied housing units \\
\hline
\end{tabular}

Data Source: Neighborhood Change Database (NCDB: Geolytics 2013)

Note: Variable names in this table all end with "\#” to represent the 4 variables in the dataset that correspond to the same measures taken in each census year. "\#" takes the place of single-digit census year indicators appending the actual variable names, which are as follows: $1980=8,1990=9,2000=0,2010=1,2006-2010$ ACS $=1 \mathrm{a}$. For example, 1980 total population is measured by TRCTPOP8.

*Annual family income categories used vary by census year (see table A4). 
Table A-4: Higher-Income Families Percentage Components

Average Family

Income

(FAVINC)

Statistics Above-Average Income Categories

\begin{tabular}{|c|c|c|c|c|c|}
\hline $\begin{array}{l}\text { Output } \\
\text { Variable }\end{array}$ & $\begin{array}{l}\text { Census } \\
\text { Year }\end{array}$ & Median & Mean & Income Ranges & $\begin{array}{l}\text { NCDB } \\
\text { Variable }\end{array}$ \\
\hline \multirow[t]{7}{*}{ PHFAMINC8 } & 1980 & $\$ 24,386$ & $\$ 25,488$ & $\$ 25,000-27,499$ & FALT288 \\
\hline & & & & $\$ 27,500-29,999$ & FALT308 \\
\hline & & & & $\$ 30,000-34,999$ & FALT358 \\
\hline & & & & $\$ 35,000-39,999$ & FALT408 \\
\hline & & & & $\$ 40,000-49,999$ & FALT498 \\
\hline & & & & $\$ 50,000-74,999$ & FALT758 \\
\hline & & & & $\$ 75,000+$ & FALTMX8 \\
\hline \multirow[t]{3}{*}{ PHFAMINC 9} & 1990 & $\$ 41,243$ & $\$ 44,895$ & $\$ 40,000-49,999$ & FALT499 \\
\hline & & & & $\$ 50,000-74,999$ & FALT759 \\
\hline & & & & $\$ 75,000+$ & FALTMX9 \\
\hline \multirow[t]{6}{*}{ PHFAMINC0 } & 2000 & $\$ 61,986$ & $\$ 69,298$ & $\$ 60,000-74,999$ & FAY0750 \\
\hline & & & & $\$ 75,000-99,999$ & FAY01000 \\
\hline & & & & $\$ 100,000-124,999$ & FAY01250 \\
\hline & & & & $\$ 125,000-149,999$ & FAY01500 \\
\hline & & & & $\$ 150,000-199,999$ & FAY02000 \\
\hline & & & & $\$ 200,000+$ & FAY0M200 \\
\hline \multirow[t]{5}{*}{ PHFAMINC1a } & $2006-10$ & $\$ 76,127$ & $\$ 86,581$ & $\$ 75,000-99,999$ & FAY01001A \\
\hline & & & & $\$ 100,000-124,999$ & FAY01251A \\
\hline & & & & $\$ 125,000-149,999$ & FAY01501A \\
\hline & & & & $\$ 150,000-199,999$ & FAY02001A \\
\hline & & & & $\$ 200,000+$ & FAY0M201A \\
\hline
\end{tabular}

Data Source: Neighborhood Change Database (NCDB: Geolytics 2013) 
Table A-5: Calculation Parameters of SES Index and its Component Variables

\begin{tabular}{|c|c|c|}
\hline Variable & Calculation Parameters & Description \\
\hline \multicolumn{3}{|l|}{ Index } \\
\hline \multicolumn{3}{|l|}{ Parameters } \\
\hline SESINDEX8 & $\begin{array}{l}\text { SUM(PCOL8, PPROF8, } \\
\text { PHFAMINC8) }\end{array}$ & $\begin{array}{l}\text { Sum of three percentage } \\
\text { variables measuring the }\end{array}$ \\
\hline SESINDEX9 & $\begin{array}{l}\text { SUM(PCOL9, PPROF9, } \\
\text { PHFAMINC9) }\end{array}$ & $\begin{array}{l}\text { share of census tract } \\
\text { population with a college }\end{array}$ \\
\hline SESINDEX0 & $\begin{array}{l}\text { SUM(PCOL0, PPROF0, } \\
\text { PHFAMINC0) }\end{array}$ & $\begin{array}{l}\text { degree, workers in } \\
\text { professional occupations, }\end{array}$ \\
\hline SESINDEX1a & $\begin{array}{l}\text { SUM(PCOL1a, PPROF1a, } \\
\text { PHFAMINC1a) }\end{array}$ & $\begin{array}{l}\text { and families in above- } \\
\text { average income categories. }\end{array}$ \\
\hline \multicolumn{3}{|l|}{$\begin{array}{l}\text { Component } \\
\text { Parameters }\end{array}$} \\
\hline PCOL8 & (EDUC168 / EDUCPP8) & Percent of population age \\
\hline PCOL9 & (EDUC169 / EDUCPP9) & $25+$ who have a bachelors \\
\hline PCOLO & (EDUC160 / EDUCPP0) & or graduate/professional \\
\hline PCOL1a & (EDUC161a / EDUCPP1a) & degree \\
\hline PPROF8 & $((\mathrm{OCC} 18+\mathrm{OCC} 28) /$ INDEMP8) & Percent of workers age $16+$ \\
\hline PPROF9 & $(($ OCC19 + OCC29) / INDEMP9) & in professional or technical \\
\hline PPROF0 & $((\mathrm{OCC} 10+\mathrm{OCC} 20) /$ INDEMP0) & occupations; or employed \\
\hline PPROF1a & $((\mathrm{OCC} 11 \mathrm{a}+\mathrm{OCC} 21 \mathrm{a}) /$ INDEMP1a $)$ & $\begin{array}{l}\text { as executives, managers, or } \\
\text { administrators (excl. farms) }\end{array}$ \\
\hline PHFAMINC8 & $\begin{array}{l}((\text { FALT288 + FALT308 + FALT358 } \\
+ \text { FALT408 + FALT498 +FALT758 } \\
+ \text { FALTMX8) / FAVINC8D })\end{array}$ & $\begin{array}{l}\text { Percent of families whose } \\
\text { annual income from } \\
\text { previous year falls into an }\end{array}$ \\
\hline PHFAMINC 9 & $\begin{array}{l}((\text { FALT499 + FALT759 + } \\
\text { FALTMX9) / FAVINC9D) }\end{array}$ & $\begin{array}{l}\text { income range category that } \\
\text { exceeds the median and }\end{array}$ \\
\hline PHFAMINC0 & $\begin{array}{l}((\text { FAY0750 + FAY01000 + } \\
\text { FAY01250 + FAY01500 + } \\
\text { FAY02000 + FAY0M200) } / \\
\text { FAVINC0D })\end{array}$ & $\begin{array}{l}\text { mean values of average } \\
\text { family income for all } \\
\text { sampled tracts at that time. }\end{array}$ \\
\hline PHFAMINC 1a & $\begin{array}{l}((\mathrm{FAY} 01001 \mathrm{~A}+\mathrm{FAY} 01251 \mathrm{~A}+ \\
\text { FAY01501A + FAY02001A + } \\
\text { FAY0M201A }) / \text { FAVINC1AD }) \\
\end{array}$ & \\
\hline
\end{tabular}


Table A-6: NCDB-Based Control Variables

\begin{tabular}{|c|c|c|c|}
\hline Variable & Name & Description & Parameters \\
\hline $\begin{array}{l}\text { Percent Non- } \\
\text { Hispanic Black }\end{array}$ & PNHBLACK & $\begin{array}{l}\text { Population percent non- } \\
\text { Hispanic Black }\end{array}$ & SHRNHB\#*100 \\
\hline $\begin{array}{l}\text { Percent Non- } \\
\text { Hispanic White }\end{array}$ & PNHWHITE & $\begin{array}{l}\text { Population percent non- } \\
\text { Hispanic white }\end{array}$ & SHRNHW\#*100 \\
\hline $\begin{array}{l}\text { Percent } \\
\text { Hispanic }\end{array}$ & PHISP & $\begin{array}{l}\text { Population percent } \\
\text { Hispanic }\end{array}$ & SHRHSP\#*100 \\
\hline $\begin{array}{l}\text { Population } \\
\text { Density }\end{array}$ & PopDensPSqM & $\begin{array}{l}\text { CT population density } \\
\text { in hundreds of people } \\
\text { per square mile. }\end{array}$ & $\begin{array}{l}(\text { TRCTPOP\# / 100) / } \\
\text { SQMILES }\end{array}$ \\
\hline $\begin{array}{l}\text { SFR Housing, } \\
2000\end{array}$ & PSFRDET0 & $\begin{array}{l}\text { Percent of CT housing } \\
\text { units designated as } \\
\text { single family detached } \\
\text { homes. }\end{array}$ & $\begin{array}{l}(\text { TTUNIT1\# / } \\
\text { TOTHSUN\#)*100. }\end{array}$ \\
\hline Median Rent & AdjMDRENT & $\begin{array}{l}\text { Median rent in CT, } \\
\text { adjusted for inflation to } \\
2010 \text { dollars. }\end{array}$ & $\begin{array}{l}\text { MDGRENT8 } * 2.65 \\
\text { MDGRENT9 } * 1.67 \\
\text { MDGRENT0 } * 1.27 \\
\text { MDGRENT1a } * 1\end{array}$ \\
\hline
\end{tabular}

Source: Neighborhood Change Database (NCDB: Geolytics 2013) 


\section{Appendix B: Alternative Sampling Methods Considered}

\section{Polygon Overlap}

The simplest GIS method for CT selection is the use of locational queries based on the spatial relationship between two or more map layers. For example, CTs could be selected only if they are completely contained within the study area boundary, or if they overlap with the boundary any amount at all. This was the first approach taken for the present study, and although 326 CTs overlap the ideal study area boundary, only 243 are completely within that boundary. The remaining CTs vary substantially in their amount of overlap, and this is depicted in Figure B1, which includes insets of example-areas where CTs have only a sliver of their areas either inside (Inset A) or outside (Inset B) of the study area. This suggests that overlap should not be the sole criterion for sample selection - selecting all 326 with any overlap would include some CTs that are predominantly outside the area of study, while, conversely, selecting only the 243 completely contained CTs would omit some like those indicated in Figure B1 Inset A, which are almost entirely within the intersection but have a sliver of area that is not.

Figure B-1: Map: Partial or Complete Overlap of Tract and Study Area

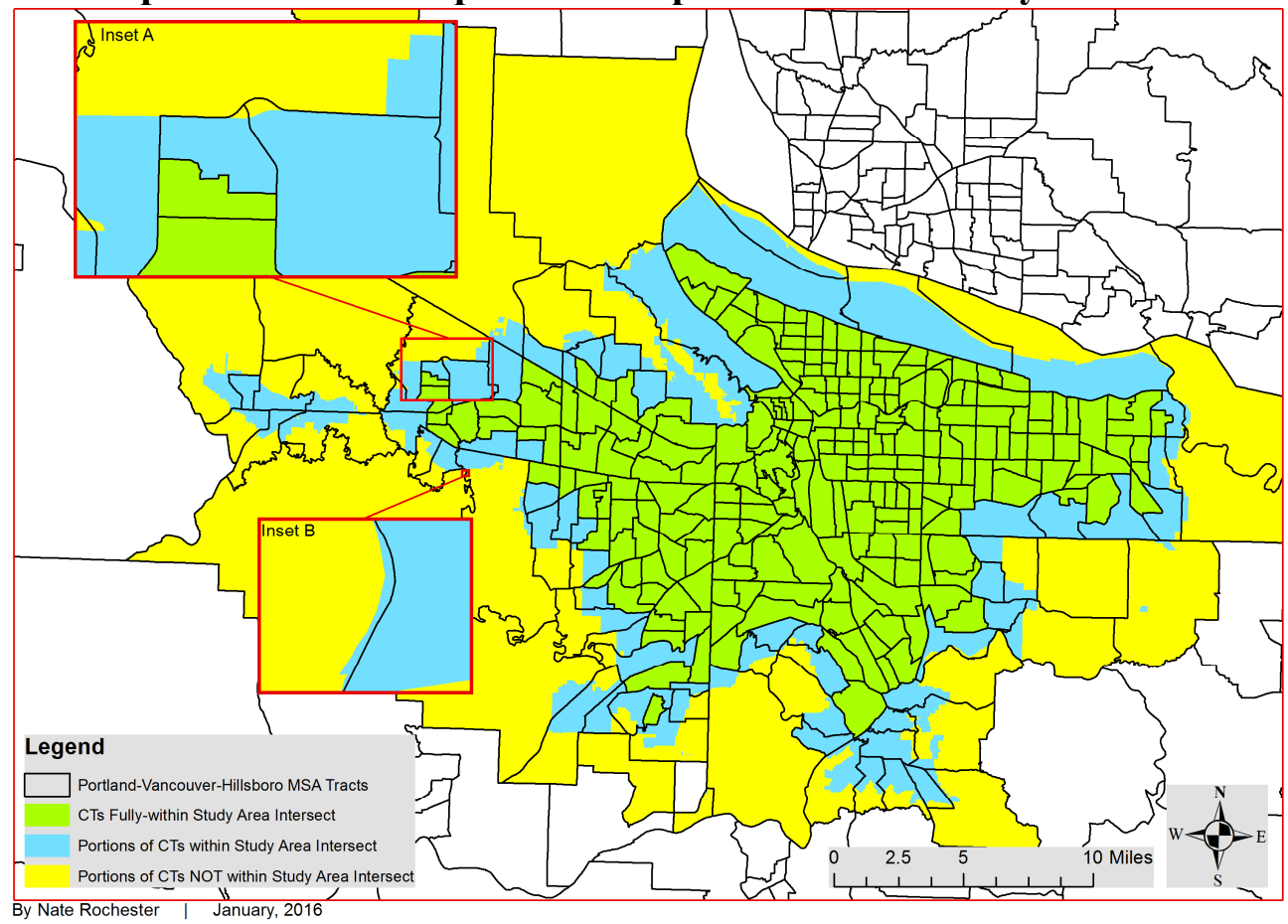




\section{Geographic Centroids}

Another option The other simple but obvious GIS selection method is to select CTs that have their geographic center-points inside the study area boundary (Figure B2). This yields a sample of 294, but it also omits several tracts that have substantial areas within the 3-boundary intersection. Most significantly, neither an analysis of CT overlap with the study area, nor CT geographic centroids within the study area - adequately accounts for whether the people who live in a given CT are within the study area. Housing does not have a perfectly even distribution across the geography of a given CT, so in many circumstances the geographic centroid does not accurately represent the spatial distribution of the tract's residents. In other words, the criteria for inclusion in analysis should be based primarily on the locations of people who live within CTs rather than the CT's overall geographical properties. Due to the inadequacies of these simple selection methods to capture the intended study area as a collection of CTs based on the distribution of population within them, a more complex approach was developed.

\section{Figure B-2: Map: Tracts with Geographic Centroids in "Ideal Study Area"}

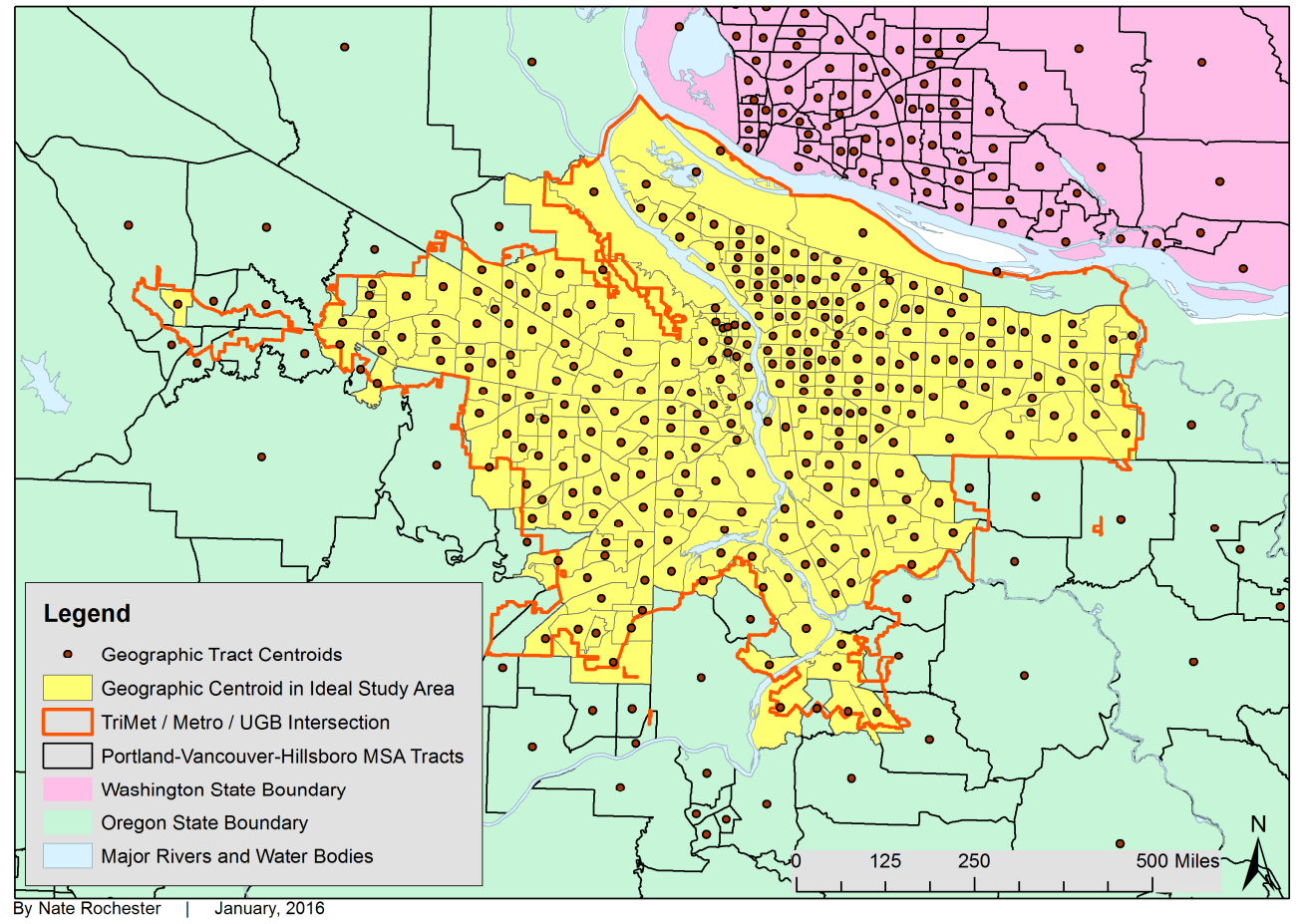




\section{Housing Centroids Versus Population-Weighted Centroids}

The housing centroids created for sample selection are similar to populationweighted centroids, which are geographic centroids that get shifted according to the relative populations of the census block groups nested within each CT. However, population-weighted centroids have the limitation that census block groups, like tracts, represent aggregated data, and therefore cannot account for variations in population density within those areas. For example, if a 200-acre block group contains 1000 residents, 950 of whom reside in high density housing that accounts for only 10 acres in one small corner of the total area, the population-weighted CT centroid would not account for that uneven population distribution within the block group. Rather, the data model would assume that the 1000 residents are evenly distributed across the total area of the block group, resulting in a population-weighted CT centroid that is closer to the CT's geographic center than it would be if based on the actual distribution of residents. This limitation of population-weighted centroids, combined with the availability of ancillary housing data from taxlots and the Multifamily Housing Inventory, motivated my creation of housing centroids, which are described in Chapter 3. 


\section{Appendix C: Changes to Census Questions and Coding}

Occupational Classifications

Table C-1 lists the occupational categories used for coding professional, technical, executive, manager, and administrator occupations in the census datasets used.

Table C-1: Coding Structure of PROF Occupational Categories Used in 19802000 Censuses and 2006-10 ACS

\section{Census Year}

1980

\section{Included Occupational Categories}

Executive, Administrative, and Managerial Occupations

Management related occupations

Engineers, surveyors and mapping scientists

Mathematical and computer scientists

Health diagnosing occupations

Health assessment and treating occupations

Therapists

Teachers, postsecondary

Teachers, except postsecondary

Librarians, archivists, and curators

Social scientists and urban planners

Social, recreation, and religious workers

Lawyers and judges

Writers, artists, entertainers, and athletes

Health technologists and technicians

Engineering and related technologists and technicians

Technicians, except health, engineering, and science

1990
Executive, Administrative, and Managerial Occupations

Management Related Occupations

Engineers, Architects, and Surveyors

Mathematical and Computer Scientists

Natural Scientists

Health Diagnosing Occupations

Health Assessment and Treating Occupations

Therapists

Teachers, Postsecondary

Teachers, Except Postsecondary

Librarians, Archivists, and Curators

Social Scientists and Urban Planners

Social, Recreation, and Religious Workers

Lawyers and Judges

Writers, Artists, Entertainers, and Athletes 


\begin{tabular}{|c|c|}
\hline 2000 & $\begin{array}{l}\text { Executive, Administrative, and Managerial Occupations } \\
\text { Management related occupations } \\
\text { Engineers, surveyors and mapping scientists } \\
\text { Mathematical and computer scientists } \\
\text { Health diagnosing occupations } \\
\text { Health assessment and treating occupations } \\
\text { Therapists } \\
\text { Teachers, postsecondary } \\
\text { Teachers, except postsecondary } \\
\text { Librarians, archivists, and curators } \\
\text { Social scientists and urban planners } \\
\text { Social, recreation, and religious workers } \\
\text { Lawyers and judges } \\
\text { Writers, artists, entertainers, and athletes } \\
\text { Health technologists and technicians } \\
\text { Engineering and related technologists and technicians } \\
\text { Technicians, except health, engineering, and science }\end{array}$ \\
\hline $2006-10$ & $\begin{array}{l}\text { Management Occupations: } \\
\text { Business and Financial Operations Occupations: } \\
\text { Computer and mathematical occupations: } \\
\text { Architecture and Engineering Occupations: } \\
\text { Life, Physical, and Social Science Occupations: } \\
\text { Community and Social Services Occupations: } \\
\text { Legal Occupations: } \\
\text { Education, Training, and Library Occupations: } \\
\text { Arts, Design, Entertainment, Sports, and Media Occupations: } \\
\text { Healthcare Practitioner and Technical Occupations: } \\
\text { Healthcare Support Occupations: }\end{array}$ \\
\hline \multicolumn{2}{|c|}{$\begin{array}{l}\text { Data Source: Standard Occupational Classification Codes (SOC) } \\
\text { - } 1980 \text { SOC: } \\
\text { https://www.nlsinfo.org/sites/nlsinfo.org/files/attachments/121217/Attachment\%203 } \\
\text { - } 19201980 \% \text { 20Census\%20Codes.pdf } \\
\text { - } 2000 \text { SOC: }: \underline{\text { http://www.bls.gov//nls/quex/r1/y97rlcbkal.pdf }} \\
\text { - } 2002 \text { SOC: } \\
\text { http://www.census.gov/people/io/files/2002\%20Census\%20Occupation\%20Codes.xls }\end{array}$} \\
\hline
\end{tabular}




\section{Race/Ethnicity}

Table C-2 below provides the original questions on race from the "short form" census enumerations of 1980-2010, showing that the greatest change is that 1980 and 1990 questionnaires allowed residents to identify with only one race, while 2000 and 2010 questionnaires introduced the "mark one or more" option for individuals who identify with multiple racial categories.

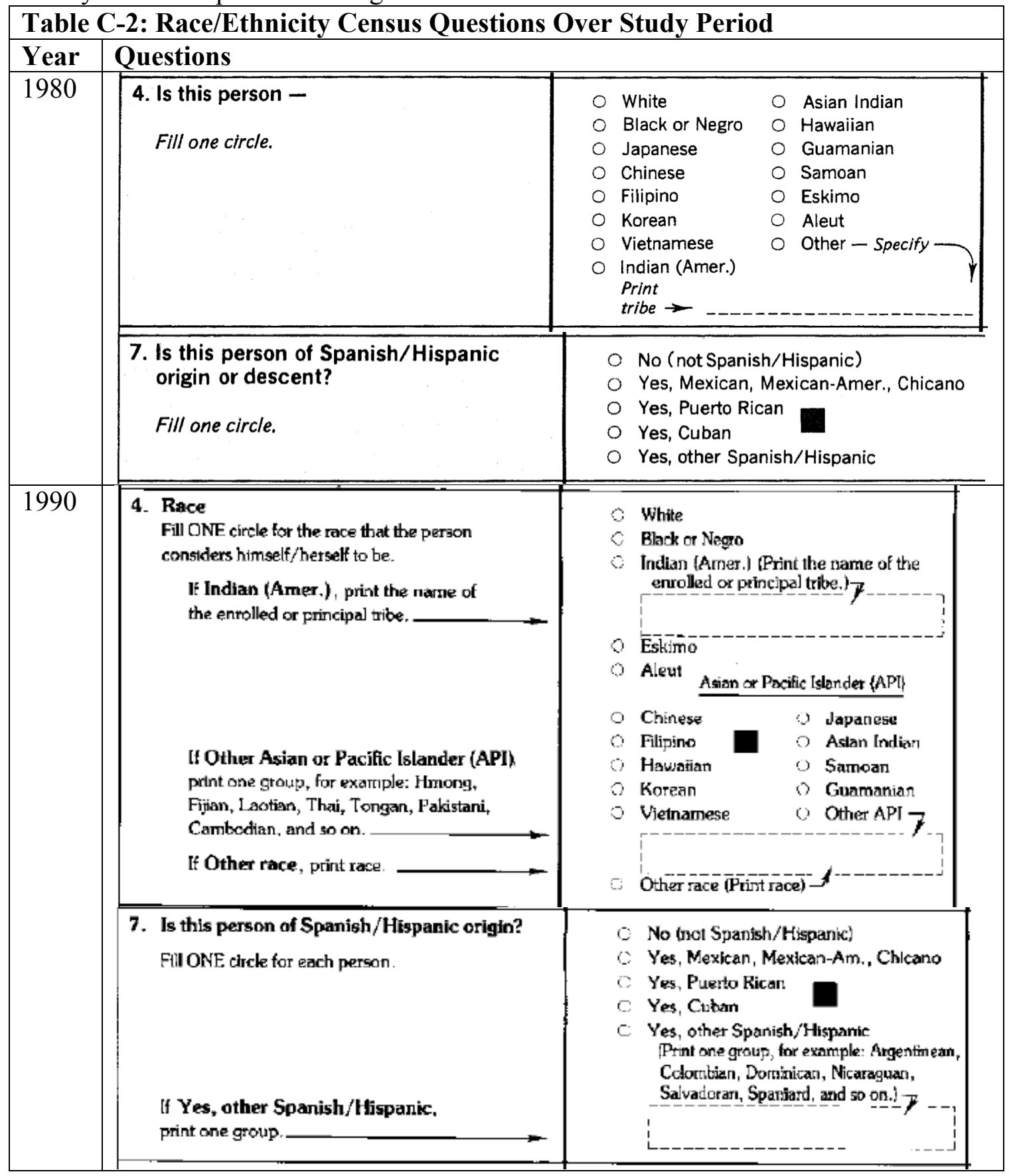




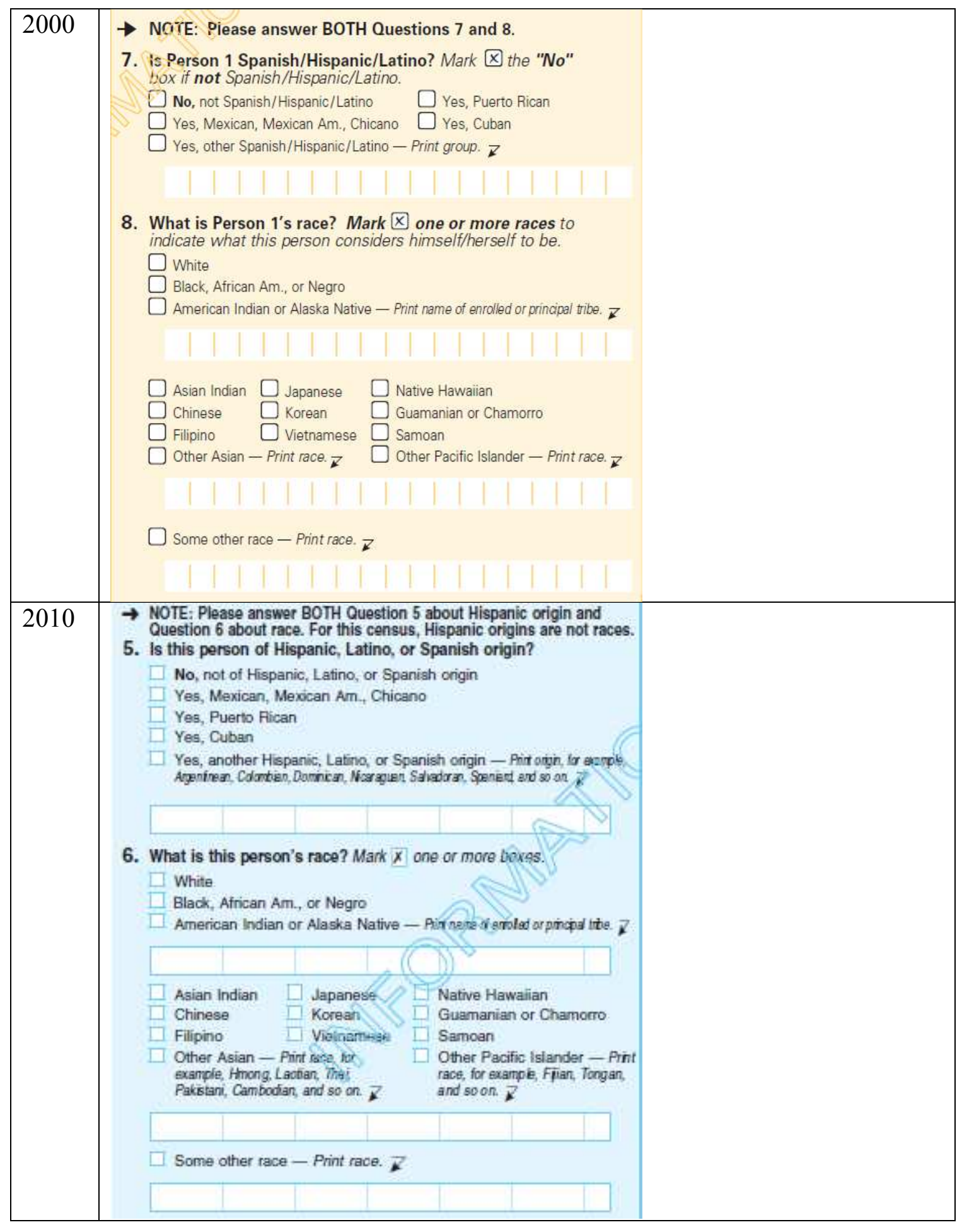

